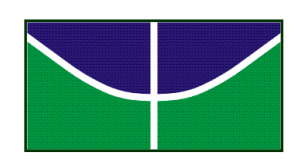

UNIVERSIDADE DE BRASÍLIA

FACULDADE DE TECNOLOGIA

DEPARTAMENTO DE ENGENHARIA CIVIL E AMBIENTAL

\title{
ÍNDICE DE AVALIAÇÃO DA QUALIDADE DO TRANSPORTE PÚBLICO POR ÔNIBUS A PARTIR DA DEFINIÇÃO DE SERVIÇO ADEQUADO
}

\section{WALYSSON TANGRINS MARTINS}

ORIENTADOR: PAULO CESAR MARQUES DA SILVA

DISSERTAÇÃO DE MESTRADO EM TRANSPORTES

PUBLICAÇÃO: T. DM - 001A/2015 
UNIVERSIDADE DE BRASÍLIA

FACULDADE DE TECNOLOGIA

DEPARTAMENTO DE ENGENHARIA CIVIL E AMBIENTAL

ÍNDICE DE AVALIAÇÃO DA QUALIDADE DO TRANSPORTE PÚBLICO POR ÔNIBUS A PARTIR DA DEFINIÇÃO DE SERVIÇO ADEQUADO

\section{WALYSSON TANGRINS MARTINS}

DISSERTAÇÃO SUBMETIDA AO DEPARTAMENTO DE ENGENHARIA CIVIL E AMBIENTAL DA FACULDADE DE TECNOLOGIA DA UNIVERSIDADE DE BRASÍLIA COMO PARTE DOS REQUISITOS NECESSÁRIOS PARA A OBTENÇÃO DO GRAU DE MESTRE EM TRANSPORTES.

APROVADA POR:

Prof. Paulo Cesar Marques da Silva, PhD, (ENC-UnB)

(Orientador)

Prof. Pastor Willy Gonzales Taco, Dr., (ENC-UnB)

(Examinador Interno)

Martha Mendes Caiafa, Dra., (ANEEL/Hepta)

(Examinadora Externa)

BRASÍLIA/DF, 04 DE MARÇO DE 2015 


\section{FICHA CATALOGRÁFICA}

MARTINS, WALYSSON TANGRINS

Índice de Avaliação da Qualidade do Transporte Público por Ônibus a Partir da Definição de Serviço Adequado. [Distrito Federal] 2015.

xxi 117 p. (ENC/FT/UnB, Mestre, Transportes, 2015). Dissertação de Mestrado Universidade de Brasília. Faculdade de Tecnologia. Departamento de Engenharia Civil e Ambiental.
1. Transporte público
2. Avaliação

3. Qualidade

4. Serviço adequado

I. ENC/FT/UnB

II. Título (série)

\section{REFERÊNCIA BIBLIOGRÁFICA}

MARTINS, Walysson Tangrins (2015). Índice de Avaliação da Qualidade do Transporte Público por Ônibus a Partir da Definição de Serviço Adequado. Dissertação de Mestrado em Transportes, Publicação T. DM - 001A/2015, março, 2015, Departamento de Engenharia Civil e Ambiental, Universidade de Brasília, Brasília, DF, $117 \mathrm{p}$.

\section{CESSÃO DE DIREITOS}

Autor: Walysson Tangrins Martins

Título: Índice de Avaliação da Qualidade do Transporte Público por Ônibus a Partir da Definição de Serviço Adequado

Grau: Mestre

Ano: 2015

É concedida à Universidade de Brasília permissão para reproduzir cópias desta dissertação de mestrado e para emprestar ou vender tais cópias somente para propósitos acadêmicos e científicos. $\mathrm{O}$ autor reserva outros direitos de publicação e nenhuma parte dessa dissertação de mestrado pode ser reproduzida sem autorização por escrito do autor.

Walysson Tangrins Martins

SQN 209 - Bloco I - Ap. 410 - Asa Norte

CEP: 70854-090 - Brasília/DF

walysson.tangrins@gmail.com 


\section{AGRADECIMENTOS}

Acima de tudo e todos, eu agradeço a Deus. Tudo só foi possível pela Sua infinita misericórdia. Ele me inspirou a aceitar o desafio e segurou minhas mãos em todos os momentos. Obrigado Senhor.

Eu agradeço aos meus pais Marcia e Juracy. Através deles eu pude provar a vida e em todos os momentos eles trabalharam além de suas forças para que eu pudesse vencer cada dia com caráter e fé. Agradeço à minha família pelo apoio incondicional e por me fazer sentir em casa mesmo estando a centenas e centenas de quilômetros do meu lar.

Agradeço ao Programa de Pós-Graduação em Transportes - PPGT por me permitir viver este sonho e por ser um berço tão acolhedor a pessoas e ideias. Obrigado a cada docente do Programa, em especial àqueles os quais tive a honra de ouvir lecionar: Ana Cláudia Farranha, Fabiana Arruda, João Carlos, José Augusto Fortes, Pastor Willy Taco e Paulo César Marques da Silva.

Agradeço aos colegas de classe, mestrandos e doutorandos do PPGT, alma vibrante da pós-graduação, uma turma com grande saber e forte opinião, que transforma qualquer assunto em debate e qualquer debate em um momento de confraternização. Agradeço especialmente e com imensa admiração os amigos mestrandos da Turma 2013. Tem um pouco de cada um de vocês nas linhas desta pesquisa.

Agradeço ao meu orientador Prof. Paulo César Marques da Silva, que desde o início me recebeu com alegria e teve paciência de ouvir e ler todas as minhas ideias. Aconselhoume como um verdadeiro pai em todos os momentos e acreditou em mim quando nem eu mesmo tinha esperança. Sem você esta pesquisa jamais existiria. Muito obrigado por ser minha referência de caráter e perseverança.

Agradeço aos meus colegas de trabalho pelo apoio e compreensão. Agradeço aos companheiros de república pelo acolhimento. Agradeço ao CNPq pelo apoio financeiro a parte desta pesquisa. Agradeço à BHTrans por ceder os dados solicitados. Agradeço a Bianca Arpini por apresentar-me o método QFD. Agradeço a Abimael pelo esclarecimento de dúvidas. Agradeço a Jessé e Leonardo Reis pelo apoio nas coletas de dados. Agradeço a cada um dos 155 entrevistados e 882 respondentes das pesquisas.

Encerrando, quero deixar um agradecimento especial aos amigos que estiveram comigo e me sustentaram de pé durante alguns dos momentos mais delicados da minha vida, que aconteceram durante esta dissertação. São eles: Marcia Maria, Dayane Cristina, Emilly Cristina, Wanderson Martins, Aline Maia, Luca Tavares, Lorena Therezo, Fabi, Gal Rodrigues, Gerardo de Sousa, Rony Arteaga, Fabiana Arruda, Paulo César, José Augusto, Ingrid Saldanha, Josué Estevão, Alessandra Queiroz, Luciana Sapore, Andiara Peixoto, Tainara Vilaça, Raul Avelar, Gislaine, Wolney, Leandro Morgado, Águida 
Nadja, Silvio Marques, Jonathan Duarte, Luiz Carlos, Diogo Oliveira, Maria Teresa Araújo, Denise Rodrigues, Thárcia Vasconcelos, Cynthia Larisse, Harley Vera, Lara Chavez, Ruy Telles, Igor Siman, Célia Brandemburg, Iuri Siman, Ingrid Siman, Raphael Vanderlei, Allan Mendes, Gabriel Sousa, Gorete, George Washington, Isabela Dario, Zuleide Feitosa, Pedro de Carvalho, Juliana César, Lucas Pimenta e João Francisco. Que Deus lhes retribua abundantemente mais toda a compaixão que tiveram comigo. 
"(Utopia) Ella está en el horizonte -dice Fernando Birri-. Me acerco dos pasos, ella se aleja dos pasos. Camino diez pasos y el horizonte se corre diez pasos más allá. Por mucho que yo camine, nunca la alcanzaré. ¿Para qué sirve la utopía? Para eso sirve: para caminar."

(Eduardo Galeano) 


\section{RESUMO}

A população brasileira tem cobrado soluções governamentais para os problemas de transporte público. O tema está se tornando o centro das discussões de diversas áreas do conhecimento e setores da sociedade. Este panorama é criado devido à influência do transporte público nas relações sociais e na qualidade de vida da população. Objetivando sustentar a busca contínua pela qualidade do serviço, esta pesquisa consiste na elaboração de um índice genérico de avaliação do serviço de transporte público, que possa ser aplicado em cidades de todos os tamanhos. Para tal, utiliza-se a definição de serviço adequado apresentada pela Lei de Concessão dos Serviços Públicos. Primeiramente é analisada a importância social do serviço e algumas formas de avaliação estudadas. Em sequência, com base nos atributos descritos na legislação, elaboram-se indicadores, utilizando pesquisas de campo e aplicando-se o método de Desdobramento da Função Qualidade (Quality Function Deployment - QFD) para atribuição de pesos. Após a definição do método, este é validado a partir de um estudo de caso na cidade de Belo Horizonte/MG. Por fim, analisa-se a aplicabilidade e efetividade do índice. 


\begin{abstract}
The Brazilian population has charged government solutions to public transportation problems. The theme is becoming the center of discussions of various knowledge areas and sectors of society. This panorama is created due to the influence of public transport in social relations and the population's quality of life. Aiming support the continuous search for quality of service, this research develops a generic evaluation index for the public transport service, which can be implemented in cities of all sizes. In order to this, we use the appropriate service definition presented by the Public Services Concession Law. First, its analyzes the social importance of service and some forms of evaluation. In sequence, based on the attributes described in the legislation, indicators are developed, using research and applying the method Quality Function Deployment (QFD) for assigning weights. After defining the method, a case study in Belo Horizonte/MG is conducted to validate this. Finally, the applicability and the effectiveness of the index method are analysed.
\end{abstract}




\section{SUMÁRIO}

1. INTRODUÇÃ

1.1 APRESENTAÇÃO ………………………………………………………

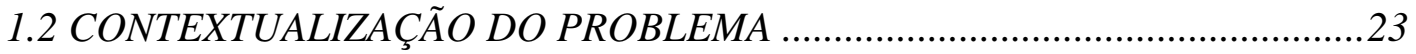

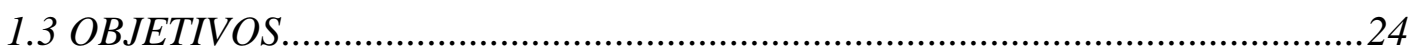

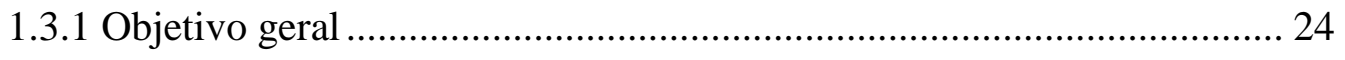

1.3.2 Objetivos específicos........................................................................... 24

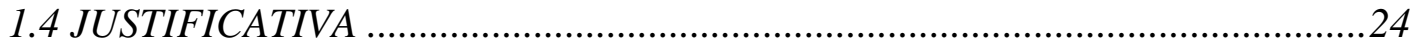

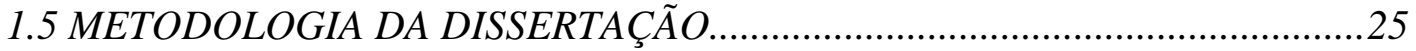

1.5.1 $1^{\mathrm{a}}$ Fase: Referencial teórico .................................................................. 25

1.5.2 2 $2^{\mathrm{a}}$ Fase: Desenvolvimento do método ..................................................... 26

1.5.3 $3^{\mathrm{a}}$ Fase: Estudo de caso ……………………………………………... 26

1.5.4 4 $4^{\mathrm{a}}$ Fase: Avaliação do método ……………………………………..... 26

1.5.5 Resumo esquemático da metodologia da dissertação................................ 26

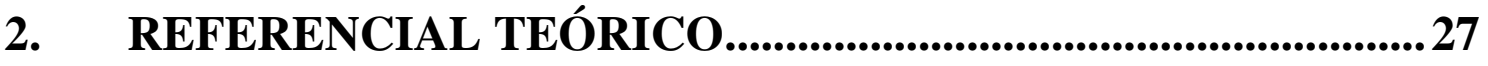

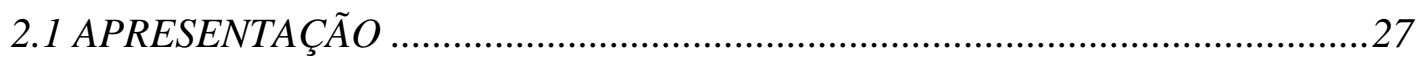

2.2 FUNÇÃO SOCIAL DO TRANSPORTE PÚBLICO.............................................

2.3 QUALIDADE

2.4 AVALIAÇÃO DA QUALIDADE DO TRANSPORTE PÚBLICO ……..................32

2.5 CONCESSÃO DE SERVIÇOS PÚBLICOS .........................................................

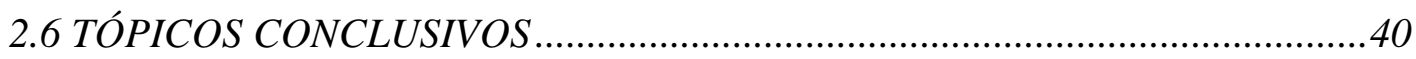

3. PROCEDIMENTO METODOLÓGICO ..........................................4 41

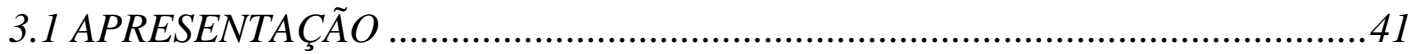

3.2 RELEVÂNCIA PARA O USUÁRIO ..................................................................

3.3 VALORAÇÃO DOS ASPECTOS SELECIONADOS ………………………......4

3.4 MÉTODO DE DESDOBRAMENTO DA FUNÇÃO QUALIDADE ……............48

3.4.1 Tabela de Desdobramento da Qualidade Exigida ..................................... 49

3.4.2 Qualidade Planejada ............................................................................... 50

3.4.3 Tabela de Desdobramento das Características da Qualidade (CQs) processo de extração .......................................................................... 51

3.4.4 Matriz de Correlação ...........................................................................52

3.4.5 Processo de Conversão: priorização das Características da Qualidade... 53 
3.4.6 Análise Competitiva: mensurando os valores das Características da Qualidade e comparando com a concorrência

3.4.7 Definindo os Valores-Metas de desempenho para as Características da Qualidade

3.4.8 Matriz Auxiliar das Características da Qualidade - Proporcionalidade.. 54

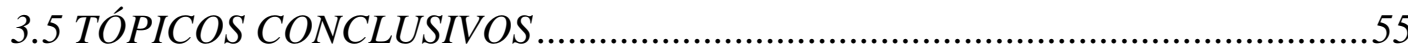

4. DESENVOLVIMENTO DO MÉTODO.......................................56

4.1 APRESENTAÇÃO ……………………………………………………........

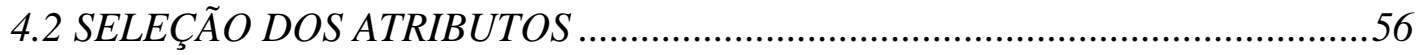

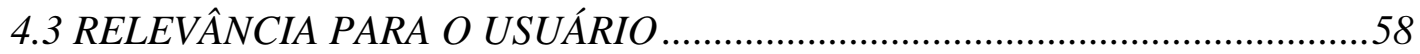

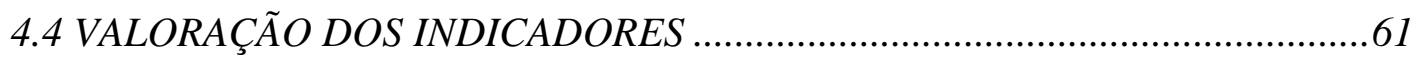

4.4.1 Tabela de Desdobramento da Qualidade Exigida ................................. 61

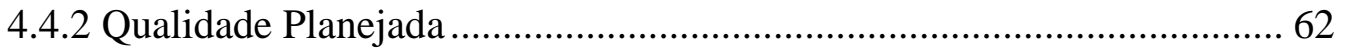

4.4.3 Tabela de Desdobramento das Características da Qualidade (CQs) ....... 63

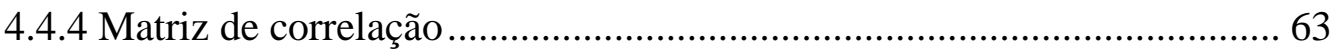

4.4.5 Processo de conversão: priorização das características da Qualidade .... 65

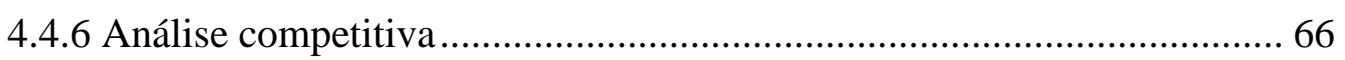

4.4.7 Definindo os Valores-Metas de desempenho para as Características da

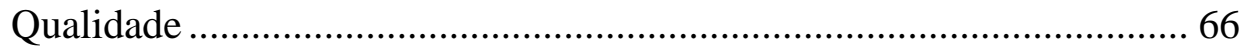

4.4.8 Matriz Auxiliar das Características da Qualidade ................................. 67

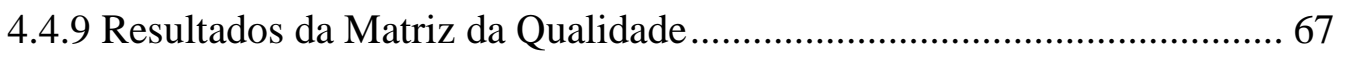

4.5 PROCEDIMENTOS E PARÂMETROS DE CÁLCULO ..................................69

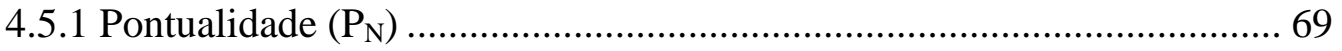

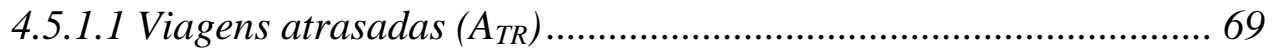

4.5.1.2 Cumprimento dos itinerários $\left(I_{T I}\right)$........................................... 70

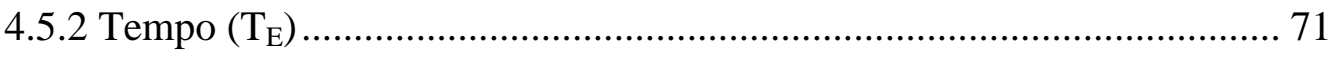

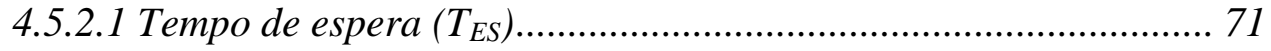

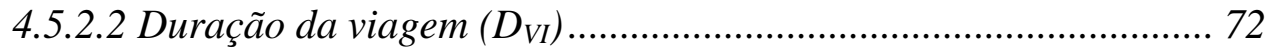

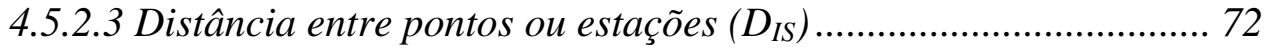

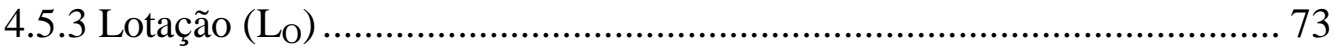

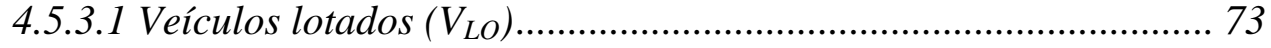

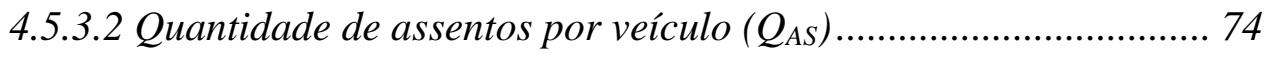


4.5.3.3 Quantidade de portas no veículo $\left(Q_{P O}\right)$....................................... 74

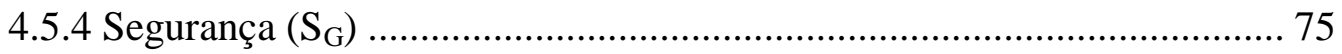

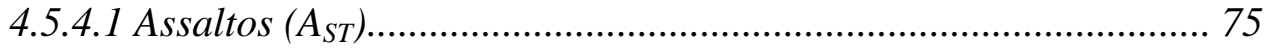

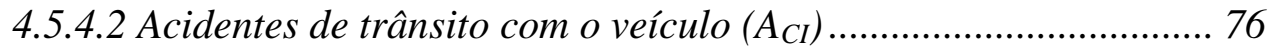

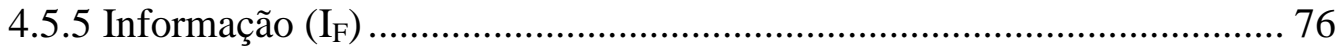

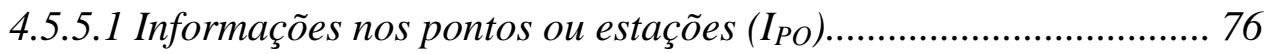

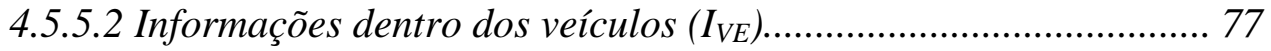

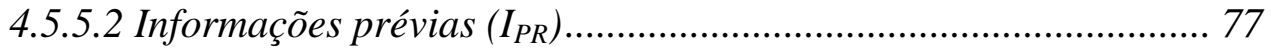

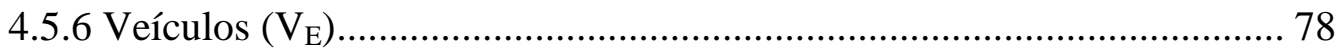

4.5.6.1 Viagens interrompidas por falha mecânica $\left(V_{I N}\right)$....................... 78

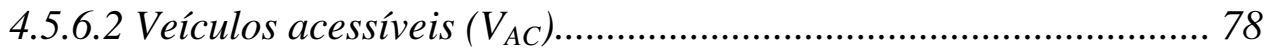

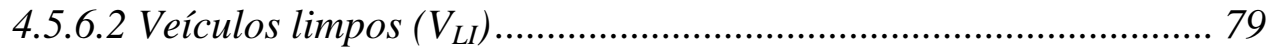

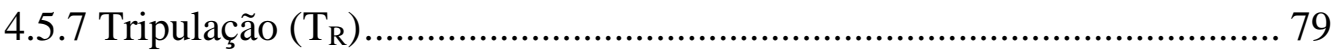

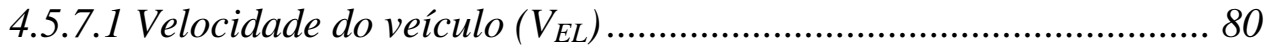

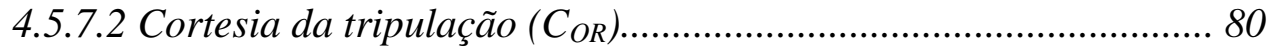

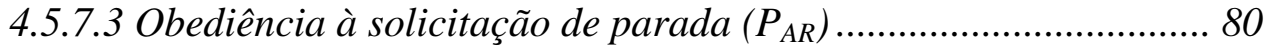

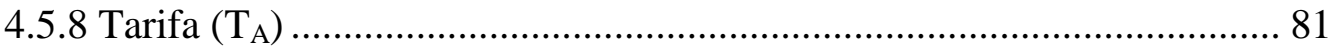

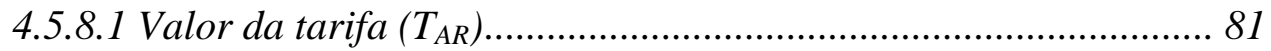

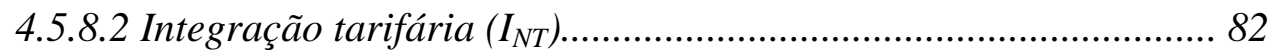

4.6 ÍNDICE DE AVALIAÇÃO DA QUALIDADE DO TRANSPORTE PÚBLICO POR ÔNIBUS A PARTIR DA DEFINIÇÃO DE SERVIÇO ADEQUADO - IQ $Q_{T P} 82$

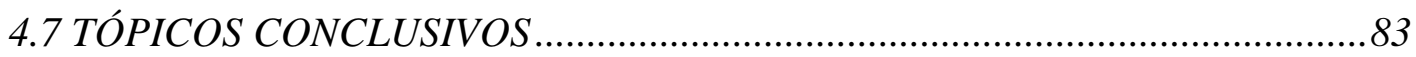

5. ESTUDO DE CASO ................................................................85

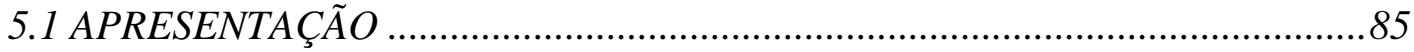

5.2 UM BREVE HISTÓRICO DO SISTEMA DE TRANSPORTE PÚBLICO DE

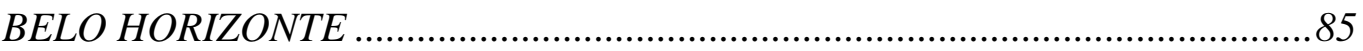

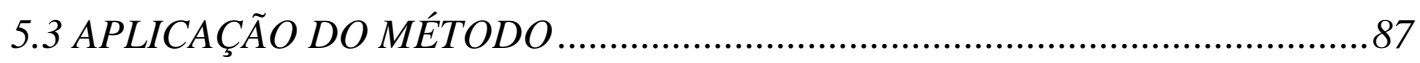

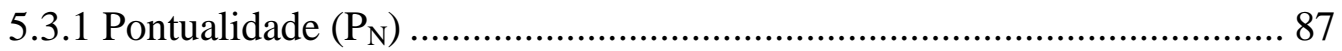

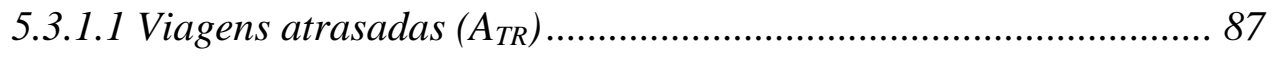




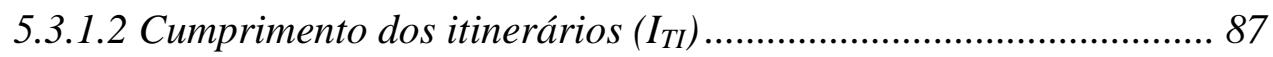

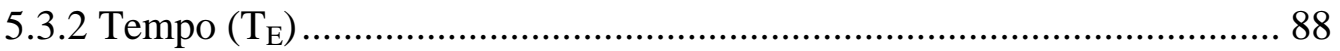

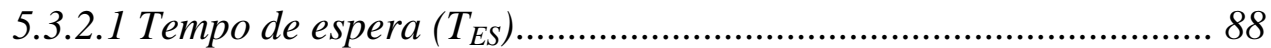

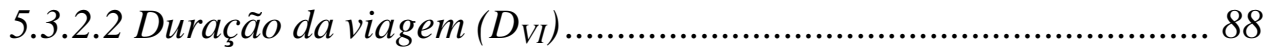

5.3.2.3 Distância entre pontos e estações $\left(D_{I S}\right)$....................................... 88

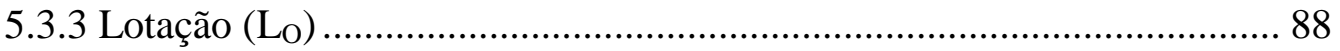

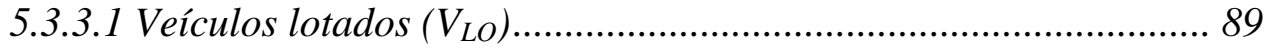

5.3.3.2 Quantidade de assentos por veículo $\left(Q_{A S}\right) \ldots \ldots \ldots \ldots \ldots \ldots \ldots \ldots \ldots \ldots \ldots \ldots . . . . . \ldots \ldots$

5.3.3.3 Quantidade de portas no veículo $\left(Q_{P O}\right)$...................................... 89

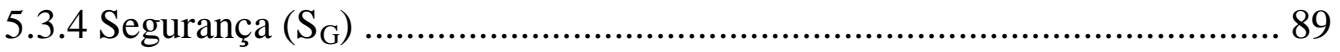

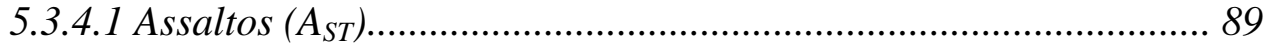

5.3.4.2 Acidentes de trânsito com o veículo $\left(A_{C I}\right)$.................................. 90

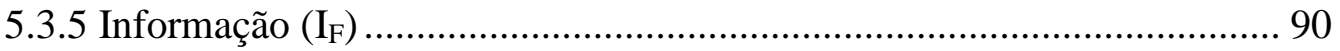

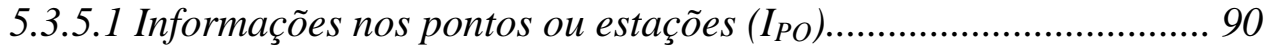

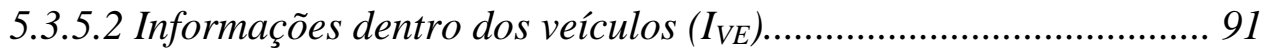

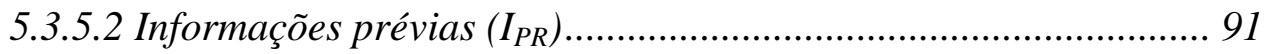

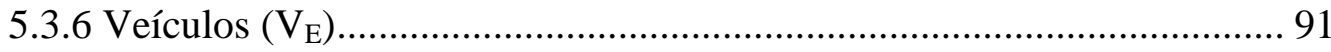

5.3.6.1 Viagens interrompidas por falha mecânica $\left(V_{I N}\right)$........................ 91

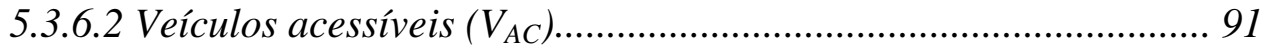

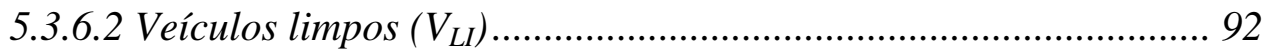

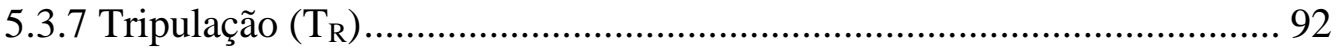

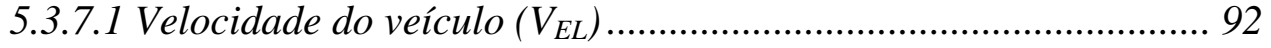

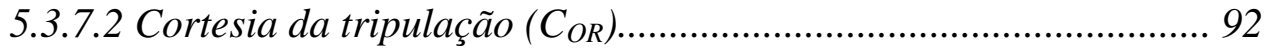

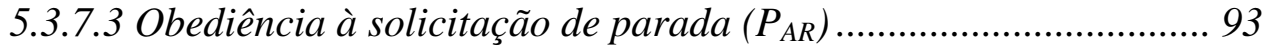

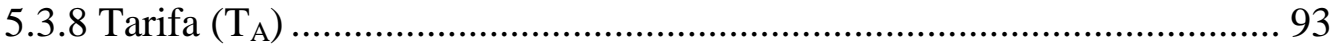

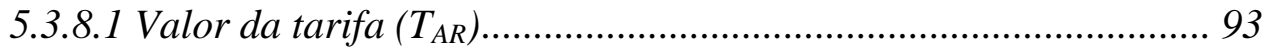

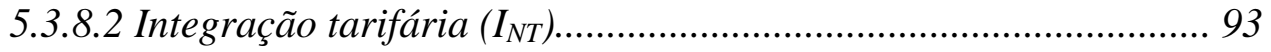

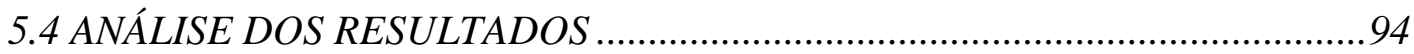




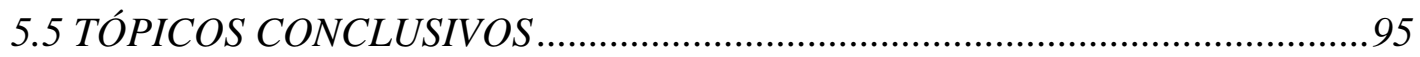

6. CONCLUSÃO ............................................................................. 97

6.1 LIMITAÇÕES E RECOMENDAÇÕES ..................................................... 97

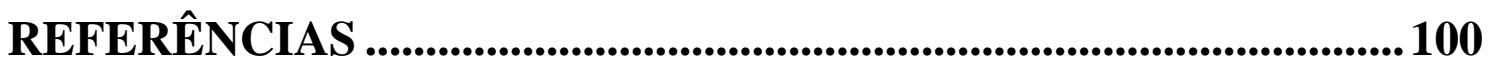

ANEXOS ...................................................................................................... 106

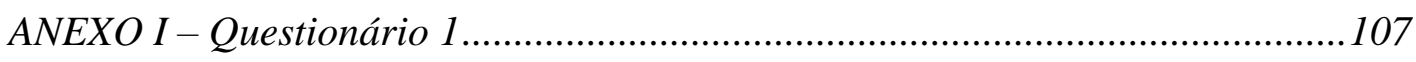

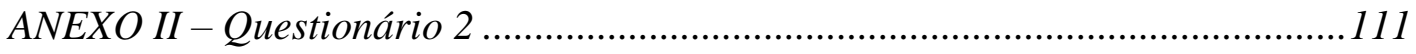

ANEXO III - Matriz da Qualidade ................................................................ 115 


\section{LISTA DE FIGURAS}

Figura 1.1: Influência do aumento do tráfego urbano sobre o desempenho do sistema de transporte público urbano coletivo.......................................................23

Figura 1.2: Resumo esquemático da metodologia da dissertação.................................26

Figura 2.1: Indicadores comparativos entre ônibus, motocicletas e automóveis............27

Figura 2.2: Impactos do transporte urbano sobre a pobreza........................................29

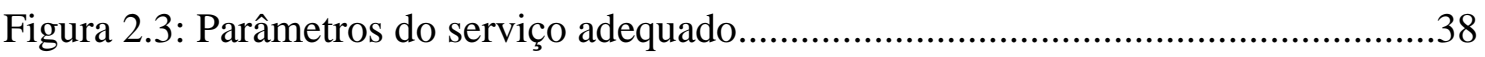

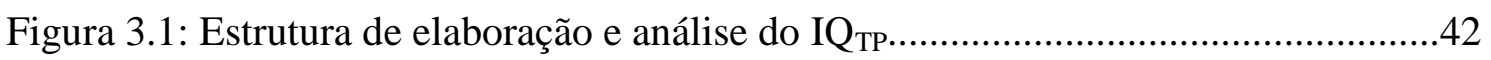

Figura 3.2: Regiões administrativas de Belo Horizonte..................................................45

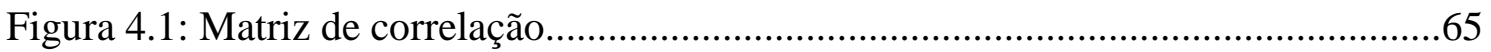

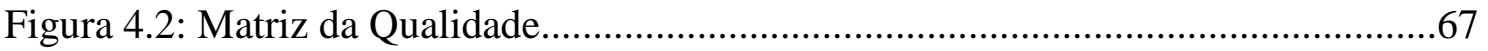




\section{LISTA DE GRÁFICOS}

Gráfico 4.1: Distribuição dos respondentes por região...............................................58

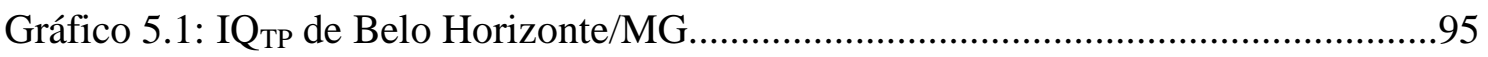




\section{LISTA DE TABELAS}

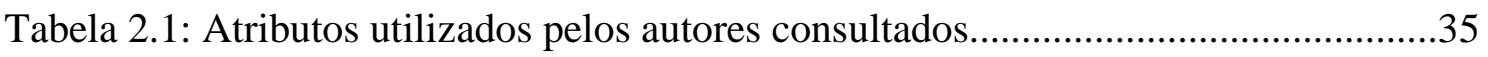

Tabela 3.1: Indicadores do serviço adequado..........................................................43

Tabela 3.2: Linhas selecionadas para a realização das entrevistas................................46

Tabela 3.3: Tabela da Qualidade Exigida elaborada para a melhoria do serviço de atendimento em uma loja de departamento...............................................50

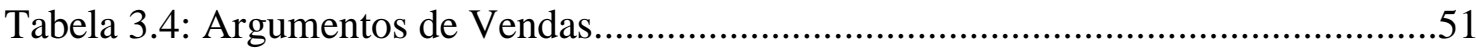

Tabela 3.5: Diferença entre elementos e características da qualidade .............................52

Tabela 3.6: Definições para as correlações da matriz de QFD.........................................53

Tabela 3.7: Exemplo da simbologia utilizada para representar o melhor comportamento

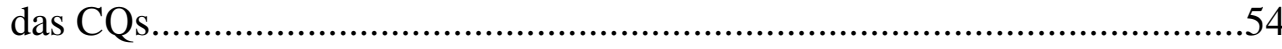

Tabela 3.8: Simbologia de correlação na Matriz CQ x CQ............................................55

Tabela 4.1: Atributos selecionados para composição dos indicadores............................57

Tabela 4.2: Distribuição dos respondentes por estado e Distrito Federal........................58

Tabela 4.3: Média do grau de importância (1 a 5) atribuído pelos usuários.....................60

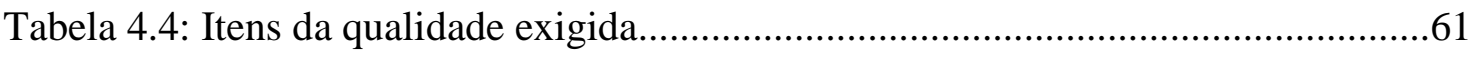

Tabela 4.5: Valoração dos itens da qualidade exigida.................................................62

Tabela 4.6: Regra de correlação entre requisitos de usuários e de serviço......................64

Tabela 4.7: Priorização dos itens das características da qualidade................................65

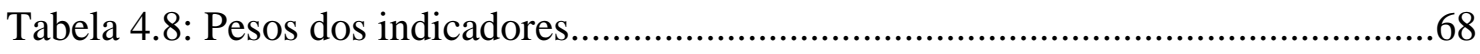

Tabela 4.9: Pesos dos atributos com diferenças expressivas..........................................68

Tabela 4.10: Padrão de qualidade de pontualidade..........................................................

Tabela 4.11: Conversão da relação de cumprimento de itinerários..................................71

Tabela 4.12: Conversão do headway médio................................................................

Tabela 4.13: Conversão da relação de duração da viagem..............................................72

Tabela 4.14: Conversão da distância entre pontos ou estações......................................73 
Tabela 4.15: Níveis de referência de lotação de veículos

Tabela 4.16: Quantidade de assentos por veículo........................................................74

Tabela 4.17: Quantidade de portas no veículo........................................................... 75

Tabela 4.18: Assaltos e acidentes registrados a cada 10000 viagens.............................76

Tabela 4.19: Reclamações a cada 100000 passageiros..................................................79

Tabela 4.20: Participação da tarifa do transporte público na renda.................................81

Tabela 4.21: Níveis de qualidade do serviço de transporte público por ônibus..............83

Tabela 5.1: Indicadores do sistema de transporte coletivo por ônibus de Belo

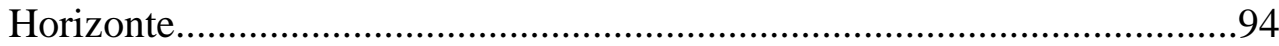




\section{LISTA DE SIGLAS E ABRERVIAÇÕES}

$\mathrm{A}_{\mathrm{C}} \quad$ Número de acidentes de trânsito com ônibus

$\mathrm{A}_{\mathrm{CI}} \quad$ Acidentes de trânsito com o veículo

AL Alagoas

AM Amazonas

ANTP Associação Nacional de Transportes Públicos

A $\quad$ Número de assaltos a ônibus registrados

A $\quad$ Assaltos

$\mathrm{A}_{\mathrm{TR}} \quad$ Viagens atrasadas

$\mathrm{A}_{\mathrm{V}} \quad$ Assentos por veículo

BA Bahia

BHBUS Plano de Reestruturação do Sistema de Transporte Coletivo de Belo Horizonte

BHTrans Empresa de Transportes e Trânsito de Belo Horizonte S/A

BRT Bus Rapid Transit

CE Ceará

CNI Confederação Nacional da Indústria

CNT Confederação Nacional do Transporte

$\mathrm{C}_{\mathrm{OR}} \quad$ Cortesia dos operadores

CQ Característica da Qualidade

DF Distrito Federal

$\mathrm{D}_{\mathrm{IS}} \quad$ Distância entre pontos ou estações

DTP Diretoria de Transporte Público

$\mathrm{D}_{\mathrm{U}} \quad$ Número de dias uteis do mês (ou período) avaliado

$\mathrm{D}_{\mathrm{VI}} \quad$ Duração da viagem

ES Espírito Santo

GO Goiás

h Horas

$\mathrm{H}_{\mathrm{L}} \quad$ Headway da linha

i Se refere à qualidade exigida (linhas $\mathrm{i}=1,2, \ldots, \mathrm{n}$ )

IBGE Instituto Brasileiro de Geografia e Estatística

IDO Índice de Desempenho Operacional 


\begin{tabular}{|c|c|}
\hline $\mathrm{I}_{\mathrm{F}}$ & Informações \\
\hline $\mathrm{I}_{\mathrm{N}}$ & Número de interrupções por falha mecânica \\
\hline $\mathrm{I}_{\mathrm{NT}}$ & Integração tarifária \\
\hline IPEA & Instituto de Pesquisa Econômica Aplicada \\
\hline $\mathrm{I}_{\mathrm{PO}}$ & Informações nos pontos ou estações \\
\hline $\mathrm{I}_{\mathrm{PR}}$ & Informações prévias \\
\hline $\mathrm{IQ}_{\mathrm{TP}}$ & Índice de Qualidade do Transporte Público por Ônibus \\
\hline IRU & Índice de Reclamações dos Usuários \\
\hline $\mathrm{I}_{\mathrm{TI}}$ & Cumprimento dos itinerários \\
\hline ITRANS & Instituto de Desenvolvimento e Informação em Transporte \\
\hline $\mathrm{I}_{\mathrm{VE}}$ & Informações dentro dos veículos \\
\hline $\mathrm{j}$ & Se refere às CQ (colunas $\mathrm{j}=1,2, \ldots, \mathrm{n})$ \\
\hline $\mathrm{km}$ & Quilômetros \\
\hline $\mathrm{km}^{2}$ & Quilômetros quadrados \\
\hline $\mathrm{K}_{\mathrm{P}}$ & Número total de quilômetros produtivos do sistema no período \\
\hline $\mathrm{L}_{\mathrm{O}}$ & Lotação \\
\hline MA & Maranhão \\
\hline MG & Minas Gerais \\
\hline MOVE & Sistema BRT de Belo Horizonte \\
\hline MS & Mato Grosso do Sul \\
\hline $\mathrm{N}^{\mathrm{o}}$ & Número \\
\hline N1 & Número de PED com um nível de informação \\
\hline $\mathrm{N} 2$ & Número de PED com dois níveis de informações \\
\hline $\mathrm{N} 3$ & Número de PED com três níveis de informações \\
\hline NTU & Associação Nacional das Empresas de Transportes Urbanos \\
\hline OMS & Organização Mundial da Saúde \\
\hline $\mathrm{P}$ & Número total de PED do sistema \\
\hline PA & Pará \\
\hline $\mathrm{PaCj}$ & Peso absoluto de cada item das características da qualidade \\
\hline$P_{A R}$ & Obediência à solicitação de parada \\
\hline PC & Ponto de Controle \\
\hline PC1 & Ponto de Controle de início da viagem da linha \\
\hline PCA & Principal Component Analysis \\
\hline
\end{tabular}




\begin{tabular}{|c|c|}
\hline PE & Pernambuco \\
\hline PED & Ponto(s) de Embarque e Desembarque de Passageiros \\
\hline PI & Piauí \\
\hline $\mathrm{P}_{\mathrm{N}}$ & Pontualidade \\
\hline PR & Paraná \\
\hline $\operatorname{PrCj}$ & Peso relativo da $\mathrm{CQ}_{\mathrm{j}}$ \\
\hline PrQi & Peso relativo de cada item das qualidades exigidas \\
\hline $\mathrm{P}_{\mathrm{T}}$ & Número total de passageiros transportados no período avaliado \\
\hline $\mathrm{P}_{\mathrm{V}}$ & Portas no veículo \\
\hline $\mathrm{Q}_{\mathrm{AS}}$ & Quantidade de assentos por veículo \\
\hline $\mathrm{Q}_{\mathrm{E}}$ & Quilometragem especificada \\
\hline QFD & Quality Function Deployment \\
\hline $\mathrm{QPO}_{\mathrm{PO}}$ & Quantidade de portas no veículo \\
\hline $\mathrm{Q}_{\mathrm{R}}$ & Quilometragem realizada \\
\hline $\mathrm{R}_{\mathrm{C}}$ & Número de reclamações sobre comportamento da tripulação no período \\
\hline RJ & Rio de Janeiro \\
\hline $\mathrm{RN}$ & Rio Grande do Norte \\
\hline RO & Rondônia \\
\hline $\mathrm{R}_{\mathrm{P}}$ & Número de reclamações sobre desobediência à solicitação de parada no período \\
\hline RS & Rio Grande do Sul \\
\hline $\mathrm{R}_{\mathrm{V}}$ & Número de reclamações sobre velocidade no período \\
\hline S/A & Sociedade Anônima \\
\hline $\mathrm{SC}$ & Santa Catarina \\
\hline SEDU/PR & Secretaria Especial de Desenvolvimento Urbano da Presidência da República \\
\hline $\mathrm{S}_{\mathrm{G}}$ & Segurança \\
\hline $\mathrm{S}_{\mathrm{M}}$ & Valor do salário mínimo vigente no período avaliado \\
\hline SP & São Paulo \\
\hline Sra & Senhora \\
\hline Sta & Santa \\
\hline $\mathrm{T}_{\mathrm{A}}$ & Tarifa \\
\hline $\mathrm{T}_{\mathrm{AR}}$ & Valor da tarifa \\
\hline $\mathrm{T}_{\mathrm{C}}$ & Valor da tarifa cheia \\
\hline $\mathrm{T}_{\mathrm{E}}$ & Tempo \\
\hline
\end{tabular}




\begin{tabular}{|c|c|}
\hline $\mathrm{T}_{\mathrm{ES}}$ & Tempo de espera \\
\hline TO & Tocantins \\
\hline TQC & Controle da Qualidade Total \\
\hline $\mathrm{T}_{\mathrm{R}}$ & Tripulação \\
\hline $\mathrm{T}_{\mathrm{V}}$ & Tempo de viagem \\
\hline UK & United Kingdom (Reino Unido) \\
\hline V & Número total de veículos no sistema \\
\hline V1 & Número de veículos com um nível de informação \\
\hline $\mathrm{V} 2$ & Número de veículos com dois níveis de informações \\
\hline $\mathrm{V}_{\mathrm{A}}$ & Número de viagens atrasadas \\
\hline $\mathrm{V}_{\mathrm{AC}}$ & Veículos acessíveis \\
\hline $\mathrm{V}_{\mathrm{C}}$ & Número de veículos acessíveis no sistema \\
\hline $\mathrm{V}_{\mathrm{D}}$ & Valor máximo de desconto para o usuário \\
\hline $\mathrm{V}_{\mathrm{E}}$ & Veículos \\
\hline $\mathrm{V}_{\mathrm{EL}}$ & Velocidade do veículo \\
\hline $\mathrm{V}_{\mathrm{I}}$ & Número total de veículos do sistema \\
\hline $\mathrm{V}_{\mathrm{IN}}$ & Viagens interrompidas por falha mecânica \\
\hline $\mathrm{V}_{\mathrm{L}}$ & Número de veículos lotados observados \\
\hline $\mathrm{V}_{\mathrm{LI}}$ & Veículos limpos \\
\hline $\mathrm{V}_{\mathrm{LO}}$ & Veículos lotados \\
\hline $\mathrm{V}_{\mathrm{N}}$ & Números de viagens não realizadas \\
\hline $\mathrm{V}_{\mathrm{O}}$ & Número de veículos observados \\
\hline $\mathrm{V}_{\mathrm{R}}$ & Número total de viagens realizadas no período \\
\hline $\mathrm{V}_{\mathrm{S}}$ & Número de veículos sujos \\
\hline $\mathrm{V}_{\mathrm{T}}$ & Número total de viagens programadas para o período \\
\hline $\mathrm{V}_{\mathrm{V}}$ & Número de veículos avaliados \\
\hline $\mathrm{Xij}$ & Correlação entre qualidade exigida e CQ \\
\hline
\end{tabular}




\section{INTRODUÇÃO}

\subsection{APRESENTAÇÃO}

O transporte público é um serviço essencial para toda a sociedade e não somente para seus usuários. O serviço é o principal meio de deslocamento nas cidades e possibilita que as pessoas tenham acesso às oportunidades de trabalho, aos equipamentos públicos, aos serviços sociais e às atividades que garantem a dignidade humana e a integração social (GOMIDE et al, 2006), além de facilitar as atividades de consumo, garantindo a movimentação da economia.

Porém, atualmente, está ocorrendo a massiva migração do uso do transporte público para o transporte privado. A taxa de crescimento de veículos nas ruas tem aumentado em escala muito superior à da população. Conforme CNI (2012), entre 2003 e 2010, no Brasil o crescimento demográfico foi de $13 \%$ enquanto o crescimento de veículos foi de $66 \%$. O aumento do uso do transporte privado faz com que alguns problemas da cidade também aumentem proporcionalmente, tais como poluição do ar, poluição sonora, congestionamentos, saturação viária, acidentes, entre outros.

O aumento da frota do transporte individual também traz sérias consequências ao desempenho do transporte coletivo, na medida em que diminui os espaços urbanos disponíveis para este tipo de transportes, reduzindo a velocidade operacional e aumentando os custos do sistema, mesmo não sendo o único fator que provoque esta reação visto que a falta de investimentos e a ineficiência de algumas empresas operadoras e órgãos gestores também contribuem para este cenário.

O Relatório Analítico da Pesquisa da Seção de Passageiros (CNT, 2002) discute tais externalidades do transporte individual sobre o transporte coletivo e concatena estas em um esquema lógico que pode ser conferido na Figura 1.1. A figura descreve a cadeia de reação dos investimentos públicos que priorizam o transporte individual (como o incentivo à compra de veículos, a criação de vagas de estacionamento, entre outros). $\mathrm{O}$ efeito imediato é o aumento da frota, que provoca o aumento dos congestionamentos, contribui para a redução da velocidade comercial dos ônibus, o que provoca o aumento da frota de ônibus e custos gerais do sistema, prejudicando a produtividade, incentivando o transporte ilegal e causando a perda de demanda do transporte público para o individual, completando o ciclo. 


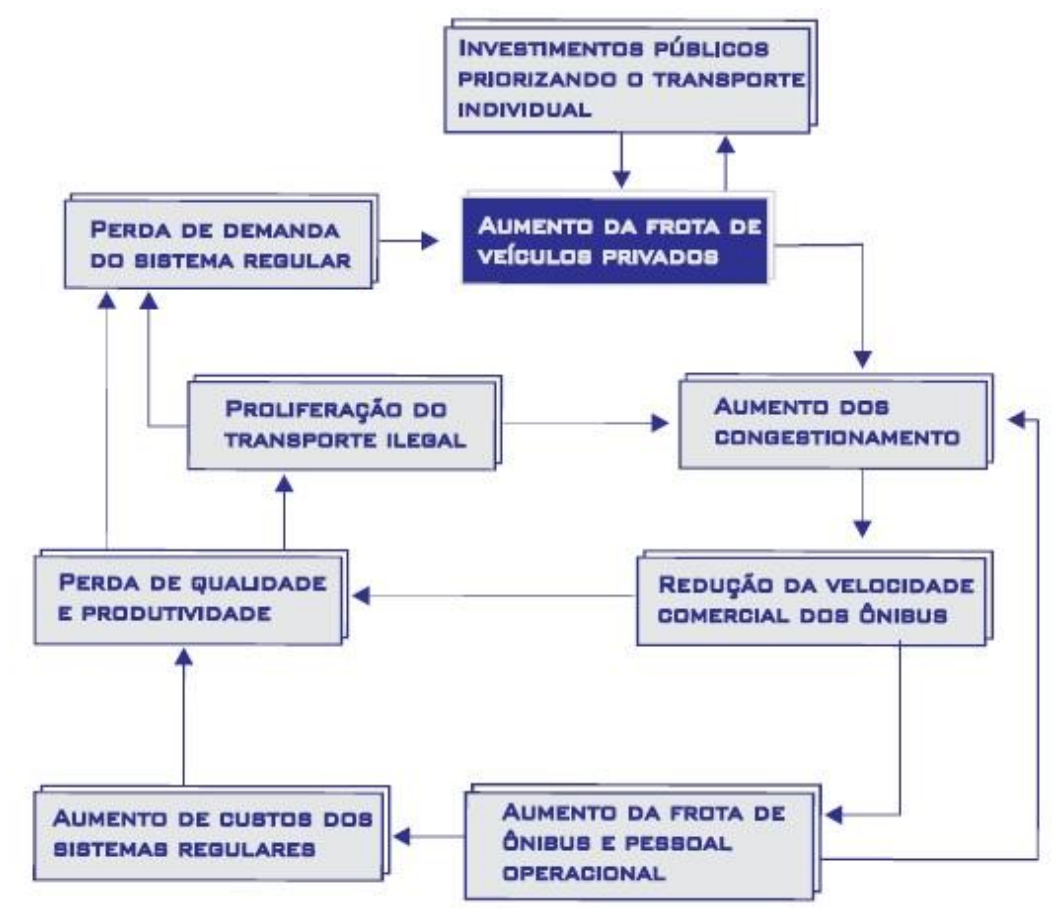

Figura 1.1. Influência do aumento do tráfego urbano sobre o desempenho do sistema de transporte público urbano coletivo.

Fonte: CNT, 2002

Para Brinco (2006), a preferência pelo uso de transporte privado é, na maioria das vezes, decorrente da ausência de alternativas de transporte coletivo que ofereçam níveis de conforto e rapidez semelhantes ao do veículo particular. Ramos (2013) sugere que aumentar o uso do transporte coletivo é uma das principais estratégias para reverter a migração para o transporte privado, e a medida mais efetiva para tal é investir na qualidade do serviço de transporte coletivo.

Ramos (2013) complementa afirmando que o primeiro passo a favor da busca por melhores serviços consiste no estabelecimento de indicadores que reflitam os vários aspectos da qualidade desejada pelo usuário. A partir destes indicadores é possível conhecer os atributos que necessitam ser melhorados para garantir um transporte público de qualidade, e assim direcionar investimentos e ações públicas e privadas.

\subsection{CONTEXTUALIZAÇÃO DO PROBLEMA}

O transporte público, no Brasil, é um serviço concedido, ou seja, é de responsabilidade da administração pública, mas pode ser concedido à operação privada mantendo a gestão pelo órgão público. Todo e qualquer serviço público concedido no país deve obedecer à Lei No 8987, de 13 de fevereiro de 1995 (BRASIL, 1995a), conhecida como Lei de Concessão dos Serviços Públicos, que rege as formalidades da gestão das concessões. Essa traz os itens mínimos de qualidade que devem ser observados no serviço público concedido, formando o que se chama de serviço adequado. 
Diante da necessidade de definição de parâmetros para medição da qualidade do transporte público, e a importância dessa medição para a mobilidade urbana das cidades brasileiras, este estudo trata do desenvolvimento de uma metodologia que considere os itens descritos em legislação federal para avaliação da qualidade do transporte público.

\subsection{OBJETIVOS}

\subsubsection{Objetivo geral}

Propõe-se a formulação de um índice para avaliação da qualidade do transporte público por ônibus que considere os aspectos de serviço adequado descritos na Lei de Concessão dos Serviços Públicos.

\subsubsection{Objetivos específicos}

I. Conhecer os aspectos do transporte público por ônibus mais importantes para a qualidade do mesmo, de acordo com os usuários;

II. Relacionar os aspectos considerados pela população com aqueles definidos na legislação federal;

III. Desenvolver um índice, genérico em todo o território nacional, para a avaliação da qualidade do transporte público por ônibus;

IV. Demonstrar a aplicação do índice através da realização de um estudo de caso.

\subsection{JUSTIFICATIVA}

A oferta de transporte público possibilita que a cidade se movimente, produza e distribua riquezas (transportando trabalhadores e consumidores), e também atenda aos seus cidadãos. Portanto, deve-se cuidar para que um serviço de tamanha importância seja oferecido dentro de parâmetros mínimos de qualidade, e que esses parâmetros sejam aferidos periodicamente por um gerenciador, agindo assim como um defensor dos usuários. Esta é a diretriz que orientou a proposta de realização desta pesquisa.

A delimitação do estudo dentro do cenário, fazendo com que esta pesquisa aborde somente o transporte público coletivo por ônibus, se deve à maior concentração de viagens neste modal. O Relatório Comparativo 2003-2011 do Sistema de Informações da Mobilidade Urbana (ANTP, 2012) destaca que, no ano de 2011, 25\% das viagens nas cidades brasileiras pesquisadas (438 municípios) foram realizadas em ônibus municipais e metropolitanos. Tal concentração se deve também à oferta de lugares, que de acordo com o mesmo relatório, era de 7,5 milhões de passageiros nos ônibus naquele ano, abrangendo $89,3 \%$ do total de lugares ofertados no transporte coletivo.

Conforme destaca Bertozzi e Lima Jr. (1998), a definição dos indicadores, bem como os instrumentos para esta medição, para a avaliação da qualidade do transporte público tem 
sido discutida por diversos autores. Porém não se chegou a um consenso sobre quais itens são mais ou menos importantes na mensuração da qualidade do transporte público.

Considerando a existência de uma lei federal em vigor (Lei $\mathrm{n}^{\circ}$ 8987) que apresenta aspectos que devem ser observados na prestação de serviços concedidos, o que faz destes comuns a todo o território nacional, esta pesquisa contribui para a elaboração de um índice único, que possa ser aplicado em todas as cidades brasileiras, trazendo ainda o adendo de possibilitar a comparação dos resultados entre as cidades.

Nesta pesquisa é realizado um estudo de caso para validação do índice. Esse estudo se dá na cidade de Belo Horizonte, capital do Estado das Minas Gerais. A escolha deu-se em função da disponibilidade de informações provindas do monitoramento contínuo do sistema de transporte público por ônibus da cidade.

\subsection{METODOLOGIA DA DISSERTAÇÃO}

O desenvolvimento da pesquisa ocorre pelo método descritivo, onde o fenômeno é discutido e analisado, e após são realizadas coletas de dados em campo. Estas coletas se dão por modelos qualitativos, que fornecem uma maior precisão sobre o sentimento dos usuários em relação ao sistema de transporte público.

A pesquisa é realizada a partir de quatro fases, estruturando esta dissertação, que está dividida em 6 capítulos, incluindo esta introdução.

\subsection{1 $1^{a}$ Fase: Referencial teórico}

Nesta primeira fase, desenvolvida no Capítulo 2, é consultada a literatura científica publicada sobre quatro temas inerentes à pesquisa. O primeiro tema, função social do transporte público, foi selecionado para que seja considerada a importância do transporte público para todos, sendo ou não usuários do sistema. Somente a partir do entendimento do impacto que este serviço tem sobre as cidades e as pessoas é que será possível discutir a necessidade de oferecer um serviço de qualidade.

O segundo tema, qualidade, considera os autores que trabalharam os conceitos e definições de qualidade e qualidade em serviços (privados e públicos). Este tema é importante para o entendimento da importância de um serviço de qualidade, em especial quando este se trata de um direito público.

O tema seguinte, avaliação da qualidade do transporte público, onde são discutidos estudos acerca do desenvolvimento de índices e métodos de avaliação da qualidade, buscando dar suporte à criação de um índice eficiente para a avaliação da qualidade do transporte público de passageiros.

Concluindo o capítulo, é abordado o tema concessão de serviços públicos, tratando da Lei de Concessão dos Serviços Públicos e seus parâmetros de serviço adequado que são utilizados nesta pesquisa. 


\subsection{2 $2^{a}$ Fase: Desenvolvimento do método}

Esta fase da pesquisa abrange os terceiro e quarto capítulos da dissertação. No Capítulo 3, intitulado Procedimento Metodológico, são abordadas as três etapas de aplicação da pesquisa (pesquisa de relevância para o usuário, valoração dos indicadores e validação), descrevendo os passos e métodos utilizados.

No Capítulo 4 são descritas as pesquisas de campo realizadas, desde a concepção até os resultados, incluindo o tratamento dos dados. Ao fim do capítulo é apresentado o índice proposto como resultado das pesquisas aplicadas.

\subsection{3 $3^{a}$ Fase: Estudo de caso}

Após a elaboração do índice, descreve-se no quinto capítulo a realização da validação do mesmo, um estudo de caso na cidade de Belo Horizonte/MG com dados da Empresa de Transportes e Trânsito de Belo Horizonte S/A - BHTrans, que monitora em tempo real todo o serviço de transporte público por ônibus da cidade e concatena diversas informações sobre este.

Nesta fase, a qualidade do serviço de transporte público de passageiros por ônibus da cidade é avaliada a partir da aplicação do índice elaborado, demonstrando como ele pode ser usado pelos órgãos gestores de transporte público.

\subsection{4 $4^{a}$ Fase: Avaliação do método}

Esta fase da pesquisa compreende o sexto capítulo da dissertação, que conclui a pesquisa, analisando os resultados sob a ótica dos objetivos traçados e comentando as limitações da pesquisa, acrescentando recomendações para estudos futuros.

\subsubsection{Resumo esquemático da metodologia da dissertação}

A Figura 1.2 apresenta o resumo esquemático da metodologia da dissertação, utilizando aspectos gráficos para descrever, em suma, as quatro fases de pesquisa.

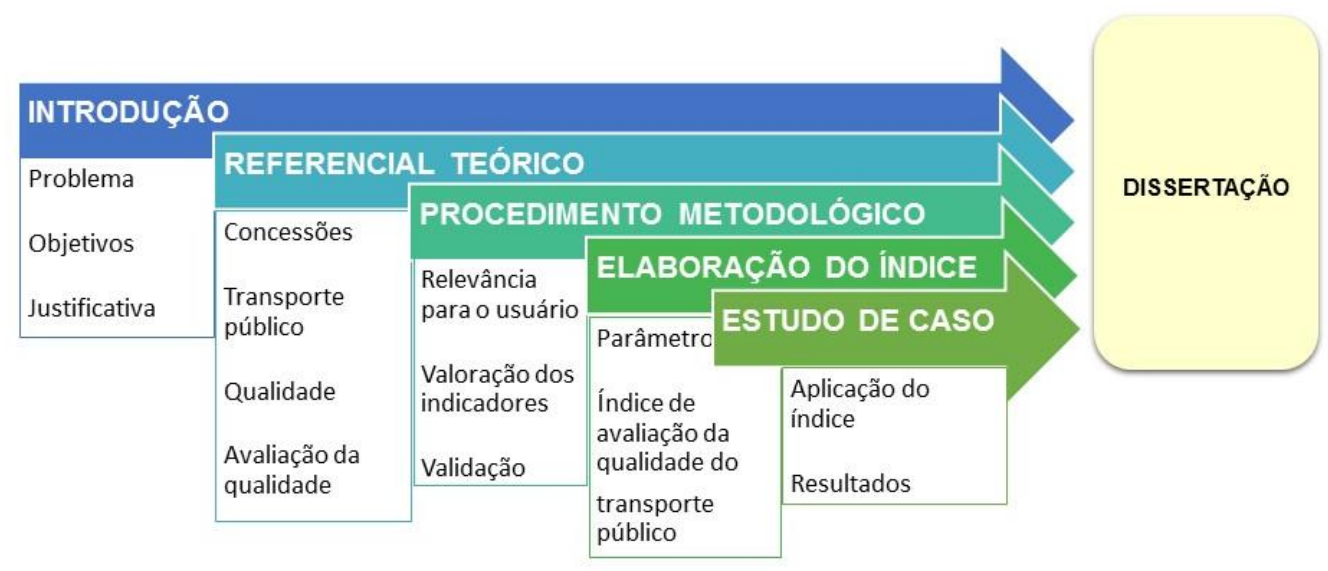

Figura 1.2: Resumo esquemático da metodologia da dissertação

Fonte: Elaborado pelo autor 


\section{REFERENCIAL TEÓRICO}

\subsection{APRESENTAÇÃO}

Uma pesquisa só pode ser pensada e planejada a partir da procura e entendimento do conhecimento existente sobre os objetos em estudo. $\mathrm{O}$ entendimento necessário à realização desta pesquisa está reunido neste capítulo. A partir da análise das publicações referenciadas ao fim do documento, este capítulo se inicia com a discussão da função social do transporte público, aborda as definições de qualidade em produtos e serviços, passando pela apresentação de alguns dos atores que já trabalharam a avaliação da qualidade do transporte público e concluindo com uma explanação sobre a Lei de Concessão do Serviço Público e seus parâmetros de serviço adequado.

\subsection{FUNÇÃO SOCIAL DO TRANSPORTE PÚBLICO}

As pessoas têm necessidade de se deslocar para terem acesso à maioria dos produtos e serviços disponíveis. Esse deslocamento é o pano de fundo do cenário urbano, o que faz das cidades um local de constante movimento. Todo esse movimento forma um sistema de transporte que, de acordo com Manheim (1979a) é a junção de pessoas e bens transportados. Mesmo essa movimentação sendo um fator coletivo, muitos optam por realizar seus deslocamentos motorizados de forma individual, seja por motivos de conforto ou falta de alternativas de transporte para o destino desejado.

Porém, o uso exagerado de veículos particulares para transporte traz problemas a toda a população, como poluição e congestionamentos, além de prejudicar a eficiência do transporte coletivo - com diminuição da velocidade operacional e da demanda, visto a migração dos passageiros insatisfeitos com a velocidade do serviço. O Relatório Técnico de Prioridade para o Transporte Público Urbano, desenvolvido por SEDU/PR e NTU (2002), discute as externalidades do transporte individual sobre o coletivo, e apresenta os índices relativos destas externalidades por passageiro/km, que pode ser verificado na Figura 2.1.

\begin{tabular}{|c|c|c|c|c|c|}
\hline \multirow{2}{*}{ MODO } & \multicolumn{4}{|c|}{ ÍNDICES RELATIVOS POR PASSAGEIRO $/ \mathrm{KM}^{2}$} & \multirow{5}{*}{ 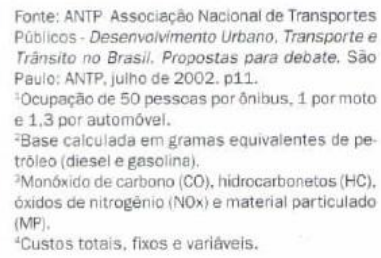 } \\
\hline & Energia ${ }^{2}$ & Poluiçāo ${ }^{3}$ & Custo Total ${ }^{4}$ & Área de Via & \\
\hline Ônibus & 1 & 1 & 1 & 1 & \\
\hline Motocicleta & 4,6 & 32,3 & 3,9 & 4,2 & \\
\hline Automóvel & 12,7 & 17,0 & 8,0 & 6,4 & \\
\hline
\end{tabular}

Figura 2.1. Indicadores comparativos entre ônibus, motocicletas e automóveis.

Fonte: ANTP (2002) apud SEDU/PR e NTU (2002)

Conforme pode ser observado, o transporte coletivo necessita de menos energia e espaço nas vias, além de poluir menos (por passageiro transportado) e ser mais barato 
do que os veículos de transporte individual. Porém, o impacto do transporte público vai muito além da mobilidade urbana: o serviço tem influência sobre a sociedade em geral, incluindo setores como economia, saúde e inclusão social.

De acordo com o relatório do ITRANS (2004), a partir das estimativas existentes com base na renda familiar per capita, a proporção de brasileiros que viviam abaixo da linha de pobreza era de cerca de 34\%, segundo cálculos do IPEA (naquele ano). Já a proporção de indigentes, ou seja, os que não tinham renda sequer para consumir o mínimo de calorias definido pela Organização Mundial da Saúde - OMS, era de cerca de $14 \%$ da população.

O documento destaca também que, em termos absolutos, a pobreza no Brasil é preponderantemente urbana. De acordo com Morais e Lima (2001), no ano da publicação, do número absoluto de pobres, $76 \%$ viviam em áreas urbanas, sendo $48 \%$ em aglomerações urbanas.

"Essas informações mostram a necessidade da priorização de políticas de combate à pobreza nas áreas urbanas, especialmente nas metrópoles e aglomerações urbanas, onde vive quase a metade da população pobre brasileira e onde são mais sérios os problemas urbanos - em particular, os problemas de transporte urbano e de mobilidade da população" (ITRANS, 2004).

"A desigualdade social e espacialidade periférica destas populações podem ser mitigadas por uma política de transporte público que promova a mobilidade destas pessoas, aumentando assim o acesso às atividades socioeconômicas, à infraestrutura pública e a serviços essenciais disponíveis" (ROSA, 2006).

Conforme IBGE (2008), num país tão extenso, e com tantas carências, a localização de serviços de saúde e educação tem de considerar as condições de acessibilidade da população aos locais onde estão instalados. Infelizmente, na prática, o sistema de transporte não é um fator considerado determinante na definição da localização dos serviços, e, portanto, a remediação do acesso se dá na adaptação do transporte público aos serviços.

De acordo com Cardoso (2008), a desigualdade social resulta de diversos fatores: (a) o desempenho da economia; (b) as condições socioeconômicas das diferentes populações que habitam a cidade; (c) a distribuição urbana, principalmente a distância entre os locais de moradia, as atividades socioeconômicas e as infraestruturas públicas (hospitais, escolas, etc.) e (d) o atendimento do transporte coletivo público à população nas diferentes regiões da cidade.

"Combater a exclusão social significa, então, lutar contra as situações de privação, exclusão e carências, de tal forma que a toda pessoa sejam dadas condições mínimas para exercer seus direitos e suas capacidades" (GOMIDE, 2003). É verdade que o investimento em transporte público somente não pode suprir tais carências, pois existem 
amplas questões sociais, políticas, econômicas e até culturais que contribuem para a exclusão social. Porém, o que se reconhece é que o transporte público é um meio que leva as pessoas às oportunidades de transpor tais barreiras.

Para Manheim (1979a), o transporte é uma demanda derivada de necessidades sociais das pessoas, tais como trabalhar, estudar e saúde, derivando do seu estilo de vida. "Os subsídios a serem concedidos dessa maneira devem ter como objetivo quebrar o círculo vicioso da pobreza (pobreza $\rightarrow$ baixa mobilidade $\rightarrow$ segregação sócio espacial $\rightarrow$ pobreza) com essas necessidades básicas, sua eficácia pode ser drasticamente comprometida" (ITRANS, 2004).

Os impactos do transporte público sobre a pobreza são diversos. Gomide (2003) resume-os em duas formas: indiretos e diretos. Os impactos indiretos relacionam-se às externalidades do serviço sobre a competitividade das cidades e o uso do solo. Os impactos diretos, por usa vez, envolvem o acesso aos serviços e às atividades sociais básicos e às oportunidades de trabalho dos mais pobres. $\mathrm{O}$ autor apresenta as formas de impacto do transporte urbano sobre a pobreza em forma de diagrama, que pode ser verificado na Figura 2.2.

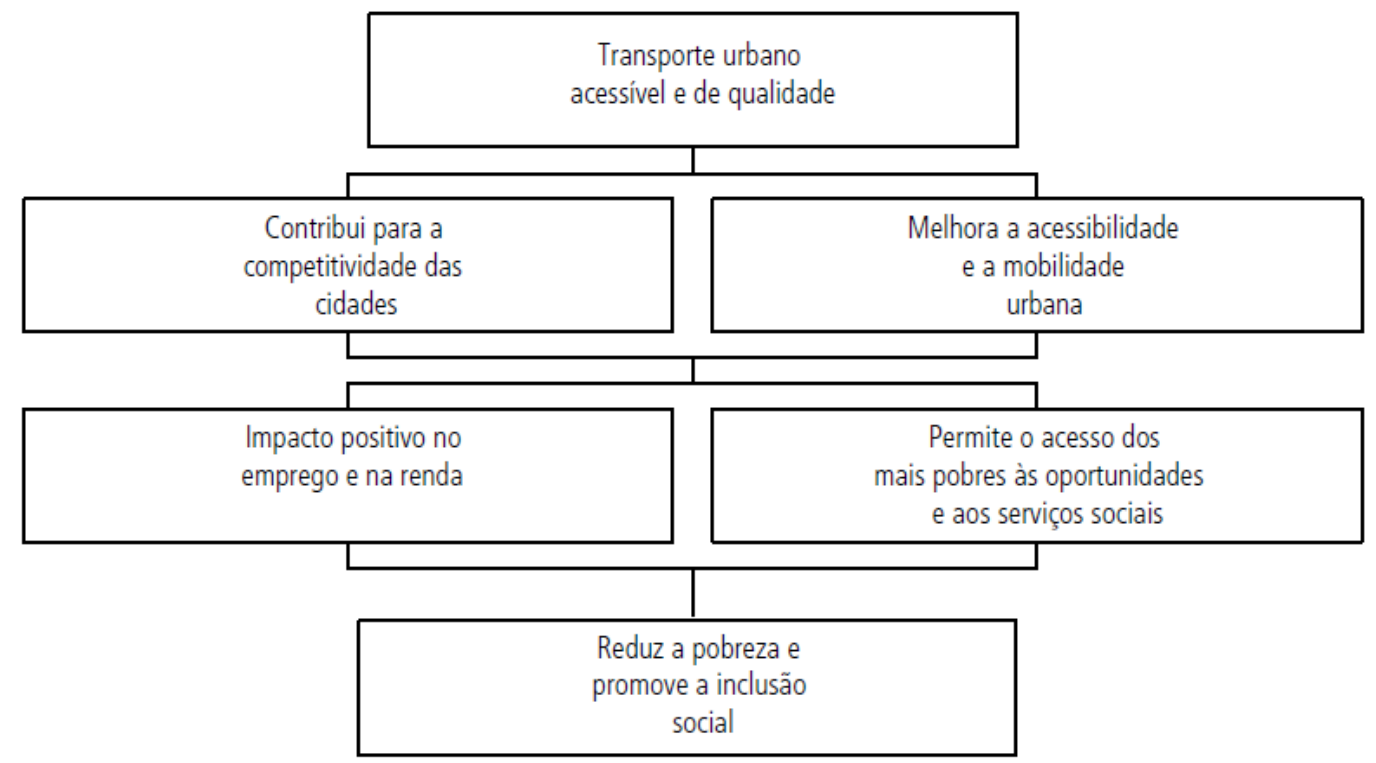

Figura 2.2. Impactos do transporte urbano sobre a pobreza.

Fonte: GOMIDE (2003)

Cardoso (2008) destaca que o sistema de transporte público está sendo usado unicamente como ferramenta para disponibilizar a força de trabalho ao capital, nas diferentes regiões produtivas da cidade, deixando de lado necessidades básicas do trabalhador como escola, saúde e lazer. Os autores alertam também para o fato de que toda pessoa necessita permanecer integrada à comunidade para preservar seu senso de valor, o que justifica a necessidade de se planejar transporte para a sociabilidade e não para o emprego como função social isolada, entendo que o serviço permite muitas 
outras oportunidades aos usuários além de unicamente o deslocamento entre local de moradia e local de trabalho.

Vasconcellos (2001) destaca que as usuais metodologias de planejamento de transporte têm sido utilizadas para reproduzir as desigualdades, para orientar um crescimento urbano ineficiente em termos ambientais e excludentes em termos sociais. Desta forma, o Estado necessita avaliar e repensar as metodologias de planejamento do serviço, reconhecendo sua importância social e econômica, pois o Estado é, constitucionalmente, o responsável por prover os direitos sociais do cidadão, direitos estes que podem ser de fácil ou difícil acesso para a população, de acordo com o sistema de transporte público ofertado.

Gomide et al., (2006) contribuem para o debate ao afirmar que o transporte público urbano, de acordo com a Constituição Brasileira, é um serviço de caráter essencial e, portanto, se o serviço não for adequado às necessidades da população, especialmente a mais pobre, ele pode transformar-se num empecilho ao acesso às oportunidades e atividades essenciais, isto é, numa barreira à inclusão social.

Em suma, Gomide (2003) define que os elementos para formulação de políticas públicas em transporte devem ser: (a) subsídios às tarifas, (b) regulação e gestão do sistema, (c) apoio aos segmentos sociais vulneráveis, (d) prioridade para o transporte coletivo e não motorizado, (e) fontes alternativas de financiamento, (f) integração de políticas e informações, e (g) participação popular no planejamento.

Este último aspecto é uma peça importante para a construção de um transporte público que atenda às necessidades da população. O próprio Gomide (2003) comenta que promover a participação dos mais pobres e de suas comunidades na vida política e nos processos de decisão é um desafio para as políticas de inclusão social e de melhoria dos serviços públicos no país.

“Os novos espaços, forjados pela Constituição de 1988, de participação popular nas instâncias decisórias de elaboração e implementação de políticas públicas (os conselhos de gestão e de direitos) precisam avançar nesse sentido, até porque a presença e a participação do cidadão nos processos decisórios públicos constituem a forma mais acabada da inclusão social" (DA SILVA et al., 2004). Os autores ainda afirmam que tais espaços de participação contribuem para o alcance da inclusão à medida que colocam o habitante como membro político atuante nas decisões de política pública em sua comunidade.

Os espaços de participação popular também são afetados pela exclusão: nem todos têm acesso às discussões, e tal exclusão acontece por diversos motivos, indo da falta de acesso à internet até a impossibilidade de se deslocar aos locais de reuniões. O Decreto $N^{\circ} 8243$, de 23 de maio de 2014 (que não mais compõe a legislação brasileira, pois fora derrubado no Congresso Nacional), no inciso VII do Artigo 4, institui que um dos objetivos da Política Nacional de Participação Social é “desenvolver mecanismos de 
participação social acessíveis aos grupos sociais historicamente excluídos e aos vulneráveis" (BRASIL, 2014), o que reforça a existência deste tipo de exclusão. Portanto, é necessária a criação de espaços e mecanismos para que os serviços prestados à população sejam planejados e elaborados de forma democrática e inclusiva.

O Relatório de Desenvolvimento Mundial de 2004 do Banco Mundial (WORLD BANK, 2004) indica que os serviços públicos atendem melhor aos mais pobres quando as comunidades estão no centro da sua prestação, ou seja, quando elas participam na determinação da qualidade e quantidade dos serviços que recebem, assim como na sua avaliação. Isso pode ser conseguido por meio do aperfeiçoamento da participação social na avaliação e definição dos serviços, apresentando à população métodos e instrumentos simples que possam ser facilmente interpretados e permitam a discussão, considerando a opinião dos usuários.

Concluindo, com base na discussão dos autores, pode-se definir o transporte como um meio de acesso à inclusão social, visto que este facilita o deslocamento da população às oportunidades, o que faz este serviço essencial para a população, em especial os mais carentes. Desta essencialidade surge a necessidade de se ouvir a população no planejamento e demais decisões do serviço. Também cabe sujeitar à população, para quem o serviço é efetivamente operado, a avaliação do mesmo, assim como deve ocorrer em todos os serviços de caráter público.

\subsection{QUALIDADE}

De acordo com Costa (1994) apud Morais (2012), qualidade é vista como o conjunto de características do produto que vão ao encontro das necessidades dos clientes, deixandoos assim satisfeitos quanto ao produto. Já Grönroos (1995) defende que a qualidade é aquilo que os clientes percebem do produto ou serviço. Ishikawa (1993) apud Cardoso (1995) acrescenta a importância da percepção rápida por parte das empresas às exigências crescentes de mercado, para que seu produto ou serviço acompanhe os desejos do cliente, e assim sejam considerados de qualidade.

Ramos (2013) destaca que a qualidade percebida é o resultado da comparação das percepções com as expectativas dos clientes e, portanto, está diretamente ligada à satisfação do cliente com o serviço recebido. Lima (1996) argumenta que as necessidades dos clientes são dinâmicas e ocorrem em função das condições econômicas e culturais de um determinado ambiente. Portanto, a qualidade é uma noção relativa abrangente e muito ampla, não podendo ser definida de uma forma breve e simples (RAMOS, 2013).

Campos (1992), que orientou a implantação do Controle da Qualidade Total - TQC no estilo japonês, afirma que um produto ou serviço de qualidade é aquele que atende perfeitamente, de forma confiável, de forma acessível, de forma segura e no tempo certo às necessidades do cliente. Portanto, as empresas devem estabelecer metas de qualidade para atender às necessidades dos clientes para sobreviverem ao mercado. Para o serviço 
de transporte público isso significa que é preciso atentar para os requisitos de qualidade para não perder demanda e desestimular a migração dos usuários para outros modos de transporte.

Qualidade nos transportes, para Braga (1995), é o resultado dos níveis de serviço da ação integrada entre os três agentes envolvidos no processo (usuários, empresas e poder público). Lima (1996) destaca que, diferente dos outros serviços e da manufatura, as atividades de transporte são realizadas em ambientes não controlados (espaço aéreo, mar, ruas), daí a necessidade de adaptação do conceito de qualidade a esse serviço.

ANTP (1997) afirma que um programa de qualidade em transporte público tem por objetivo obter uma melhoria geral na prestação do serviço, e que essa melhoria não apenas cumpre um objetivo essencial da administração pública, como também gera condições para a reorganização do crescimento da cidade, para a redução dos impactos ambientais, para a maior atratividade dos meios públicos de transporte e para a melhoria geral da qualidade de vida.

Conforme Morais (2012), a percepção dos usuários sobre a qualidade do transporte público urbano influencia na decisão sobre qual modo de transporte utilizar para a realização dos deslocamentos. Dessa forma, um serviço de transporte público de qualidade deve considerar as necessidades e opiniões de todos no que tange aos fatores críticos - aqueles mais sensíveis ao usuário, e suas adequações (ARPINI e RIBEIRO, 2012).

Valente (2008) traz o enfoque da discussão para a precisa identificação do tipo de oferta desejada, para que o planejamento do transporte urbano possa acompanhar não somente os desejos, mas as necessidades da população, visto que, conforme Campos (1992), as necessidades das pessoas mudam continuamente.

Correia (2004) esclarece que é necessário descobrir o que os usuários do produto julgam por qualidade, ou seja, verificar quais são as características importantes de acordo com as necessidades do cliente, ou promover sua satisfação. Uma vez descobertas, tais características devem ser mensuradas e ponderadas para a avaliação da qualidade final do produto. Portanto, considerando o serviço de transporte público, é essencial que existam indicadores e outros mecanismos de avaliação da qualidade do sistema para promover a satisfação da oferta desejada pelos usuários.

\subsection{AVALIAÇÃO DA QUALIDADE DO TRANSPORTE PÚBLICO}

Hoffmann (1991), ao trabalhar o modelo de avaliação educacional, introduz a "avaliação mediadora", trazendo a perspectiva da ação avaliativa como uma das mediações pela qual se encoraja a reorganização do saber. A autora se opõe ao modelo de "transmitir-verificar-registrar", buscando inserir a avaliação como um momento de diálogo entre professores e alunos sobre o conteúdo, resultando em construção do conhecimento e melhoria dos métodos. 
Sendo o transporte público um serviço essencial, assim como é a educação, faz-se necessário que também tenhamos o entendimento de que a avaliação não é somente um processo de registro da situação do serviço, mas um momento em que todos os envolvidos devem ser ouvidos e melhorias devem ser discutidas.

Apresentar os atributos relevantes para o usuário na sua avaliação da qualidade do serviço prestado tem sido discutido por diversos autores, bem como os instrumentos para esta medição (BERTOZZI e LIMA JÚNIOR, 1998). Foram elencados diversos atributos para determinação da qualidade do serviço como resultados destas pesquisas, visto as particularidades de cada ambiente estudado, sendo que muitos autores repetiram atributos em seus trabalhos. Ressalta-se que as diferenças são nominais e conceituais, sendo que um mesmo atributo utilizado por autores diferentes pode apresentar diferenças em seu conceito ou instrumentalização.

Os atributos utilizados (ou encontrados em pesquisas com usuários) pelos autores consultados nesta pesquisa são apresentados em sequência e resumidos, juntando os atributos semelhantes, na Tabela 2.1:

- Parasuraman et al. (1988): confiabilidade, responsividade, segurança, empatia e tangibilidade;

- Lima Jr. (1995): ambiente, conforto, acessibilidade, preço, momentos de interação, comunicação, experiência anterior, imagem e confronto entre o que é realizado, comunicado e percebido;

- Lima Jr. e Gualda (1995) e Bertozzi e Lima Jr. (1998): confiabilidade, responsabilidade, empatia, segurança, tangibilidade, ambiente, conforto, acessibilidade, preço, comunicação, imagem e momentos de interação;

- Department for Transport, UK (2003) e Gomide et al. (2006): acessibilidade financeira, disponibilidade, acessibilidade física e aceitabilidade;

- Oliveira (2003): generalidade, eficiência, modicidade, cortesia e continuidade;

- Ferraz e Torres (2004): acessibilidade, frequência de atendimento, segurança, tempo de viagem, lotação, características dos veículos, características dos locais de parada, sistema de informação, conectividade, comportamento dos operadores e estado das vias;

- Cardoso (2006): acessibilidade, conforto, confiabilidade, conveniência, rapidez e segurança;

- Cordeiro et al. (2006): conservação e limpeza dos ônibus e terminais, comodidade, essencialidade, confiabilidade, segurança e atendimento; 
- Rodrigues (2006): acessibilidade, frequência, tempo de viagem, lotação, confiabilidade, segurança, veículos, locais de parada, sistema de informação, conectividade, operadores e vias;

- Antunes (2009): acessibilidade, frequência, tempo de viagem, características dos pontos de parada, características dos veículos, sistema de informações, segurança e comportamento dos operadores;

- Bubicz e Sellitto (2009): lotação dos veículos, urbanidade da tripulação, não deixar clientes nas paradas, respeito aos horários, tempo de espera, preço da passagem, informações prestadas, limpeza do veículo, segurança e qualidade das paradas;

- Couto (2011) e Ramos (2013): cobertura da rede, oportunidade, pontualidade e conforto;

- Arpini e Ribeiro (2012): lotação dos ônibus, tarifa, segurança pública dentro do ônibus, tempo de espera, condições ambientais dentro do veículo, estado de conservação dos pontos de parada, cumprimento do itinerário programado, tratamento dado aos idosos e deficientes, tempo de viagem, conforto dos assentos, qualidade do terminal, limpeza dos ônibus, respeito aos pontos de parada, segurança no transporte, educação e cortesia dos funcionários da empresa, estado de conservação dos ônibus, obediência ao percurso do ônibus, serviço de atendimento ao passageiro, conforto do serviço e características dos terminais;

- Morais (2012): eficiência das políticas públicas, corredores exclusivos, confiabilidade, acessibilidade, pontualidade, atuação do órgão gestor, qualificação dos operadores, equilíbrio econômico-financeiro das empresas, conservação dos terminais, informação aos usuários, segurança, apoio dos órgãos municipais de trânsito, conservação e manutenção dos veículos, lotação, eficiência da rede e vias com prioridade para o transporte público. 
Tabela 2.1: Atributos utilizados pelos autores consultados

\begin{tabular}{|c|c|c|c|c|c|c|c|c|c|c|c|c|c|c|c|c|c|}
\hline 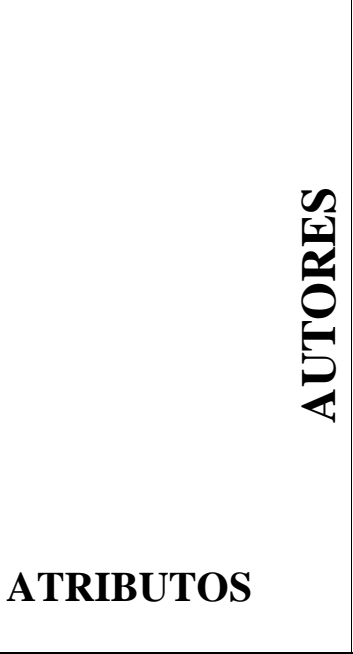 & 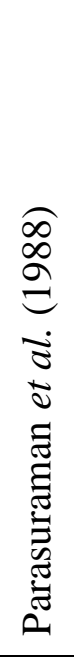 & 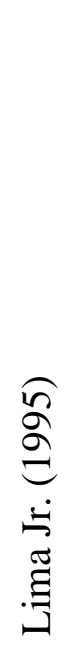 & 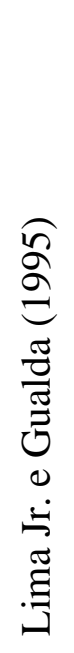 & 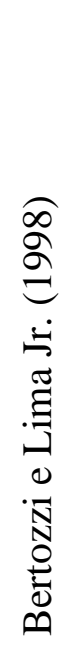 & 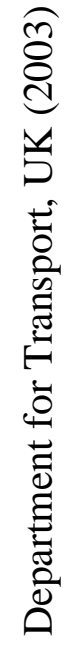 & 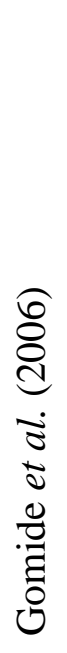 & 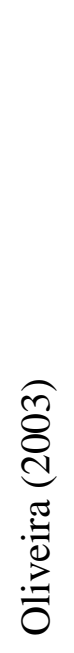 & 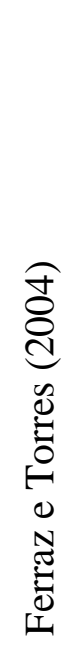 & 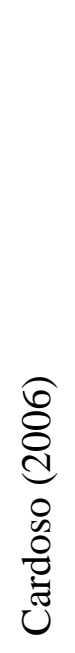 & 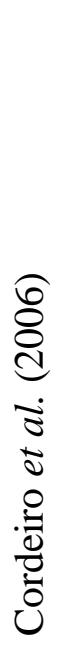 & 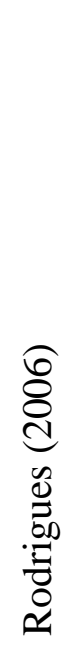 & 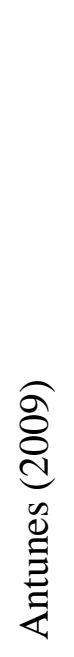 & 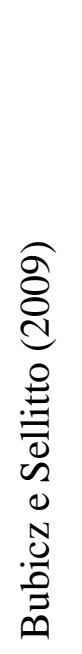 & 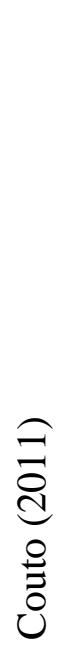 & 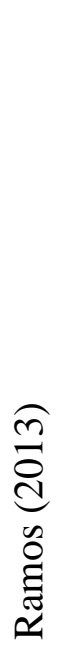 & 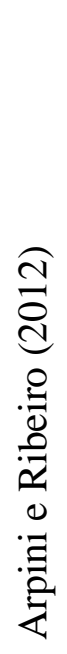 & 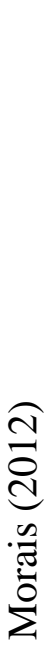 \\
\hline Aceitabilidade & & & & & $\mathrm{X}$ & $\mathrm{X}$ & & & & & & & & & & & \\
\hline Acessibilidade & & $\mathrm{X}$ & $\mathrm{X}$ & $\mathrm{X}$ & $\mathrm{X}$ & $\mathrm{X}$ & & $\mathrm{X}$ & $\mathrm{X}$ & & $\mathrm{X}$ & $\mathrm{X}$ & & & & & $\mathrm{X}$ \\
\hline Ambiente & & $\mathrm{X}$ & $\mathrm{X}$ & $\mathrm{X}$ & & & & & & & & & & & & $\mathrm{X}$ & \\
\hline $\begin{array}{c}\text { Apoio dos órgãos } \\
\text { de trânsito }\end{array}$ & & & & & & & & & & & & & & & & & $\mathrm{X}$ \\
\hline Atuação do gestor & & & & & & & & & & & & & & & & & $\mathrm{X}$ \\
\hline $\begin{array}{l}\text { Características dos } \\
\text { pontos e terminais }\end{array}$ & & & & & & & & $\mathrm{X}$ & & & & $\mathrm{X}$ & $\mathrm{X}$ & & & $X$ & \\
\hline $\begin{array}{c}\text { Características dos } \\
\text { veículos }\end{array}$ & & & & & & & & $\mathrm{X}$ & & & & $\mathrm{X}$ & & & & & \\
\hline Cobertura da rede & & & & & & & & & & $X$ & & & & $X$ & X & & \\
\hline $\begin{array}{c}\text { Comportamento } \\
\text { dos operadores }\end{array}$ & & & & & & & $X$ & $\mathrm{X}$ & & & $\mathrm{X}$ & $\mathrm{X}$ & $\mathrm{X}$ & & & $X$ & \\
\hline Comunicação & & $\mathrm{X}$ & $\mathrm{X}$ & $\mathrm{X}$ & & & & & & & & & & & & & \\
\hline Conectividade & & & & & & & & $\mathrm{X}$ & & & $\mathrm{X}$ & & & & & & \\
\hline Confiabilidade & $\mathrm{X}$ & & $\mathrm{X}$ & $\mathrm{X}$ & & & & & $\mathrm{X}$ & $\mathrm{X}$ & $\mathrm{X}$ & & & & & & $\mathrm{X}$ \\
\hline Conforto & & $\mathrm{X}$ & $\mathrm{X}$ & $\mathrm{X}$ & & & & & $\mathrm{X}$ & $\mathrm{X}$ & & & & $\mathrm{X}$ & $\mathrm{X}$ & $\mathrm{X}$ & \\
\hline $\begin{array}{l}\text { Confronto entre o } \\
\text { que é realizado, } \\
\text { comunicado e } \\
\text { percebido }\end{array}$ & & $X$ & & & & & & & & & & & & & & & \\
\hline $\begin{array}{l}\text { Conservação dos } \\
\text { pontos e terminais }\end{array}$ & & & & & & & & & & $\mathrm{X}$ & $X$ & & & & & $X$ & $\mathrm{X}$ \\
\hline
\end{tabular}




\begin{tabular}{|c|c|c|c|c|c|c|c|c|c|c|c|c|c|c|c|c|c|}
\hline $\begin{array}{l}\text { Conservação e } \\
\text { manutenção dos } \\
\text { veículos }\end{array}$ & & & & & & & & & & $X$ & $\mathrm{X}$ & & & & & $\mathrm{X}$ & $\mathrm{X}$ \\
\hline Continuidade & & & & & & & $\mathrm{X}$ & & & & & & & & & & \\
\hline Conveniência & & & & & & & & & $\mathrm{X}$ & & & & & & & & \\
\hline $\begin{array}{l}\text { Corredores } \\
\text { exclusivos }\end{array}$ & & & & & & & & & & & & & & & & & $X$ \\
\hline $\begin{array}{l}\text { Cumprimento do } \\
\text { itinerário }\end{array}$ & & & & & & & & & & & & & & & & $X$ & \\
\hline Disponibilidade & & & & & $\mathrm{X}$ & $\mathrm{X}$ & & & & & & & & & & & \\
\hline Eficiência da rede & & & & & & & $\mathrm{X}$ & & & & & & & & & & $\mathrm{X}$ \\
\hline $\begin{array}{c}\text { Eficiência das } \\
\text { políticas públicas }\end{array}$ & & & & & & & & & & & & & & & & & $\mathrm{X}$ \\
\hline Empatia & $\mathrm{X}$ & & $\mathrm{X}$ & $\mathrm{X}$ & & & & & & & & & & & & & \\
\hline $\begin{array}{c}\text { Equilíbrio } \\
\text { econômico- } \\
\text { financeiro das } \\
\text { empresas }\end{array}$ & & & & & & & & & & & & & & & & & $X$ \\
\hline Essencialidade & & & & & & & & & & $X$ & & & & & & & \\
\hline Estado das vias & & & & & & & & $\mathrm{X}$ & & & $\mathrm{X}$ & & & & & & \\
\hline $\begin{array}{l}\text { Experiência } \\
\text { anterior }\end{array}$ & & $X$ & & & & & & & & & & & & & & & \\
\hline Frequência & & & & & & & & $\mathrm{X}$ & & & $\mathrm{X}$ & $\mathrm{X}$ & & & & & \\
\hline Generalidade & & & & & & & $X$ & & & & & & & & & & \\
\hline Imagem & & $\mathrm{X}$ & $\mathrm{X}$ & $\mathrm{X}$ & & & & & & & & & & & & & \\
\hline $\begin{array}{c}\text { Informação aos } \\
\text { usuários }\end{array}$ & & & & & & & & & & & & & & & & & $\mathrm{X}$ \\
\hline Lotação & & & & & & & & $\mathrm{X}$ & & & $X$ & & $X$ & & & $X$ & $\mathrm{X}$ \\
\hline $\begin{array}{l}\text { Momentos de } \\
\text { interação }\end{array}$ & & $X$ & $\mathrm{X}$ & $\mathrm{X}$ & & & & & & & & & & & & & \\
\hline Oportunidade & & & & & & & & & & & & & & $\mathrm{X}$ & $\mathrm{X}$ & & \\
\hline Pontualidade & & & & & & & & & & & & & $X$ & $\mathrm{X}$ & $X$ & & $\mathrm{X}$ \\
\hline $\begin{array}{c}\text { Qualificação dos } \\
\text { operadores }\end{array}$ & & & & & & & & & & & & & & & & & $\mathrm{X}$ \\
\hline $\begin{array}{c}\text { Respeito aos } \\
\text { pontos de parada }\end{array}$ & & & & & & & & & & & & & $\mathrm{X}$ & & & $X$ & \\
\hline
\end{tabular}




\begin{tabular}{c|l|l|l|l|l|l|l|l|l|l|l|l|l|l|l|l|l}
\hline Responsabilidade & & & $\mathrm{X}$ & $\mathrm{X}$ & & & & & & & & & & & & & \\
\hline Responsividade & $\mathrm{X}$ & & & & & & & & & & & & & & & & \\
\hline Segurança & $\mathrm{X}$ & & $\mathrm{X}$ & $\mathrm{X}$ & & & & $\mathrm{X}$ & $\mathrm{X}$ & & $\mathrm{X}$ & $\mathrm{X}$ & $\mathrm{X}$ & & & $\mathrm{X}$ & $\mathrm{X}$ \\
\hline $\begin{array}{c}\text { Serviço de } \\
\text { atendimento ao } \\
\text { passageiro }\end{array}$ & & & & & & & & & & $\mathrm{X}$ & & & & & & $\mathrm{X}$ & \\
\hline $\begin{array}{c}\text { Sistema de } \\
\text { informações }\end{array}$ & & & & & & & & $\mathrm{X}$ & & & $\mathrm{X}$ & $\mathrm{X}$ & & & & & \\
\hline $\begin{array}{c}\text { Tangibilidade } \\
\text { Tarifa }\end{array}$ & $\mathrm{X}$ & & $\mathrm{X}$ & $\mathrm{X}$ & & & & & & & & & & & & & \\
\hline $\begin{array}{c}\text { Tempo de espera } \\
\text { Tempo de viagem }\end{array}$ & & & & & & & & & & & & & $\mathrm{X}$ & & & $\mathrm{X}$ & \\
\hline $\begin{array}{c}\text { Tratamento dado } \\
\text { aos idosos e } \\
\text { deficientes }\end{array}$ & & & & & & & & & & & & & & & & &
\end{tabular}

Fonte: elaborado pelo autor

Como pode ser verificado, são muitos os atributos que podem ser considerados na avaliação da qualidade do transporte público. Tal variabilidade dá-se, especialmente, devido às características do local em que é realizado o estudo, visto que grande parte destes se baseia na opinião dos usuários. A partir deste cenário, justifica-se a necessidade de um índice genérico, que contenha os atributos mais importantes para os usuários (coletados a partir da opinião destes) e que possa ser aplicado em qualquer localidade.

\subsection{CONCESSÃO DE SERVIÇOS PÚBLICOS}

A Constituição Federal, em seu artigo 175, determina que o Poder Público execute os serviços públicos, podendo ocorrer através de permissão ou concessão (BRASIL, 1988). A fim de sobre este regime de concessão e permissão do serviço público, foi publicada, em 13 de fevereiro de 1995 (e em vigor desde esta data), a Lei n 8.987, também conhecida como Lei de Concessão dos Serviços Públicos. Esta legislação trata das formas de realização das concessões e permissões e também sobre a gestão dos contratos destas.

De acordo com Gomide (2011), a promulgação da Lei deu a base que faltava para o governo Executivo desestatizasse os serviços públicos, dando continuidade às ideias de redução da intervenção do Estado como forma de enfrentar a crise fiscal e a estagnação econômica. 
Como todo serviço público, a forma de execução do transporte coletivo também é regida por esta Lei, cabendo aos gestores do serviço observar todas as disposições relativas ao serviço que são abrangidas em lei.

Um dos itens discutidos no documento é a qualidade do serviço prestado. Chamado de "serviço adequado", a qualidade do serviço é especificada em todo o Capítulo II da Lei, que abrange o artigo $6^{\circ}$, que traz a seguinte redação no seu caput: "Toda concessão ou permissão pressupõe a prestação de serviço adequado ao pleno atendimento dos usuários, conforme estabelecido nesta Lei, nas normas pertinentes e no respectivo contrato" (BRASIL, 1995a).

No parágrafo primeiro do mesmo artigo é definido que "serviço adequado é o que satisfaz as condições de regularidade, continuidade, eficiência, segurança, atualidade, generalidade, cortesia na sua prestação e modicidade das tarifas" (BRASIL, 1995a). Nesta pesquisa, a qualidade do transporte público, ora um serviço público concedido e, portanto regido por esta lei, é entendida como este serviço adequado, obedecendo aos mesmos parâmetros, entendendo que o atendimento a estes se traduza em qualidade para o usuário.

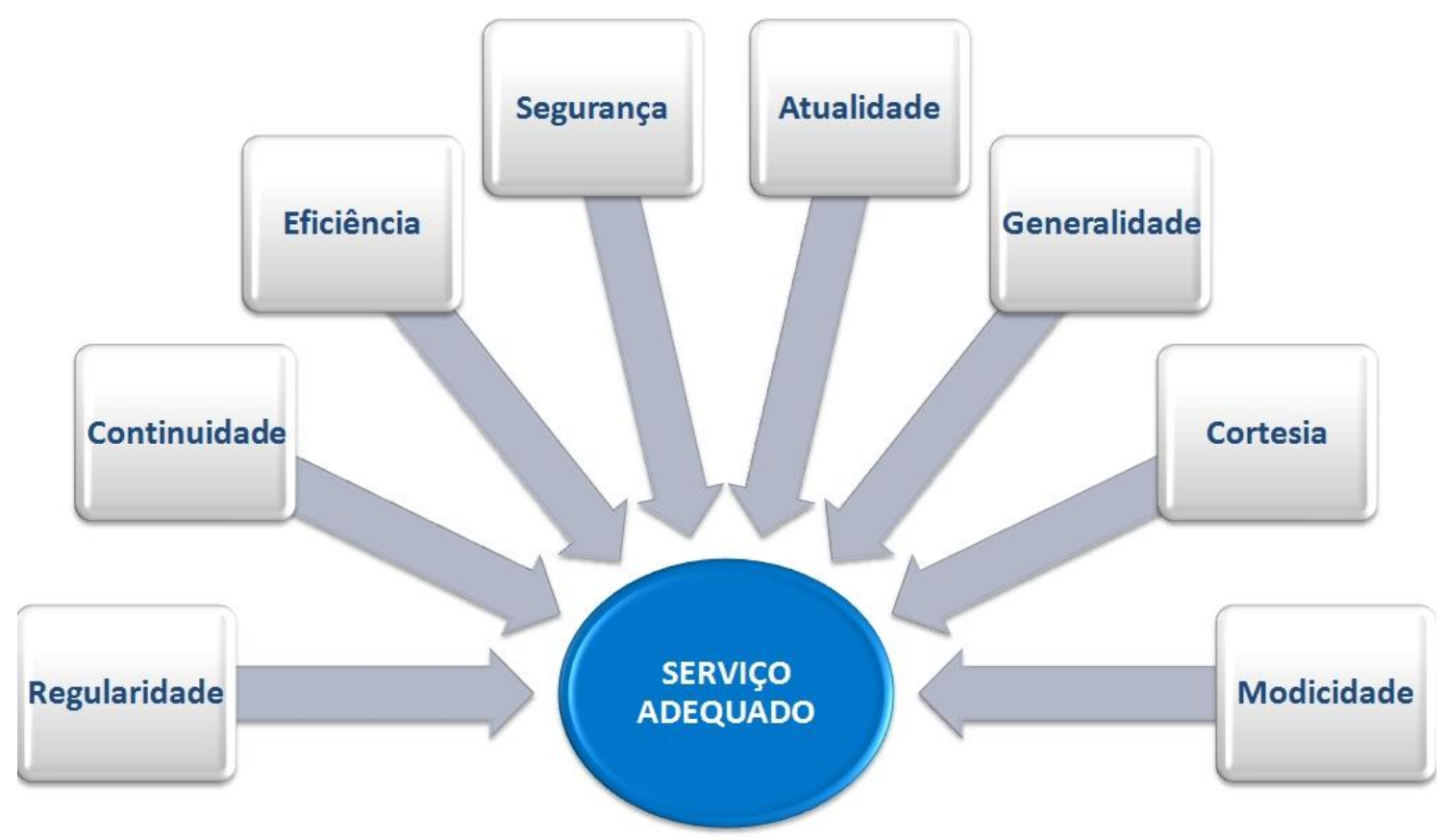

Figura 2.3. Parâmetros do serviço adequado

Fonte: elaborado pelo autor conforme Brasil (1995a)

A Lei de Concessão dos Serviços Públicos dispõe de grande destaque para a qualidade do serviço, regulamentando seus parâmetros e delegando responsabilidades e direitos aos envolvidos no serviço público. 
Ao usuário do serviço é garantido o direito de receber serviço adequado, conforme o inciso I do artigo $7^{\circ}$ da Lei. Isso significa que poder concedente e a concessionária devem trabalhar para realizar um serviço que atenda a esta qualidade. Para tal, a Lei, no inciso III do artigo 23, estabelece que os critérios, indicadores, fórmulas e parâmetros definidores da qualidade do serviço sejam definidos em cláusula essencial do contrato de concessão.

Desta forma, ao poder concedente cabe a realização de medição e fiscalização desta qualidade, sendo responsável pelo atendimento das expectativas do usuário quanto à qualidade do serviço. No artigo 29, inciso VII, esse encargo do poder concedente fica legalmente estabelecido: "[Incumbe ao poder concedente] zelar pela boa qualidade do serviço (...)" (BRASIL, 1995a).

Quanto aos deveres da concessionária, o inciso I do artigo 31 rege que esta deve prestar serviço de qualidade, sob os critérios estabelecidos no contrato. $\mathrm{O}$ não cumprimento deste dever delega autoridade e obrigatoriedade ao concedente de intervir na concessão, a fim de assegurar a qualidade do serviço, segundo o artigo 32 da Lei. Ainda, conforme o artigo 38, parágrafo primeiro, inciso I, pode ser declarada a caducidade da concessão se o serviço estiver sendo prestado de forma inadequada ou ineficiente, de acordo com os critérios definidos em contrato.

De posse destas informações, o usuário deve também agir como um fiscal da qualidade do serviço prestado, sendo sua a voz mais importante no quesito, visto que são as suas expectativas que devem ser atendidas pelo serviço. Ao poder concedente resta a obrigação de acompanhar continuamente a qualidade do serviço e incentivar melhorias no processo, agindo em defesa do usuário em caso de prestação de serviço inadequado.

Conforme Bernardes (2006), a legislação brasileira vigente não explica os atributos do serviço adequado, dessa forma buscou-se, para a elaboração de sua pesquisa, o entendimento de cada termo. Consultando Souto (2002), Vasconcelos (2004), Brasil (1995a), Brasil (1995b), Brasil (1998), Lima (1996) e Blanchet (2000), o autor definiu cada um dos atributos conforme se resume a seguir.

Por regularidade, entende-se da prestação do serviço nas condições estabelecidas na legislação vigente, no contrato e nas normas técnicas aplicáveis, sem interrupções. Continuidade pode ser definida como a manutenção, em caráter permanente, da oferta dos serviços, sem interrupções injustificadas. Eficiência vem da premissa de que o serviço atenda plenamente à necessidade que lhe deu origem (o deslocamento do usuário) com o melhor uso possível dos recursos. Já segurança pode ser entendida como o grau de confiança oferecido ao usuário durante a prestação do serviço, em relação a acidentes automobilísticos, crimes e outros eventos que venham a comprometer a integridade física do usuário.

A atualidade, de acordo com o artigo $6^{\circ}$ da Lei 8987/95 "compreende a modernidade das técnicas, dos equipamentos e das instalações e sua conservação, bem como a 
melhoria e expansão do serviço", ou seja, é intrinsecamente ligada à atualização do serviço conforme avanço tecnológico. Generalidade ou universalidade relaciona-se com o princípio da igualdade ou uniformidade dos usuários, significando que o serviço público pode ser exigido e utilizado por todos que dele necessitem, sem distinções. Cortesia na prestação é o tratamento adequado com urbanidade aos usuários do serviço e também o fácil acesso do usuário ao responsável pela prestação do serviço para críticas e sugestões. Por fim, modicidade das tarifas é quando estas permitem que todas as pessoas que necessitam do serviço possam utilizá-lo.

\subsection{TÓPICOS CONCLUSIVOS}

- O transporte público é um serviço essencial para as cidades, sendo aspecto importante para a qualidade de vida da população (o que abrange usuários e não usuários do sistema) e ainda influencia na disposição dos serviços e urbanização de áreas.

- A avaliação contínua da qualidade do transporte público é necessária para que se conheça a oferta desejada para a população e sejam consideradas soluções para a satisfação de suas necessidades.

- Os serviços concedidos no Brasil, incluindo o transporte público de passageiros, são regidos por Lei que determina os requisitos mínimos de qualidade que devem ser observados na sua prestação, sendo de responsabilidade do órgão gestor a avaliação e correção destes requisitos em seu sistema. 


\section{PROCEDIMENTO METODOLÓGICO}

\subsection{APRESENTAÇÃO}

Neste capítulo é abordada a metodologia da pesquisa, ou seja, a forma como é realizado o levantamento e análise dos dados, bem como a apresentação do método de Desdobramento da Função Qualidade - QFD, utilizado para valoração dos indicadores selecionados em pesquisas de campo.

Esta metodologia está divida em três etapas: pesquisa de relevância para o usuário, valoração dos indicadores e validação. Na primeira, são definidos os indicadores a serem utilizados (com base no serviço adequado definido em lei) e realiza-se uma pesquisa junto aos usuários do transporte público por ônibus para que se conheçam os atributos relevantes por indicador.

Na segunda etapa é realizada nova pesquisa junto aos usuários, buscando encontrar pesos para cada atributo dos indicadores e para cada indicador dentro do índice proposto. Na ultima etapa, é realizada a validação do índice, quando ele é aplicado na cidade de Belo Horizonte/MG (procedimento completo no Capítulo 5 desta dissertação).

\subsection{RELEVÂNCIA PARA O USUÁRIO}

As condições descritas na Lei de Concessão dos Serviços Públicos como parâmetros do serviço adequado são genéricas a todo e qualquer serviço público sob concessão ou permissão. A interpretação destas condições deve acontecer conforme as especificidades de cada serviço.

Nesta pesquisa, a definição destes parâmetros para a oferta de um serviço de transporte público adequado é realizada considerando o entendimento de Gomide et al (2006) e Bernardes (2006). Nos estudos citados, os autores explicam os parâmetros legais conforme estes entendem suas aplicações ao serviço de transporte público, estabelecendo assim um indicador para cada parâmetro.

A construção do índice segue instrumentalização semelhante ao método de causa e efeito, também conhecido como espinha de peixe, sendo que o índice será composto de oito indicadores - relativos aos parâmetros legais, e cada um dos indicadores compostos pelos atributos selecionados pelos usuários, conforme Figura 3.1 


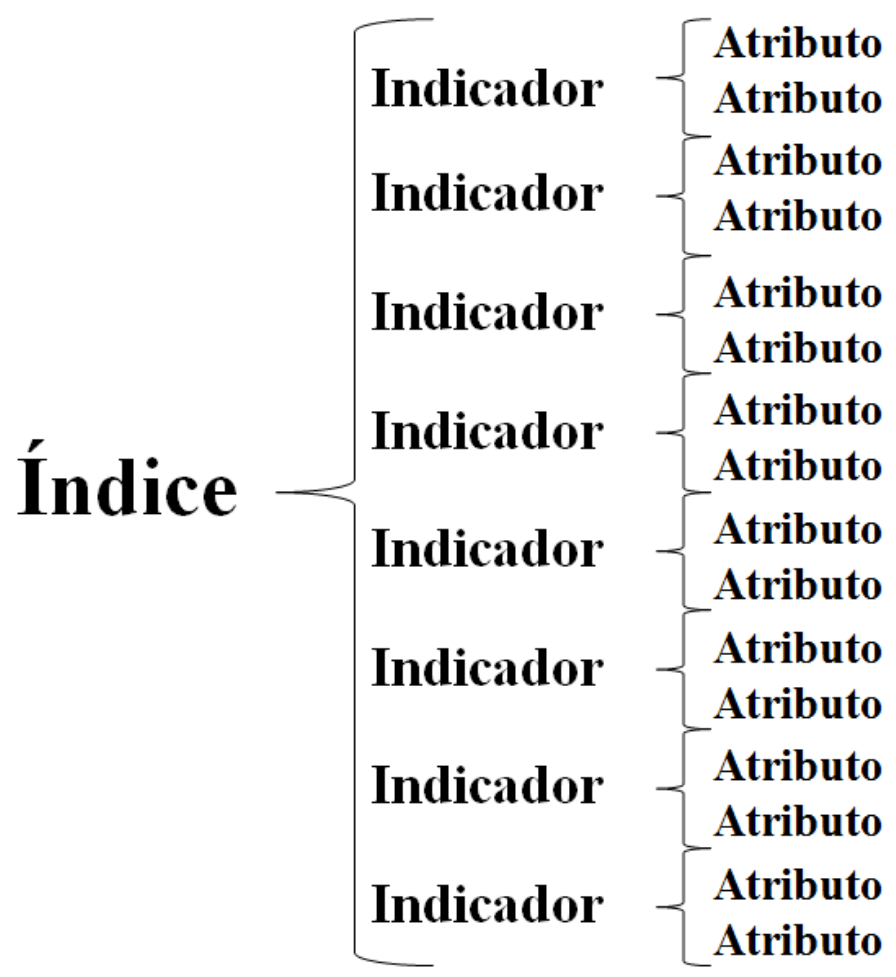

Figura 3.1: Estrutura de elaboração e análise do IQ $\mathrm{TP}_{\mathrm{T}}$

Fonte: elaborado pelo autor

Para que o índice proposto mantenha a generalidade que se espera, procurou-se simplificar os indicadores, de modo que estes possam ser calculados a partir de dados brutos do sistema, que, em geral, não necessitam de sistemas de informação para coleta, o que torna o índice aplicável a cidades que ainda não possuem esta tecnologia na gestão do transporte público.

Durante a seleção dos indicadores também busca-se utilizar aqueles que representem a visão que o usuário tem do sistema, considerando que o sistema existe para satisfazer às necessidades de locomoção do cliente (usuário). Os indicadores selecionados para cada parâmetro, como também a definição (específica para transporte) e a sigla utilizada nesta pesquisa, estão descritos na Tabela 3.1. 
Tabela 3.1: Indicadores do serviço adequado

\begin{tabular}{|c|c|c|c|c|}
\hline $\begin{array}{c}\text { PARÂMETRO } \\
\text { DO SERVIÇO } \\
\text { ADEQUADO }\end{array}$ & $\begin{array}{c}\text { DEFINIÇÃO DO } \\
\text { PARÂMETRO }\end{array}$ & $\begin{array}{c}\text { INDICADOR } \\
\text { EQUIVALENTE }\end{array}$ & SIGLA & $\begin{array}{c}\text { DEFINIÇÃO } \\
\text { ADOTADA NO } \\
\text { INDICADOR }\end{array}$ \\
\hline Regularidade & $\begin{array}{l}\text { Prestação do serviço } \\
\text { conforme contrato, sem } \\
\text { interrupções }\end{array}$ & Pontualidade & $\mathrm{P}_{\mathrm{N}}$ & $\begin{array}{l}\text { Oferta do serviço de } \\
\text { forma contínua e } \\
\text { conforme planejado }\end{array}$ \\
\hline Continuidade & $\begin{array}{l}\text { Manutenção da oferta } \\
\text { em caráter permanente }\end{array}$ & Tempo & $\mathrm{T}_{\mathrm{E}}$ & $\begin{array}{c}\text { Tempo de realização } \\
\text { da viagem, incluindo } \\
\text { transbordos }\end{array}$ \\
\hline Eficiência & $\begin{array}{l}\text { Atendimento ao usuário } \\
\text { com o melhor uso dos } \\
\text { recursos }\end{array}$ & Lotação & $\mathrm{L}_{\mathrm{O}}$ & $\begin{array}{l}\text { Oferta de lugares e } \\
\text { conforto das viagens }\end{array}$ \\
\hline Segurança & $\begin{array}{c}\text { Confiança oferecida ao } \\
\text { usuário na prestação do } \\
\text { serviço }\end{array}$ & Segurança & $\mathrm{S}_{\mathrm{G}}$ & $\begin{array}{l}\text { Serviço seguro, sem } \\
\text { incidência de } \\
\text { acidentes e assaltos }\end{array}$ \\
\hline Atualidade & $\begin{array}{c}\text { Modernidade de } \\
\text { técnicas, equipamentos } \\
\text { e instalações }\end{array}$ & Informações & $\mathrm{I}_{\mathrm{F}}$ & $\begin{array}{l}\text { Uso de técnicas para } \\
\text { fornecer informação } \\
\text { ao usuário, sem } \\
\text { necessidade de } \\
\text { solicitação }\end{array}$ \\
\hline Generalidade & $\begin{array}{l}\text { Serviço com } \\
\text { atendimento a todos os } \\
\text { usuários, sem distinções }\end{array}$ & Veículos & $\mathrm{V}_{\mathrm{E}}$ & $\begin{array}{l}\text { Acesso de pessoas } \\
\text { com necessidades } \\
\text { especiais e } \\
\text { conservação dos } \\
\text { veículos }\end{array}$ \\
\hline Cortesia & $\begin{array}{l}\text { Serviço prestado com } \\
\text { urbanidade ao usuário }\end{array}$ & Tripulação & $\mathrm{T}_{\mathrm{R}}$ & $\begin{array}{l}\text { Comportamento dos } \\
\text { operadores e sua } \\
\text { relação com usuários }\end{array}$ \\
\hline $\begin{array}{l}\text { Modicidade das } \\
\text { tarifas }\end{array}$ & $\begin{array}{l}\text { Tarifas compatíveis } \\
\text { com a renda do usuário }\end{array}$ & Tarifa & $\mathrm{T}_{\mathrm{A}}$ & $\begin{array}{c}\text { Representatividade } \\
\text { da tarifa na renda do } \\
\text { usuário }\end{array}$ \\
\hline
\end{tabular}

Fonte: Elaborado pelo autor

Apenas três indicadores apresentam diferenças para com a definição geral do parâmetro:

Tempo (para Continuidade), Lotação (para Eficiência) e Informações (para Atualidade). 
A escolha do indicador "Tempo" para o parâmetro "Continuidade" deu-se devido à ausência do tempo de espera e de viagem de forma clara nos parâmetros, mesmo sendo um item importante na decisão de utilizar ou não o transporte público. A mudança do conceito do indicador foi possível, pois a definição apresentada por Gomide et al. (2006) já está contemplada no indicador "Pontualidade" (serviço prestado sem interrupção).

A escolha do indicador "Lotação" para o parâmetro "Eficiência" aconteceu devido ao impacto que a lotação dos veículos tem sobre a eficiência dos mesmos, aqui entendendo eficiência como o melhor uso possível dos recursos disponíveis mantendo a sua qualidade (GOMIDE et al., 2006). Entende-se também que veículos superlotados não são operacionalmente eficientes e não garantem conforto dos usuários.

Já o uso do indicador "Informações" para o parâmetro "Atualidade" ocorreu com foco na simplicidade de aplicação do índice proposto. Considera-se que muitos gestores não terão acesso às tecnologias disponíveis para o transporte público e, como comentam Crainic et al. (2009), vivemos na era da informação, sendo necessário buscar meios de utilização do pleno potencial das informações, destacando-se as informações em tempo real. Para tal, este indicador medirá a existência de informações ao usuário, independentemente da forma como esta será apresentada.

A fim de se conhecer quais atributos devem ser considerados na elaboração destes indicadores buscou-se conhecer a opinião dos usuários do sistema. Para a coleta destas opiniões, é utilizado o método de levantamento denominado de associação ou evocação livre, que se resume em abordar o entrevistado solicitando que este cite as palavras que primeiro recordar a respeito de determinado assunto. Este tipo de pesquisa foi utilizado por Morais (2012) exatamente pela sua característica espontânea e por apontar elementos implícitos que seriam perdidos em produções discursivas.

Para coletar estes dados, realizou-se entrevista a usuários que aguardavam embarque em ônibus nos pontos de controle (PC) de nove linhas de transporte público por ônibus da cidade de Belo Horizonte, capital de Minas Gerais. O local foi escolhido em detrimento dos pontos de embarque e desembarque de passageiros (PED) comuns devido ao maior tempo que o usuário tem para aguardar o início da viagem do veículo que já se encontra no local, e assim pode dedicar mais atenção e seriedade à pesquisa.

A seleção das linhas deu-se a partir da localização do seu ponto de controle e demanda registrada no mês de novembro de 2013, período escolhido por ser o último mês típico antes da implantação do novo sistema de transporte público na cidade em 8 de março de 2014 (conforme explanado no Capítulo 5).

Como a cidade de Belo Horizonte é subdividida em nove Regiões Administrativas (Centro-Sul, Oeste, Barreiro, Noroeste, Pampulha, Venda Nova, Norte, Nordeste e Leste), conforme Figura 3.2, foram selecionadas as linhas de maior demanda destas em busca do maior número possível de respondentes, sendo uma linha partindo de cada 
região. Para as linhas diametrais, que possuem dois PC's, um em cada bairro de origem/destino, considerou-se nesta seleção a localização do PC1 da linha. Desta forma, as opiniões colhidas são relativas a usuários de todos os pontos da cidade.

Ressalta-se que foram desconsideradas as linhas que partem ou atendem estações de integração ônibus/ônibus, pois nestas alguns embarques ocorrem sem registro na catraca do veículo (os passageiros utilizam as linhas de bloqueio das estações).

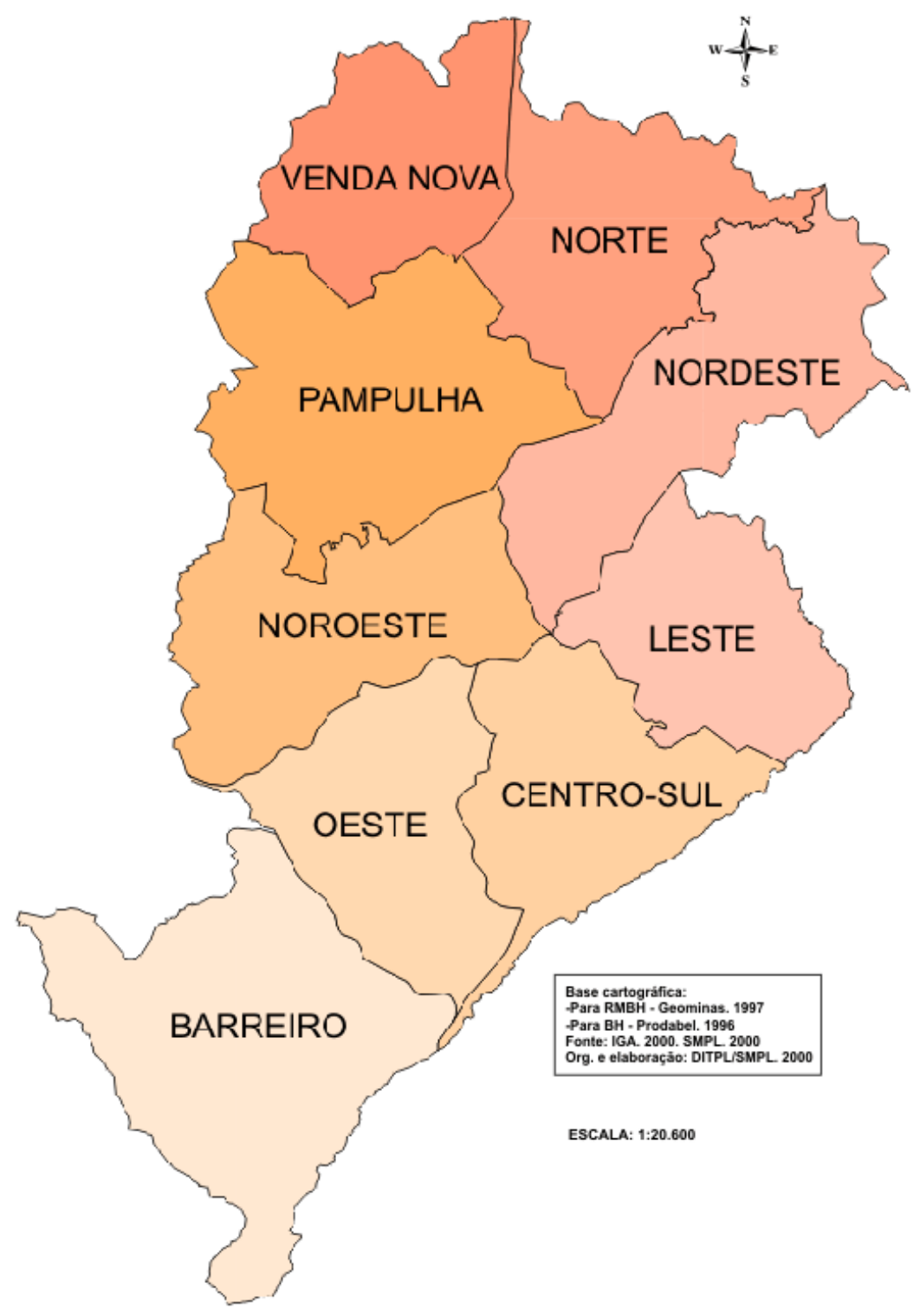

Figura 3.2: Regiões administrativas de Belo Horizonte

Fonte: Horizonte (2014)

As linhas selecionadas, bem como sua demanda média mensal e regional em que se localiza seu PC, estão descritas na Tabela 3.2. 
Tabela 3.2: Linhas selecionadas para a realização das entrevistas

\begin{tabular}{|c|c|c|c|}
\hline LINHA & NOME DA LINHA & REGIONAL & $\begin{array}{c}\text { DEMANDA } \\
\text { (Nov/13) }\end{array}$ \\
\hline 104 & Estação Lagoinha (metrô) / Avenida & Centro-Sul & 255.600 \\
\hline 1502 & Vista Alegre / Guarani & Oeste & 501.209 \\
\hline 3054 & Milionários / Centro & Barreiro & 204.896 \\
\hline $3503 \mathrm{~A}$ & Santa Terezinha / São Gabriel & Noroeste & 637.608 \\
\hline 5201 & Dona Clara / Buritis & Pampulha & 399.495 \\
\hline 607 & Esplendor / Jaqueline & Venda Nova & 294.115 \\
\hline $2402 \mathrm{~A}$ & São Bernardo / N. Sra. Da Glória A & Norte & 335.357 \\
\hline 8207 & Maria Goretti / Estrela Dalva & Nordeste & 392.215 \\
\hline 9250 & Caetano Furquim / Nova Cintra & Leste & 456.298 \\
\hline \multicolumn{3}{|c|}{ TOTAL - Linhas selecionadas } & 3.476 .793 \\
\hline \multicolumn{3}{|c|}{ TOTAL - Sistema } & 36.618 .394 \\
\hline
\end{tabular}

Fonte: Elaborado pelo autor com dados de BHTrans (2013)

Foram realizadas 155 entrevistas completas nos nove pontos de controle pesquisados. Decidiu-se por realizar as entrevistas neste local e no período da manhã para que o usuário fosse abordado antes de utilizar o serviço, sendo assim, suas percepções serão da experiência já vivida no sistema e não de algum evento ocorrido em alguma viagem recém realizada. As entrevistas ocorreram entre os dias 15 e 27 de maio de 2014, iniciando-se sempre às $07 \mathrm{~h} 00$ e terminando, no máximo, às $11 \mathrm{~h} 40$. Os endereços dos PC's onde foram realizadas as entrevistas são:

- Linha 104: Avenida do Contorno, 11675 - Bairro Centro;

- Linha 1502: Avenida Padre José Maurício, 1285 - Bairro Vista Alegre;

- Linha 3054: Rua Dona Lala Fernandes, 470 - Bairro Milionários;

- Linha 3503A: Avenida Ayres da Mata Machado, 173 - Bairro Sta. Terezinha;

- Linha 5201: Rua Zenita de Souza, 95 - Bairro Dona Clara;

- Linha 607: Rua William Malacco, 232 - Bairro Esplendor; 
- Linha 2402A: Rua Souza Gomes, 972 - Bairro São Bernardo;

- Linha 8207: Rua Maria das Graças, 140 - Bairro Maria Goretti;

- Linha 9250: Rua Burnier, 197 - Bairro Caetano Furquim.

Para a elaboração do formulário foram elencadas oito questões, uma para cada aspecto do serviço adequado definido pela Lei, e nestas se pedia ao respondente que citasse três aspectos que considerava importante para avaliar a qualidade do sistema, após apresentação verbal de todos os aspectos. Os resultados foram tabulados por número de citações dos atributos e foram selecionados aqueles que foram citados por mais de $60 \%$ do total de respondentes (93 citações). Decidiu-se por este número de corte com base na lacuna entre os atributos que alcançaram este patamar e os que não alcançaram (uma diferença aproximada de 30 pontos percentuais), permitindo que estes de menor citação fossem descartados graças a sua pouca importância declarada para o usuário. Os resultados das entrevistas são apresentados no Capítulo 4 desta pesquisa.

\subsection{VALORAÇÃO DOS ASPECTOS SELECIONADOS}

Após a definição dos aspectos que formam os indicadores do método proposto, é necessário que se encontre o fator de importância de cada indicador dentro do método. Para isso, foi realizada uma nova pesquisa de opinião, desta vez aplicada em formulário eletrônico, distribuída para respondentes em todo o Brasil, visto que a Lei de Concessão dos Serviços Públicos, texto base para o método, é válida em todo o território nacional.

O formulário eletrônico foi elaborado com questões do tipo Escala Likert. Esta escala, descrita inicialmente por Likert (1932), é um método de pesquisa onde se coleta a opinião dos usuários sobre um determinado assunto, sendo que estes comentam o nível de concordância ou não sobre uma afirmação. A partir dos dados coletados é possível classificar os termos afirmados a partir da importância que cada um tem para os entrevistados.

Nesta pesquisa, os respondentes foram convidados a indicar a importância de cada indicador e atributo selecionado na pesquisa anterior aplicando-lhes um grau de importância que varia de 1 (pouco importante) a 5 (muito importante) na consideração deste para a avaliação da qualidade do sistema de transporte público por ônibus. Decidiu-se por não usar uma escala mais ampla (como de 1 a 10, por exemplo) para que o respondente não atribua notas distintas do seu sentimento geral do sistema em função de alguma situação ocorrida recentemente, o que comprometeria os pesos aplicados no método.

A pesquisa foi divulgada pela internet e esteve aberta para respostas entre os dias 01 de junho e 30 de julho de 2014. Neste período foram coletadas 882 respostas válidas (excluindo-se os questionários incompletos). Os resultados desta etapa da pesquisa estão detalhados no Capítulo 4. 


\subsection{MÉTODO DE DESDOBRAMENTO DA FUNÇÃO QUALIDADE}

Com os resultados coletados a partir da aplicação deste questionário continua-se o processo de valoração dos aspectos a partir da aplicação do método de Desdobramento da Função Qualidade - QFD (do inglês: Quality Function Deployment), comumente utilizado por empresas para transformar a qualidade exigida pelo cliente (medida em pesquisa de opinião) em requisitos técnicos do produto ou serviço (ARPINI e RIBEIRO, 2012).

A partir de autores consultados que utilizaram o método em suas respectivas pesquisas, encontramos a aplicação do método em diferentes cenários sobre os transportes:

- Silva et al. (2000): utilizaram o método para traçar o perfil da tecnologia embarcada em ônibus urbano;

- Bastidas et al. (2001): utilizaram o QFD na avaliação, pelos usuários, de uma transportadora rodoviária de cargas;

- Silveira (2002): utilizou o método para analisar a preferência do cliente na melhoria da distribuição rodoferroviária de arroz a partir do Rio Grande do Sul;

- Sperandio (2005): utilizou o QFD para priorização dos itens de fiscalização do transporte ferroviário de cargas no Brasil;

- Oliveira (2006): aplicou a metodologia QFD no transporte rodoviário interestadual de Vitória/ES;

- Pêgo (2006): testou o QFD aplicando-o no transporte coletivo urbano de passageiros;

- Korzenowski et al. (2008): utilizaram o QFD na priorização dos requisitos dos usuários no serviço de transporte coletivo por ônibus;

- Holz et al. (2010): utilizaram o método QFD na identificação dos principais itens demandados pelos usuários de rodovias pedagiadas no Rio Grande do Sul;

- Jammal (2010): utilizou o método QFD na análise dos critérios de qualidade do transporte urbano da cidade de São José do Rio Preto/SP;

- Arpini e Ribeiro (2012): utilizaram o QFD para avaliar a qualidade no serviço de transporte coletivo urbano de passageiros e priorizar ações de melhorias na Grande Vitória/ES;

- Da Rosa et al. (2013): utilizaram o QFD para avaliar a qualidade no transporte de usuários da Trensurb em horários de pico; 
- Weber et al. (2013): utilizaram o método QFD juntamente com o método PCA (Principal Component Analysis) na construção de uma metodologia de pesquisa para avaliar aeroportos.

O método QFD é realizado através da construção de uma Matriz da Qualidade, definida por Cheng e Melo Filho (2010) como uma matriz que amplia e realiza o projeto da qualidade, reunindo as qualidades exigidas pelos clientes e convertendo a importância atribuída aos itens para as características de qualidade que devem ser projetadas.

Conforme Akao (1996), a Matriz da Qualidade resulta da união da Tabela de Desdobramento da Qualidade Exigida com a Tabela de Desdobramento das Características da Qualidade, coordenando as informações dos pontos de vista mercado e empresa.

A construção das tabelas e, consequentemente, da matriz, é apresentada por Arpini e Ribeiro (2012) como resultado de um processo de oito etapas, que se descreve a seguir.

\subsubsection{Tabela de Desdobramento da Qualidade Exigida}

Como o QFD trata-se de um método usado para o desenvolvimento de projetos focado na satisfação do(s) cliente(s), o ponto inicial para efetuar desdobramentos sistemáticos é a voz do cliente, a fim de identificar suas necessidades e desejos (CHENG e MELO FILHO, 2010).

Dessa forma, esta primeira etapa consiste em obter informações junto ao consumidor dos itens que mais influenciam na qualidade do produto ou serviço segundo percepção deste, ou seja, "captar a voz do cliente” (ARPINI e RIBEIRO, 2012).

Conforme Cheng et al. (1995), a técnica mais adequada é o levantamento por questionário, assim obtém-se avaliações numéricas ou escalas de preferência dos consumidores. Tais informações obtidas junto aos clientes por meio de pesquisas de mercado ou por outro meio, geram uma grande quantidade de informações que são chamadas de dados originais ou informações primitivas (AKAO, 1996). Estes dados podem ser complementados por outros secundários, já coletados, que podem ser estatísticas governamentais, publicações técnicas, entre outros (CHENG et al., 1995).

As informações obtidas nesta etapa devem ser agrupadas por semelhança e então se convertem esses dados em necessidades do cliente, chamadas de itens exigidos, o que define os aspectos da qualidade exigida. A Tabela de Qualidade Exigida é representada a partir destes dados, em forma de diagrama de árvore de vários níveis, conforme Tabela 3.3. 
Tabela 3.3: Tabela da Qualidade Exigida elaborada para a melhoria do serviço de atendimento em uma loja de departamento

\begin{tabular}{|c|c|c|}
\hline Nível 1 & Nível 2 & Nível 3 \\
\hline \multirow{10}{*}{ Bom atendimento } & \multirow{3}{*}{ Ter boa orientação na compra } & $\begin{array}{l}\text { Ter bom conhecimento do } \\
\text { produto }\end{array}$ \\
\hline & & Ter informações corretas \\
\hline & & $\begin{array}{l}\text { Ter facilidade de obter } \\
\text { informações }\end{array}$ \\
\hline & \multirow{3}{*}{ Ter atendimento diferenciado } & Ter atendimento personalizado \\
\hline & & Ter atendimento pró-ativo \\
\hline & & Ter atendimento especializado \\
\hline & \multirow{2}{*}{$\begin{array}{l}\text { Boa aparência dos } \\
\text { funcionários }\end{array}$} & $\begin{array}{l}\text { Boas condições de higiene } \\
\text { pessoal }\end{array}$ \\
\hline & & Boa apresentação \\
\hline & \multirow{2}{*}{ Boa postura no atendimento } & Ter atendimento cortês \\
\hline & & Ter atendimento com respeito \\
\hline
\end{tabular}

Fonte: Cheng e Melo Filho (2010)

\subsubsection{Qualidade Planejada}

De acordo com Cheng et al. (1995), a qualidade planejada é uma complementação da tabela de Desdobramento da Qualidade Exigida. Nesta, acrescentam-se as informações de preferência do cliente (a partir do grau de importância que atribuem a cada item) e a percepção que os clientes têm dos produtos atuais (por avaliação de desempenho do produto ou dos concorrentes).

Akao (1996) explica que existem vários métodos de se classificar os itens de qualidade demandada de acordo com a importância. Pode-se utilizar a frequência de repetição dos itens nos questionários abertos aplicadas ou classificação estatística por meio de escalas. Este último método também pode ser utilizado para avaliação do desempenho do produto ou concorrentes.

A partir de então se estabelece o Plano de Qualidade, que consiste na decisão estratégica da avaliação que se pretende obter dos clientes, baseando-se em escala igual à usada na avaliação de desempenho. Após, calcula-se o índice de melhoria, conforme a Equação 3.1 (CHENG e MELO FILHO, 2010).

$$
\text { ÍNDICE DE MELHORIA }=\frac{\text { Plano de qualidade }}{\text { empresa }}
$$

Em sequência, definem-se os argumentos de vendas, que são pesos acrescentados aos itens de qualidade exigida, variando conforme a previsão de quanto este item vá contribuir para a venda do produto (CHENG e MELO FILHO, 2010). A Tabela 3.4 
apresenta alguns valores que podem ser utilizados. A simbologia é demonstrativa, podendo-se utilizar cores ou qualquer outra forma de apresentação (ARPINI e RIBEIRO, 2012). O valor do argumento de venda de 1,5 aumenta o valor do peso em $50 \%$, enquanto o valor de 1,2 aumenta em $20 \%$.

Tabela 3.4: Argumentos de Vendas

\begin{tabular}{|c|c|c|}
\hline Classificação do argumento de venda & Símbolo & Valor \\
\hline Especial & & 1,5 \\
\hline Comum & 0 & 1,2 \\
\hline Sem argumento & "vazio" & 1 \\
\hline
\end{tabular}

Fonte: Cheng e Melo Filho (2010)

O peso absoluto de cada item é calculado conforme a Equação 3.2.

$$
\text { PESO }=\text { Grau de importância } \times \text { índice de Melhoria } \times \text { Argumento de venda }
$$

Por fim, calcula-se o peso relativo de cada item da qualidade exigida, conforme a Equação 3.3.

$$
\text { PESO RELATIVO }=\frac{\text { Peso absoluto }}{(\text { Soma de todos os pesoas absolutos })}
$$

Conforme Arpini e Ribeiro (2012), os pesos relativos possibilitam uma melhor comparação entre os itens de qualidade exigida, permitindo a sua priorização, demonstrando aqueles que necessitam receber mais enfoque. Portanto, temos que a qualidade planejada é obtida pela priorização dos itens de qualidade exigida.

\subsubsection{Tabela de Desdobramento das Características da Qualidade (CQs) - processo de extração}

Para cada item da qualidade exigida é preciso encontrar as características da qualidade que devem ser mensuradas no produto ou serviço para avaliar se as exigências dos clientes estão sendo atendidas (CHENG et al., 1995). A essência do trabalho está na obtenção de características técnicas para o produto final que atendam à necessidade do mercado (CHENG e MELO FILHO, 2010). Para tal, faz-se uso da técnica de brainstorming e organizam-se os grupos gerados sob a forma de diagrama de árvore.

Alguns itens de qualidade exigida não podem ser mensurados, então se utilizam "elementos da qualidade" para representá-los. Para os itens mensuráveis, utilizam-se 
"características da qualidade". A Tabela 3.5 apresenta a diferença entre elemento de qualidade e característica da qualidade para o caso de uma estrutura metálica.

Tabela 3.5: Diferença entre elementos e características da qualidade

\begin{tabular}{|l|l|}
\hline \multicolumn{1}{|c|}{ ELEMENTOS } & \multicolumn{1}{c|}{ CARACTERÍSTICAS } \\
\hline \multirow{4}{*}{ Resistência } & Resistência à tração \\
\cline { 2 - 2 } & Resistência à torção \\
\cline { 2 - 2 } & Resistência à compressão \\
\cline { 2 - 2 } & Limite de escoamento \\
\hline \multirow{2}{*}{ Rigidez } & Rigidez horizontal \\
\cline { 2 - 2 } & Rigidez vertical \\
\hline \multirow{4}{*}{ Dimensões } & Comprimento \\
\cline { 2 - 2 } & Largura \\
\cline { 2 - 2 } & Altura \\
\cline { 2 - 2 } & Peso \\
\hline
\end{tabular}

Fonte: Cheng e Melo Filho (2010)

Após a determinação das características da qualidade, organizam-se as mesmas em grupos afins para elaboração da Tabela de Desdobramento das Características da Qualidade, que é um arranjo sistemático das características e dos elementos da qualidade que constituem o produto final (CHENG e MELO FILHO, 2010).

\subsubsection{Matriz de Correlação}

Esta etapa consiste na concatenação das tabelas de qualidade exigida e de características da qualidade, identificando o grau de influência que cada item de uma tabela exerce sobre o outro (ARPINI e RIBEIRO, 2012). Conforme Cheng et al. (1995), esse processo deve ser realizado com base na experiência da equipe, que se reúne e busca consenso para as correlações da matriz.

Antes de definir as correlações, determinam-se as intensidades e os critérios que serão usados. A Tabela 3.6 apresenta sugestões de representação das intensidades das correlações. Tais intensidades devem estar associadas a um valor numérico para permitir a conversão da priorização dos itens.

A representação sugerida por Cheng e Melo Filho (2010) traz 3 escalas diferentes de valores possíveis, sendo explicado que a diferença entre os números permite ao pesquisador escolher o nível de sensibilidade estatística dos resultados. Por exemplo, para resultados em que os pesos não são tão relevantes para tomada de decisões, podese utilizar 4-2-1, mas para pesquisas onde a importância das características para o usuário é um dos principais resultados, utiliza-se 9-3-1, de forma que as correlações serão mais fortes e visíveis para o avaliador. 
Tabela 3.6: Definições para as correlações da matriz de QFD

\begin{tabular}{|l|c|c|c|c|c|}
\hline \multirow{2}{*}{ Correlação } & \multicolumn{5}{|c|}{ Representação sugerida } \\
\cline { 2 - 6 } & Cor & Símbolo & \multicolumn{3}{|c|}{ Valores Possíveis } \\
\hline Forte & Vermelho & $\bullet$ & 9 & 5 & 4 \\
\hline Média & Verde & $\triangle$ & 3 & 3 & 2 \\
\hline Fraca & Azul & $\bigcirc$ & 1 & 1 & 1 \\
\hline Inexistente & & Vazio & - & - & - \\
\hline
\end{tabular}

Fonte: Cheng e Melo Filho (2010)

\subsubsection{Processo de Conversão: priorização das Características da Qualidade}

A conversão consiste em transferir a importância (peso atribuído a cada item de uma tabela para os itens de outra tabela) a partir das correlações identificadas na matriz (CHENG et al., 1995).

Para realizar a conversão, multiplicam-se as correlações pelos pesos relativos das qualidades exigidas por linha da matriz e soma-se este produto por coluna (CHENG e MELO FILHO, 2010). O peso relativo de cada característica da qualidade pode então ser obtido, convertendo-se os valores do peso absoluto em pesos relativos percentuais (CHENG et al., 1995), conforme demonstrado nas Equações 3.4 e 3.5.

$$
\mathrm{PaC}_{j}=\sum_{i=1}^{n} \operatorname{PrQ}_{i} \cdot \mathrm{X}_{i j}
$$

Em que:

- $\quad \mathrm{PaC}_{\mathrm{j}}$ : Peso absoluto de cada item das características da qualidade (CQ);

- $\operatorname{PrQ}_{\mathrm{i}}$ : Peso relativo de cada item das qualidades exigidas;

- $\mathrm{X}_{\mathrm{ij}}$ : Correlação entre qualidade exigida e CQ;

- i: se refere à qualidade exigida (linhas $\mathrm{i}=1,2, \ldots, \mathrm{n}$ );

- $\mathrm{j}$ : se refere às CQ (colunas $\mathrm{j}=1,2, \ldots, \mathrm{n})$.

$$
\mathrm{PrC}_{J}=\frac{\mathrm{PaC}_{j}}{\sum \mathrm{PaC}}
$$

Em que:

- $\quad \operatorname{PrC}_{\mathrm{j}}$ : Peso relativo da $\mathrm{CQ}_{\mathrm{j}}$.

A partir do cálculo dos pesos relativos, faz-se a priorização das características da qualidade, classificando as CQs em ordem decrescente. Aquelas classificadas com níveis maiores demonstram onde a empresa deve concentrar esforços para maximizar a satisfação do cliente (ARPINI e RIBEIRO, 2012). 


\subsubsection{Análise Competitiva: mensurando os valores das Características da Qualidade e comparando com a concorrência}

Nesta etapa mede-se o valor de cada característica da qualidade do produto/serviço atual da empresa, e em seguida medem-se as CQs dos produtos que competem no mercadoalvo. Após, os valores devem ser comparados e dispostos na Qualidade Projetada da Matriz da Qualidade. É importante, nesta etapa, classificar as características conforme o melhor comportamento dos seus valores (CHENG e MELO FILHO, 2010), conforme demonstra a Tabela 3.7.

Tabela 3.7: Exemplo da simbologia utilizada para representar o melhor comportamento das CQs

\begin{tabular}{|l|l|l|l|}
\hline Quanto maior melhor & $\uparrow$ & Quanto maior melhor, mas possui um valor limite superior & $\uparrow$ \\
\hline Quanto menor melhor & $\downarrow$ & Quanto menor melhor, mas possui um valor limite inferior & $\downarrow$ \\
\hline \multirow{2}{*}{ Valor especificado em um limite superior e inferior } & \\
\cline { 2 - 4 }
\end{tabular}

Fonte: Cheng e Melo Filho (2010)

\subsubsection{Definindo os Valores-Metas de desempenho para as Características da Qualidade}

Nesta etapa, devem ser estabelecidos os Valores-Metas de Desempenho, ou seja, a definição das especificações técnicas do novo produto/serviço que melhor supram às necessidades dos clientes. Instituir os Valores-Metas significa delinear o plano de melhoria para as características da qualidade do produto ou serviço. Isso implica na manutenção ou definição de novos valores para as CQs, visando superar a concorrência nos itens considerados mais estratégicos, isto é, de maior peso relativo (CHENG e MELO FILHO, 2010).

\subsubsection{Matriz Auxiliar das Características da Qualidade - Proporcionalidade}

O processo de proporcionalidade do QFD visa identificar as relações entre os elementos desdobrados de uma mesma tabela que constituem uma matriz (CHENG e MELO FILHO, 2010). Constrói-se, então, a matriz CQ X CQ, também chamada de Casa da Qualidade, que é uma matriz auxiliar que relaciona duas tabelas iguais de desdobramento da qualidade para apoiar a definição das metas de desempenho (CHENG et al., 1995).

Efetua-se nesta matriz uma avaliação da interdependência das CQs de um produto ou serviço que está sendo desenvolvido. Nela apontam-se o sentido e o grau de 
interdependência. A Tabela 3.8 apresenta a simbologia utilizada para demonstrar o tipo e a intensidade das correlações na Matriz CQ X CQ (Casa da Qualidade).

Tabela 3.8: Simbologia de correlação na Matriz CQ x CQ

\begin{tabular}{|c|c|}
\hline- & Fortemente positiva \\
\hline $\mathbf{X}$ & Positiva \\
\hline $\mathbf{X}$ & Negativa \\
\hline$\#$ & Fortemente negativa \\
\hline
\end{tabular}

Fonte: Cheng e Melo Filho (2010)

Ressalta-se que durante a construção, deve-se considerar somente um dos lados da diagonal, pois a matriz é triangular e simétrica. Por representar os campos em que uma CQ se relaciona com ela mesma, a diagonal da matriz nunca será preenchida (CHENG e MELO FILHO, 2010).

Concluídas todas as etapas anteriores, a Matriz da Qualidade ou Casa da Qualidade estará completa, constituindo-se em uma ferramenta muito eficaz no fornecimento de significativas informações relativas às necessidades dos clientes, as quais são muito relevantes para o processo de desenvolvimento de produtos ou serviços de uma empresa (ARPINI e RIBEIRO, 2012).

\subsection{TÓPICOS CONCLUSIVOS}

- Para a elaboração de um índice de avaliação da qualidade do transporte público é necessário conhecer o cliente do serviço (o usuário), e suas considerações sobre este. O método de coleta de dados por entrevista pessoal no local de contato do usuário com o serviço proporciona esse conhecimento da realidade do usuário e atribui confiabilidade às respostas do mesmo.

- A aplicação dos questionários por meio da internet proporciona o alcance rápido de maiores respondentes, mas exige um formulário mais explicado e fechado, evitando dúvidas, além de um tempo de aplicação mais curto, visto a variabilidade temporal da opinião dos respondentes, influenciada por acontecimentos e cenários. A Escala de Likert, utilizada nesta pesquisa, mostrase um excelente método para construção de formulários deste tipo.

- O QFD é um método construído para aplicação empresarial no desenvolvimento de produtos, porém foi aplicado por diversos autores em avaliações de serviços (muitos destes públicos) e mostrou-se efetiva na valoração dos indicadores de qualidade dos mesmos. 


\section{DESENVOLVIMENTO DO MÉTODO}

\subsection{APRESENTAÇÃO}

Neste capítulo demonstram-se os procedimentos de coletas e análises de dados realizados para a elaboração do índice de qualidade do transporte coletivo por ônibus, culminando na apresentação do índice proposto.

O capítulo se inicia com a pesquisa de relevância para o usuário, onde 155 usuários do sistema de transporte público por ônibus da cidade de Belo Horizonte indicaram os atributos de qualidade considerados mais importantes por estes na utilização do serviço.

Após, estes atributos foram selecionados e submetidos a uma pesquisa de valoração, por meio de formulário digital, com análise e resultados demonstrados neste capítulo. Completando o procedimento, aborda-se também a aplicação do método de Desdobramento da Função Qualidade - QFD para atribuição de pesos aos indicadores.

Para elaboração do índice proposto realiza-se a formulação do cálculo e parâmetros de cada um dos indicadores. Após, elabora-se o método de cálculo do índice de avaliação da qualidade do transporte público por ônibus, considerando os pesos atribuídos a cada indicador e atributo.

\subsection{SELEÇÃO DOS ATRIBUTOS}

Conforme explanado no capítulo 3 desta pesquisa, a fim de se conhecer quais atributos devem ser considerados na elaboração dos indicadores proposto, buscou-se saber a opinião dos usuários do sistema de transporte público por ônibus da cidade de Belo Horizonte/MG. Para esta etapa da pesquisa decidiu-se pela realização de uma pesquisa qualitativa por entrevista, pois, conforme Richardson et al. (2012), este método provoca a proximidade entre o pesquisador e o fenômeno em estudo, podendo ser fonte vital de informações que completem o processo de pesquisa.

Aplicou-se, então, um questionário aberto, onde cada respondente deve indicar três atributos para cada indicador selecionado na elaboração do índice. As pesquisas foram realizadas em nove Pontos de Controle (PC's) de linhas de ônibus da cidade de Belo Horizonte, entre os dias 15 e 27 de maio de 2014. Os resultados provenientes das 155 entrevistas foram tabulados por número de citações dos atributos e selecionaram-se aqueles que foram citados por mais de $60 \%$ do total de respondentes (93 citações), conforme Tabela 4.1. 
Tabela 4.1: Atributos selecionados para composição dos indicadores

\begin{tabular}{|c|c|c|c|}
\hline $\begin{array}{c}\text { Indicador } \\
\text { (Parâmetro } \\
\text { legal) }\end{array}$ & Atributo & Sigla & $\begin{array}{c}\text { Citações } \\
(\%)\end{array}$ \\
\hline Pontualidade & Viagens atrasadas & $\overline{A_{T R}}$ & $140(90 \%)$ \\
\hline (Regularidade) & Cumprimento dos itinerários & $\mathrm{I}_{\mathrm{TI}}$ & $126(81 \%)$ \\
\hline \multirow{3}{*}{$\begin{array}{c}\text { Tempo } \\
\text { (Continuidade) }\end{array}$} & Tempo de espera & $\mathrm{T}_{\mathrm{ES}}$ & $121(78 \%)$ \\
\hline & Duração da viagem & $\mathrm{D}_{\mathrm{VI}}$ & $102(66 \%)$ \\
\hline & Distância entre pontos ou estações & $\mathrm{D}_{\mathrm{IS}}$ & $98(63 \%)$ \\
\hline \multirow{3}{*}{$\begin{array}{c}\text { Lotação } \\
\text { (Eficiência) }\end{array}$} & Veículos lotados & $\mathrm{V}_{\mathrm{LO}}$ & $139(90 \%)$ \\
\hline & Quantidade de assentos por veículo & $\mathrm{Q}_{\mathrm{AS}}$ & $122(79 \%)$ \\
\hline & Quantidade de portas no veículo & $\mathrm{QPO}_{\mathrm{PO}}$ & $99(64 \%)$ \\
\hline \multirow{2}{*}{ Segurança } & Assaltos & $\mathrm{A}_{\mathrm{ST}}$ & $127(82 \%)$ \\
\hline & Acidentes de trânsito com o veículo & $\mathrm{A}_{\mathrm{CI}}$ & $105(68 \%)$ \\
\hline \multirow{3}{*}{$\begin{array}{l}\text { Informações } \\
\text { (Atualidade) }\end{array}$} & Informações nos pontos ou estações & $\mathrm{I}_{\mathrm{PO}}$ & $134(86 \%)$ \\
\hline & Informações prévias & $\mathrm{I}_{\mathrm{PR}}$ & $105(68 \%)$ \\
\hline & Informações dentro dos veículos & $\mathrm{I}_{\mathrm{VE}}$ & $99(64 \%)$ \\
\hline \multirow{3}{*}{$\begin{array}{c}\text { Veículos } \\
\text { (Generalidade) }\end{array}$} & Viagens interrompidas por falha mecânica & $\mathrm{V}_{\mathrm{IN}}$ & $110(71 \%)$ \\
\hline & Veículos acessíveis & $\mathrm{V}_{\mathrm{AC}}$ & $105(68 \%)$ \\
\hline & Veículos limpos & $\mathrm{V}_{\mathrm{LI}}$ & $98(63 \%)$ \\
\hline \multirow{3}{*}{$\begin{array}{l}\text { Tripulação } \\
\text { (Cortesia) }\end{array}$} & Obediência à solicitação de parada & $\mathrm{P}_{\mathrm{AR}}$ & $127(82 \%)$ \\
\hline & Velocidade do veículo & $\mathrm{V}_{\mathrm{EL}}$ & $118(76 \%)$ \\
\hline & Cortesia dos operadores & $\mathrm{C}_{\mathrm{OR}}$ & $95(61 \%)$ \\
\hline Tarifa & Valor da tarifa & $\mathrm{T}_{\mathrm{AR}}$ & $123(79 \%)$ \\
\hline $\begin{array}{c}\text { (Modicidade } \\
\text { das tarifas) }\end{array}$ & Integração tarifária & $\mathrm{I}_{\mathrm{NT}}$ & $118(76 \%)$ \\
\hline
\end{tabular}

Fonte: Elaborado pelo autor 


\subsection{RELEVÂNCIA PARA O USUÁRIO}

Definidos os atributos que compõem cada indicador, de acordo com a opinião do usuário, é necessário tratar a representatividade destes no índice final, atribuindo pesos conforme a relevância de cada atributo.

Para esta coleta de dados definiu-se a realização de uma nova pesquisa de opinião, utilizando-se uma escala do tipo Likert (LIKERT, 1932), a fim de que o usuário expresse a importância do atributo no indicador conforme sua opinião. Para que a pesquisa fosse respondida por um número maior de usuários, utilizou-se um formulário eletrônico, distribuído e divulgado a partir do site Google Docs, de acordo com os métodos sugeridos por Dekeyser e Watson (2006).

A pesquisa foi aplicada entre os dias 01 de junho e 30 de julho do ano de 2014, coletando um total de 882 respostas provindas de todas as cinco regiões do território nacional. O Gráfico 4.1 apresenta a distribuição percentual dos respondentes por região do país e a Tabela 4.2 apresenta a distribuição dos respondentes por estado e Distrito Federal.

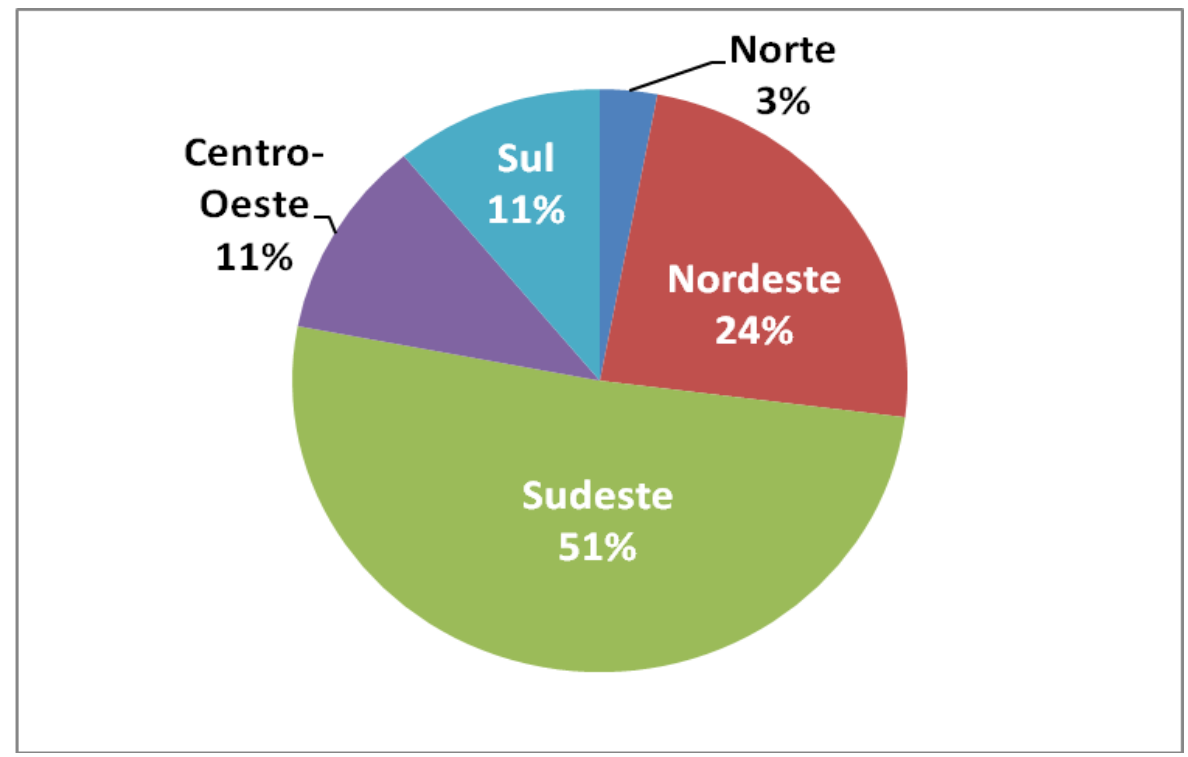

Gráfico 4.1: Distribuição dos respondentes por região

Fonte: Elaborado pelo autor

Tabela 4.2: Distribuição dos respondentes por estado e Distrito Federal

\begin{tabular}{ccc}
\hline Estado & Sigla & Respostas \\
\hline Minas Gerais & MG & 255 \\
\hline Bahia & BA & 141 \\
\hline
\end{tabular}




\begin{tabular}{|c|c|c|}
\hline São Paulo & SP & 97 \\
\hline Rio de Janeiro & RJ & 89 \\
\hline Distrito Federal & DF & 78 \\
\hline Paraná & PR & 39 \\
\hline Rio Grande do Sul & $\mathrm{RS}$ & 34 \\
\hline Santa Catarina & $\mathrm{SC}$ & 26 \\
\hline Maranhão & MA & 18 \\
\hline Goiás & GO & 17 \\
\hline Pará & $\mathrm{PA}$ & 17 \\
\hline Pernambuco & $\mathrm{PE}$ & 17 \\
\hline Ceará & $\mathrm{CE}$ & 16 \\
\hline Rio Grande do Norte & RN & 14 \\
\hline Espírito Santo & $\mathrm{ES}$ & 12 \\
\hline Amazonas & AM & 4 \\
\hline Alagoas & AL & 2 \\
\hline Mato Grosso do Sul & MS & 2 \\
\hline Tocantins & TO & 2 \\
\hline Piauí & PI & 1 \\
\hline Rondônia & $\mathrm{RO}$ & 1 \\
\hline
\end{tabular}

Fonte: Elaborado pelo autor

No formulário os respondentes são convidados a aplicar um grau de importância que varia de 1 (pouco importante) a 5 (muito importante) na consideração dos atributos definidos na pesquisa anterior e indicadores propostos para a avaliação da qualidade do sistema de transporte público por ônibus, de acordo com a influência de cada sobre a sua decisão de usar ou não o serviço. No formulário (Anexo II desta pesquisa) é oferecida ao respondente uma sucinta definição de cada indicador e atributo, na forma em que estão sendo utilizados nesta pesquisa.

Os resultados obtidos foram organizados em uma planilha eletrônica e encontrou-se a média do peso definida para cada atributo e indicador. Os resultados encontrados foram 
muito próximos entre si, o que indica a semelhança das opiniões colhidas. A média do grau de importância atribuído pode ser conferida na Tabela 4.3.

Tabela 4.3: Média do grau de importância (1 a 5) atribuído pelos usuários

\begin{tabular}{|c|c|c|c|}
\hline Indicador & Importância & Atributos & Importância \\
\hline \multirow{2}{*}{ Pontualidade } & \multirow{2}{*}{3,39} & Viagens atrasadas & 3,95 \\
\hline & & Cumprimento dos itinerários & 3,90 \\
\hline \multirow[t]{3}{*}{ Tempo } & \multirow[t]{3}{*}{3,61} & Tempo de espera & 4,17 \\
\hline & & Duração da viagem & 3,90 \\
\hline & & Distância entre pontos ou estações & 3,60 \\
\hline \multirow{3}{*}{ Lotação } & \multirow{3}{*}{3,79} & Veículos lotados & 4,35 \\
\hline & & Quantidade de assentos por veículos & 3,86 \\
\hline & & Quantidade de portas no veículo & 3,56 \\
\hline \multirow{2}{*}{ Segurança } & \multirow{2}{*}{3,29} & Assaltos & 3,79 \\
\hline & & Acidentes de trânsito com o veículo & 3,50 \\
\hline \multirow{3}{*}{ Informações } & \multirow{3}{*}{3,82} & Informações nos pontos ou estações & 4,10 \\
\hline & & Informações dentro dos veículos & 4,09 \\
\hline & & Informações prévias & 3,91 \\
\hline \multirow{3}{*}{ Veículos } & \multirow{3}{*}{3,76} & Viagens interrompidas por falha mecânica & 4,33 \\
\hline & & Veículos limpos & 4,22 \\
\hline & & Veículos acessíveis & 3,62 \\
\hline \multirow{3}{*}{ Tripulação } & \multirow{3}{*}{4,07} & Velocidade do veículo & 4,19 \\
\hline & & Cortesia dos operadores & 3,55 \\
\hline & & Obediência à solicitação de parada & 3,54 \\
\hline \multirow{2}{*}{ Tarifa } & \multirow{2}{*}{4,14} & Valor da tarifa & 4,17 \\
\hline & & Integração tarifária & 4,10 \\
\hline
\end{tabular}

Fonte: Elaborado pelo autor 


\subsection{VALORAÇÃO DOS INDICADORES}

Com a realização da pesquisa de relevância para o usuário, encontram-se os pesos necessários à aplicação do método QFD. A construção da matriz, que se destina a encontrar pesos para os indicadores do índice, seguiu o processo de oito etapas descritos na seção 3.4. Demonstram-se, a seguir, os resultados destas etapas.

\subsubsection{Tabela de Desdobramento da Qualidade Exigida}

A tabela foi construída em primeiro e segundo nível a partir dos indicadores (apontados na literatura) e atributos (levantados sob a ótica do usuário), formando assim a Tabela 4.4.

Tabela 4.4: Itens da qualidade exigida

\begin{tabular}{|c|c|}
\hline Itens primários & Itens secundários \\
\hline \multirow{2}{*}{ Pontualidade } & Viagens atrasadas \\
\hline & Cumprimento dos itinerários \\
\hline \multirow{3}{*}{ Tempo } & Tempo de espera \\
\hline & Duração da viagem \\
\hline & Distância entre pontos ou estações \\
\hline \multirow{3}{*}{ Lotação } & Veículos lotados \\
\hline & Quantidade de assentos por veículo \\
\hline & Quantidade de portas no veículo \\
\hline \multirow{2}{*}{ Segurança } & Assaltos \\
\hline & Acidentes de trânsito com o veículo \\
\hline \multirow{3}{*}{ Informações } & Informações nos pontos ou estações \\
\hline & Informações prévias \\
\hline & Informações dentro dos veículos \\
\hline \multirow{3}{*}{ Veículos } & Viagens interrompidas por falha mecânica \\
\hline & Veículos acessíveis \\
\hline & Veículos limpos \\
\hline
\end{tabular}




\begin{tabular}{cc}
\hline Tripulação & Obediência à solicitação de parada \\
& Velocidade do veículo \\
& Cortesia dos operadores \\
\hline Tarifa & Valor da tarifa \\
& Integração tarifária \\
\hline
\end{tabular}

Fonte: Elaborado pelo autor

\subsubsection{Qualidade Planejada}

Para priorizar os itens da qualidade demandada deve-se calcular o peso absoluto através da Equação 3.1. Porém, decidiu-se considerar somente o elemento "Grau de importância”, semelhantemente à adaptação feita por Arpini e Ribeiro (2012). Os outros dois elementos, "Índice de melhoria" e "Argumento de venda" foram desprezados devido à generalidade do índice de qualidade proposto, o que inviabiliza a análise de concorrência necessária à obtenção destes elementos.

Dessa forma, os pesos dos indicadores e atributos foram definidos a partir da nota média atribuída a estes na pesquisa de relevância para o usuário. Para a definição dos valores, calculou-se a relação entre a nota média de cada indicador/atributo com a soma das notas dos indicadores/atributos, obtendo-se os resultados demonstrados na Tabela 4.5. Desta forma, a soma dos pesos dos indicadores/atributos será 1 (ou 100\%).

Tabela 4.5: Valoração dos itens da qualidade exigida

\begin{tabular}{cccc}
\hline $\begin{array}{c}\text { Itens } \\
\text { primários }\end{array}$ & Peso & Itens secundários & Peso \\
\hline Pontualidade & 0,11 & Viagens atrasadas & 0,05 \\
& & Cumprimento dos itinerários & 0,05 \\
Tempo & 0,12 & Tempo de espera & 0,05 \\
& & Duração da viagem & 0,05 \\
& & Veículos lotados & 0,04 \\
\hline \multirow{2}{*}{ Lotação } & 0,12 & Quantidade de assentos por veículo & 0,05 \\
& & Quantidade de portas no veículo & 0,04 \\
\cline { 2 - 4 } & &
\end{tabular}




\begin{tabular}{|c|c|c|c|}
\hline \multirow{2}{*}{ Segurança } & \multirow{2}{*}{0,11} & Assaltos & 0,05 \\
\hline & & Acidentes de trânsito com o veículo & 0,04 \\
\hline \multirow{3}{*}{ Informações } & \multirow{3}{*}{0,13} & Informações nos pontos ou estações & 0,05 \\
\hline & & Informações prévias & 0,05 \\
\hline & & Informações dentro dos veículos & 0,05 \\
\hline \multirow{3}{*}{ Veículos } & \multirow{3}{*}{0,13} & Viagens interrompidas por falha mecânica & 0,05 \\
\hline & & Veículos acessíveis & 0,05 \\
\hline & & Veículos limpos & 0,04 \\
\hline \multirow{3}{*}{ Tripulação } & \multirow{3}{*}{0,14} & Obediência à solicitação de parada & 0,05 \\
\hline & & Velocidade do veículo & 0,04 \\
\hline & & Cortesia dos operadores & 0,04 \\
\hline \multirow{2}{*}{ Tarifa } & \multirow{2}{*}{0,14} & Valor da tarifa & 0,05 \\
\hline & & Integração tarifária & 0,05 \\
\hline
\end{tabular}

Fonte: Elaborado pelo autor

\subsubsection{Tabela de Desdobramento das Características da Qualidade (CQs)}

Esta etapa consiste no desdobramento dos itens da qualidade demandada em características da qualidade mensuráveis. Nesta pesquisa, as características da qualidade foram apontadas pelos usuários, apresentando itens mensuráveis quantitativamente, não sendo necessária a aplicação de novas ferramentas de levantamento das características, como brainstorming ou revisão da literatura.

\subsubsection{Matriz de correlação}

Desdobrados os itens de qualidade demandada em itens das características da qualidade, define-se a correlação entre estes por meio da construção de uma matriz. Os itens de qualidade são dispostos em linhas e as características em colunas, determinando-se critérios que liguem as duas tabelas em uma relação de causa e efeito.

Nesta pesquisa esta etapa é a mais importante do método, pois é a mais sensível para a definição dos pesos dos indicadores e atributos, visto que os valores médios encontrados são próximos entre si. Portanto, é importante que as correlações definidas descrevam nitidamente a influência que um item tem sobre o outro. Para tal, definiu-se a utilização da simbologia e valores apresentados na Tabela 4.6 para as correlações. Os valores 9-31 são os mais discrepantes entre si na Tabela 3.6, onde Cheng e Melo Filho (2010) 
apresentam sugestões para a matriz, resultando em pesos que destaquem os atributos mais importantes dos demais.

Tabela 4.6: Regra de correlação entre requisitos de usuários e de serviço

\begin{tabular}{c|c|c}
\hline Símbolo & Correlação & Peso \\
\hline $\boldsymbol{O}$ & Forte & 9 \\
\hline $\boldsymbol{\Delta}$ & Moderada & 3 \\
\hline$\bigcirc$ & Fraca & 1 \\
\hline "Em branco" & Inexistente & - \\
\hline
\end{tabular}

Fonte: Arpini e Ribeiro (2012)

Para a realização das correlações na matriz, foram considerado os aspectos de influência direta e com fácil assimilação da influência da influência entre si, a partir do conhecimento da rotina de diversos sistemas de transporte público por ônibus e leitura das publicações que consultaram os usuários ara medir a qualidade do serviço (conforme Tabela 2.1).

As intensidades das correlações foram atribuídas seguindo a ordem das linhas (qualidade exigida), sendo analisadas as correlações com todas as características da qualidade, não sendo indicada intensidade nas correlações para os itens que não apresentem notória influência entre si. Após, as correlações foram verificadas a partir da inversão da sequência: foram observadas as correlações a partir das colunas, verificando se condizem as intensidades atribuídas a cada linha, corrigindo alguns equívocos.

Após, a matriz foi submetida à avaliação de um especialista, analista de transporte e trânsito da BHTrans há 20 anos, corrigindo algumas intensidades atribuídas. Por fim, foram encontradas 44 correlações, resultando na matriz apresentada na Figura 4.1. 


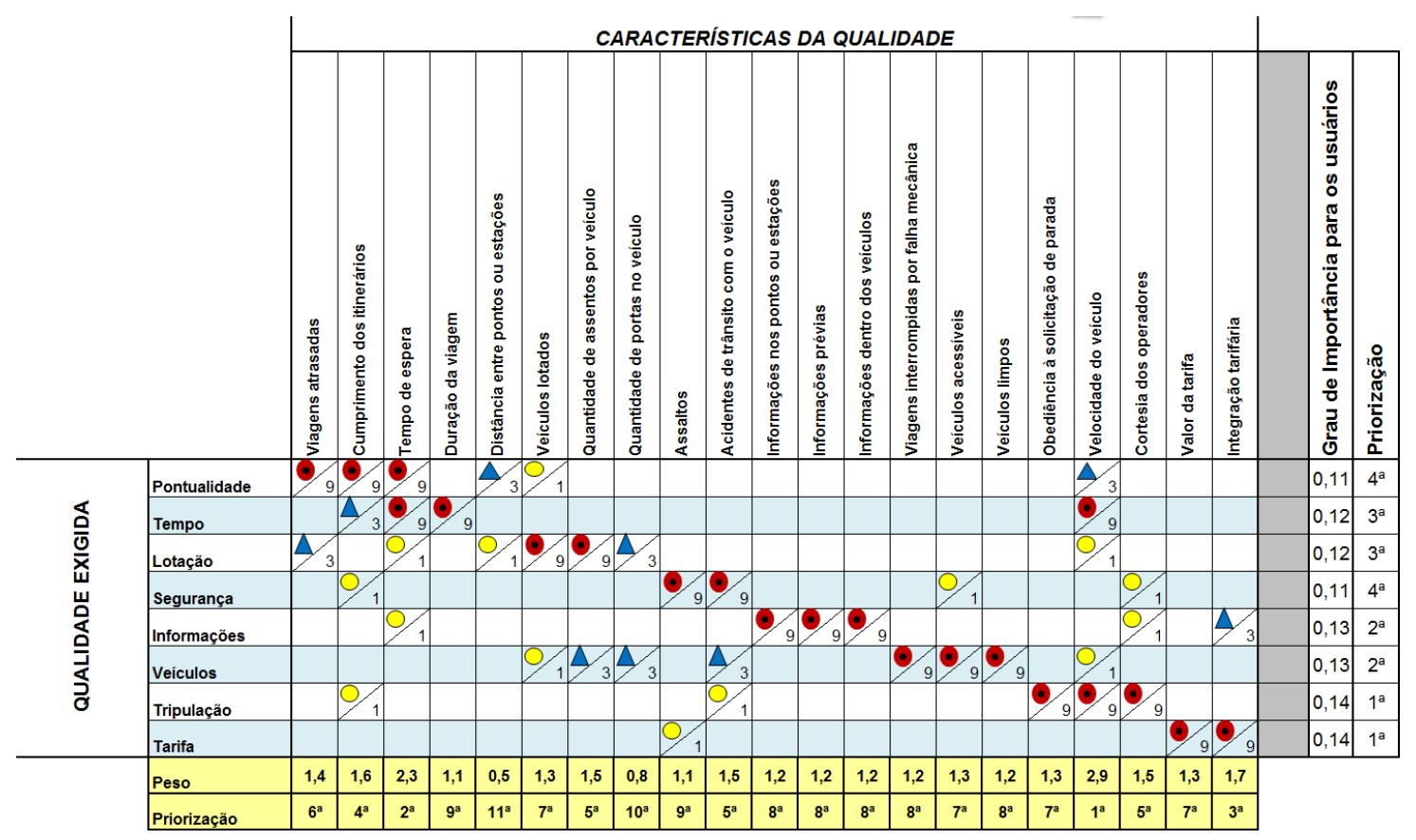

Figura 4.1: Matriz de correlação

Fonte: elaborada pelo autor a partir de Cheng e Melo Filho (2010)

\subsubsection{Processo de conversão: priorização das características da Qualidade}

Na Figura 4.1 são demonstrados os pesos resultantes do processo de conversão. A partir destes é realizada a priorização dos itens das características da qualidade, conforme Tabela 4.7.

Tabela 4.7: Priorização dos itens das características da qualidade

\begin{tabular}{cccc}
\hline Qualidade exigida & Características da qualidade & Peso & Prioridade \\
\hline Tripulação & Velocidade do veículo & 2,9 & $1^{\mathrm{a}}$ \\
\hline Tempo & Tempo de espera & 2,3 & $2^{\mathrm{a}}$ \\
\hline Tarifa & Integração tarifária & 1,7 & $3^{\mathrm{a}}$ \\
\hline Pontualidade & Cumprimento dos itinerários & 1,6 & $4^{\mathrm{a}}$ \\
\hline Lotação & Quantidade de assentos por veículo & 1,5 & $5^{\mathrm{a}}$ \\
\hline Segurança & Acidentes de trânsito com o veículo & 1,5 & $5^{\mathrm{a}}$ \\
\hline Tripulação & Cortesia dos operadores & 1,5 & $5^{\mathrm{a}}$ \\
\hline Pontualidade & Viagens atrasadas & 1,4 & $6^{\mathrm{a}}$ \\
\hline & & & 65
\end{tabular}




\begin{tabular}{|c|c|c|c|}
\hline Lotação & Veículos lotados & 1,3 & $7^{\mathrm{a}}$ \\
\hline Veículos & Veículos acessíveis & 1,3 & $7^{\mathrm{a}}$ \\
\hline Tripulação & Obediência à solicitação de parada & 1,3 & $7^{\mathrm{a}}$ \\
\hline Tarifa & Valor da tarifa & 1,3 & $7^{a}$ \\
\hline Informações & Informações nos pontos ou estações & 1,2 & $8^{\mathrm{a}}$ \\
\hline Informações & Informações prévias & 1,2 & $8^{a}$ \\
\hline Informações & Informações dentro dos veículos & 1,2 & $8^{a}$ \\
\hline Veículos & Viagens interrompidas por falha mecânica & 1,2 & $8^{a}$ \\
\hline Veículos & Veículos limpos & 1,2 & $8^{\mathrm{a}}$ \\
\hline Tempo & Duração da viagem & 1,1 & $9^{\mathrm{a}}$ \\
\hline Segurança & Assaltos & 1,1 & $9^{a}$ \\
\hline Lotação & Quantidade de portas no veículo & 0,8 & $10^{\mathrm{a}}$ \\
\hline Tempo & Distância entre pontos ou estações & 0,5 & $11^{\mathrm{a}}$ \\
\hline
\end{tabular}

Fonte: Elaborado pelo autor

\subsubsection{Análise competitiva}

Nesta etapa, o valor de cada característica da qualidade do produto/serviço atual da empresa é comparado e disposto na Qualidade Projetada da Matriz da Qualidade. Porém, esta pesquisa destina-se a construir um índice geral, desprezando-se as análises de concorrência (medir forças entre o produto/serviço oferecido e os disponíveis no mercado), pois ao comparar um sistema de transporte público com outro ocorreria a limitação do método para somente estas duas localidades. Desta forma, desdobrou-se na matriz apenas o melhor comportamento das CQs, conforme Tabela 3.7.

\subsubsection{Definindo os Valores-Metas de desempenho para as Características da Qualidade}

Nesta etapa devem ser estabelecidos os Valores-Metas, que são os parâmetros de valores mínimos e máximos admissíveis para cada atributo. Nesta pesquisa os ValoresMetas são demonstrados na elaboração das equações dos atributos, na seção 4.5. 


\subsubsection{Matriz Auxiliar das Características da Qualidade}

Nesta etapa constrói-se uma matriz auxiliar que relaciona duas tabelas iguais de desdobramento da qualidade, visando apoiar definições de metas de desempenho e demais decisões, concluindo assim a matriz da Qualidade (ou casa da Qualidade), apresentada na Figura 4.2 e Anexo III (para visualização com melhor resolução gráfica).
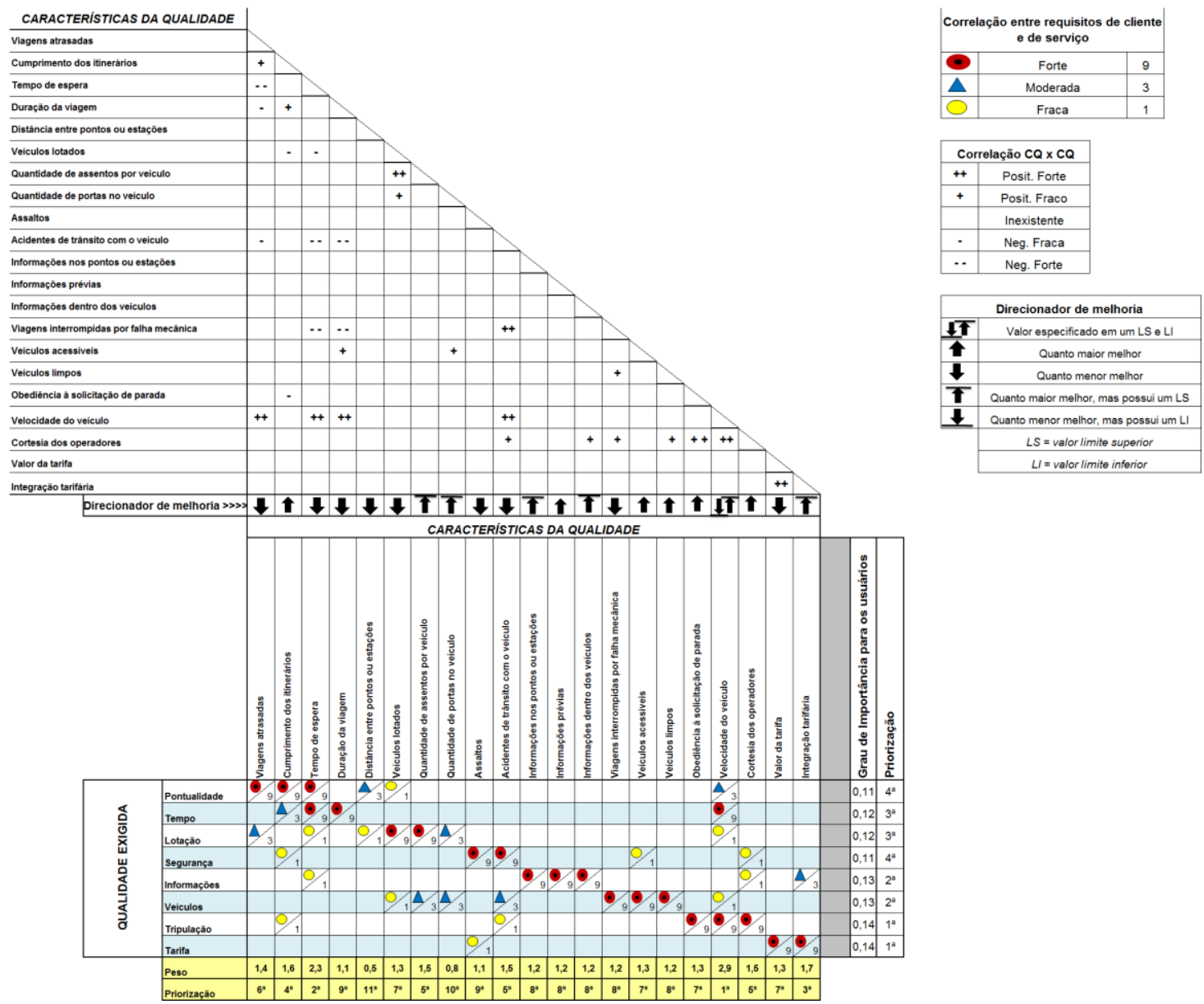

Figura 4.2: Matriz da Qualidade

Fonte: elaborado pelo autor a partir de Cheng e Melo Filho (2010)

\subsubsection{Resultados da Matriz da Qualidade}

Verificou-se que apenas dois indicadores (Tempo e Tripulação) resultaram diferenças significativas (maiores que cinco posições) na priorização dos atributos. Portanto, decidiu-se pela aplicação de pesos somente aos atributos destes dois indicadores, considerando iguais os pesos dos demais atributos, visto a baixa relevância estatística dos seus resultados.

Considerar os pesos a partir de cinco posições na priorização dos atributos foi uma decisão com suporte em testes no desenvolvimento do método, que resultaria em pesos inexpressivos se considerado quatro posições ou menos. 
A adoção de pesos para estes atributos segue a metodologia de valoração dos indicadores realizada por Arpini e Ribeiro (2012). Para tal, os números ordinais (de priorização) são transformados em números fracionários, a partir da inversão do número ordinal. Por exemplo, um indicador priorizado em $4^{\circ}$ é convertido para $1 / 4(0,25)$.

Após, os pesos calculados são parametrizados para que somem 1 e atendam aos requisitos do índice proposto. Desta forma, encontraram-se pesos para os indicadores conforme Tabela 4.8. Os pesos para os atributos dos indicadores Tempo e Tripulação são apresentados na Tabela 4.9.

Tabela 4.8: Pesos dos indicadores

\begin{tabular}{ccc}
\hline Indicador & Peso & Peso parametrizado \\
\hline Pontualidade & 0,25 & 0,06 \\
\hline Tempo & 0,33 & 0,08 \\
\hline Lotação & 0,33 & 0,08 \\
\hline Segurança & 0,25 & 0,06 \\
\hline Informações & 0,5 & 0,12 \\
\hline Veículos & 0,5 & 0,12 \\
\hline Tripulação & 1 & 0,24 \\
\hline Tarifa & 1 & 0,24 \\
\hline
\end{tabular}

Fonte: elaborado pelo autor

Tabela 4.9: Pesos dos atributos com diferenças significativas

\begin{tabular}{cccc}
\hline Indicador & Atributo & Peso & Peso parametrizado \\
\hline \multirow{2}{*}{ Tempo } & Tempo de espera & 0,5 & 0,71 \\
\cline { 2 - 4 } & Duração da viagem & 0,11 & 0,16 \\
\cline { 2 - 4 } & Distância entre pontos e estações & 0,09 & 0,13 \\
\hline \multirow{2}{*}{ Tripulação } & Velocidade do veículo & 1 & 0,75 \\
\cline { 2 - 4 } & Cortesia dos operadores & 0,2 & 0,15 \\
\cline { 2 - 4 } & Obediência à solicitação de parada & 0,14 & 0,1 \\
\hline
\end{tabular}

Fonte: elaborado pelo autor 


\subsection{PROCEDIMENTOS E PARÂMETROS DE CÁLCULO}

Após a identificação dos atributos de cada indicador e os pesos destes, esta seção trata dos procedimentos e parâmetros de cálculo de cada atributo e consequente indicador. As equações são especificadas para que cada atributo e indicador retorne um valor entre 0 e 1. Dessa forma, ao calcular o índice final, encontrar-se-á um valor dentro deste intervalo que, convertido em porcentagem, responde à qualidade do sistema avaliado demonstrando a participação e importância de cada item. Alguns indicadores são calculados por média simples e outros por média ponderada. Tal diferença deve-se à aplicação ou não de peso aos atributos, que nesta pesquisa ocorreu apenas nos indicadores Tempo e Tripulação.

Utilizam-se tabelas de conversão para tornar os atributos mais representativos e facilitar a interpretação do índice pelo avaliador. As tabelas são dividas em faixas e estas, quando não apresentadas pelos autores consultados, foram definidas a partir dos valores máximos e mínimos encontrados na literatura, além da experiência em rotina de sistemas de transporte coletivo e testes de resultados possíveis para os atributos, encontrando-se os valores intermediários ao atribuir lacunas de valor igual ou aproximado entre estes.

\subsubsection{Pontualidade $\left(\boldsymbol{P}_{N}\right)$}

$\mathrm{O}$ indicador Pontualidade $\left(\mathrm{P}_{\mathrm{N}}\right)$ considera os atributos Viagens atrasadas $\left(\mathrm{A}_{\mathrm{TR}}\right)$ e Cumprimento dos itinerários $\left(\mathrm{I}_{\mathrm{TI}}\right.$ ), sendo calculado pela média dos dois atributos, dessa forma, tem-se:

$$
P_{N}=\frac{A_{T R}+I_{T I}}{2}
$$

\subsubsection{Viagens atrasadas $\left(A_{T R}\right)$}

$\mathrm{O}$ atributo de viagens atrasadas é obtido através da relação entre o número de viagens não realizadas e realizadas com atraso e o número de viagens programadas, podendo ser calculado para uma linha ou todo o sistema em determinado período, conforme Equação 4.2 .

$$
A_{T R}=\frac{V_{T}-\left(V_{A}+V_{N}\right)}{V_{T}}
$$

Onde:

- $\mathrm{V}_{\mathrm{A}}=$ Número de viagens atrasadas;

- $\mathrm{V}_{\mathrm{N}}=$ Número de viagens não realizadas;

- $\mathrm{V}_{\mathrm{T}}=$ Número total de viagens programadas para o período. 
Geralmente, os percentuais encontrados nesta equação são altos. Para tornar o atributo representativo dentro do indicador, utiliza-se, para conversão do valor final, a Tabela 4.10 .

Tabela 4.10: Padrão de qualidade de pontualidade

\begin{tabular}{cc}
\hline $\mathbf{A}_{\mathbf{T R}}$ & Valor do atributo \\
\hline$>0,9$ & 1 \\
\hline Entre 0,9 e 0,75 & 0,5 \\
\hline$<0,75$ & 0,1 \\
\hline
\end{tabular}

Fonte: elaborado pelo autor

\subsubsection{Cumprimento dos itinerários $\left(I_{T I}\right)$}

$\mathrm{O}$ atributo de cumprimento dos itinerários depende de tecnologias de rastreamento e análise das rotas realizadas pelos veículos. Seguindo a premissa de tornar o índice um método de simples aplicação, independente de tecnologias específicas, este atributo é calculado com base na relação entre a quilometragem realizada com a quilometragem especificada, adaptando o Índice de Cumprimento da Quilometragem elaborado por Lima (1996).

Para tornar o atributo representativo e oferecer uma margem de tolerância às ocorrências operacionais que obrigam a realização de desvios de itinerários, é realizada a conversão dos resultados conforme Tabela 4.11. Para se encontrar a quilometragem especificada, deve-se considerar a quilometragem de projeto de cada viagem da linha, desprezando o número de viagens incompletas e somando-se o número de viagens extras.

Neste atributo, tanto as variações positivas quanto negativas (acima ou abaixo de 1) são consideradas para a conversão.

$$
I_{T I}=\frac{Q_{R}}{Q_{E}}
$$

Onde:

- $\mathrm{Q}_{\mathrm{R}}=$ Quilometragem realizada;

- $\mathrm{Q}_{\mathrm{E}}=$ Quilometragem especificada. 
Tabela 4.11: Conversão da relação de cumprimento de itinerários

\begin{tabular}{cc}
\hline $\mathbf{I}_{\text {TI }}$ & $\begin{array}{c}\text { Valor do } \\
\text { atributo }\end{array}$ \\
\hline Entre 0,8 e 1,2 & 1 \\
\hline Entre 0,5 e 0,79 ou entre 1,21 e 1,5 & 0,5 \\
\hline Menor que 0,5 ou maior que 1,5 & 0,1 \\
\hline
\end{tabular}

Fonte: elaborado pelo autor

\subsubsection{Tempo $\left(T_{E}\right)$}

$\mathrm{O}$ indicador Tempo $\left(\mathrm{T}_{\mathrm{E}}\right)$ considera os atributos Tempo de espera $\left(\mathrm{T}_{\mathrm{ES}}\right)$, Duração da viagem $\left(D_{\mathrm{VI}}\right)$ e Distância entre pontos e estações $\left(\mathrm{D}_{\mathrm{IS}}\right)$. O indicador é obtido através da soma dos três atributos, aplicados os pesos definidos na Matriz da Qualidade.

$$
T_{E}=0,71 T_{E S}+0,16 D_{V I}+0,13 D_{I S}
$$

\subsubsection{Tempo de espera $\left(T_{E S}\right)$}

O tempo de espera é determinado a partir do headway (intervalo entre viagens) médio das linhas em dias úteis. Primeiramente calcula-se a média dos headways das linhas e após realiza-se a conversão do resultado conforme a Tabela 4.12, que utiliza os headways médios baseados nos parâmetros de melhor e pior valores para headway em dia útil encontrados por Gomide et al. (2006).

$$
T_{E S}=\frac{\sum_{i=1}^{n} H_{L}}{n}
$$

Onde:

- $\mathrm{n}=$ número de linhas avaliadas;

- $\mathrm{H}_{\mathrm{L}}=$ Headway da linha.

Tabela 4.12: Conversão do headway médio

\begin{tabular}{cc}
\hline $\mathbf{T}_{\mathbf{E S}}$ & Valor do atributo \\
\hline$<6$ & 1 \\
\hline Entre 6 e 10 & 0,8 \\
\hline Entre 11 e 15 & 0,6 \\
\hline Entre 16 e 20 & 0,4 \\
\hline
\end{tabular}




\begin{tabular}{cc}
\hline Entre 21 e 35 & 0,2 \\
\hline$>35$ & 0 \\
\hline
\end{tabular}

Fonte: adaptado de Gomide et al. (2006)

\subsubsection{Duração da viagem $\left(D_{V I}\right)$}

Para que não seja necessário o uso de softwares de informações geográficas, este atributo é calculado a partir do tempo total de viagem das linhas avaliadas. Considerase, portanto, que o usuário permaneça metade deste tempo no interior do veículo, atingindo seu destino no ponto de retorno ou central da viagem. Desta forma, temos o atributo calculado conforme a Equação 4.13. Após o cálculo, utiliza-se a Tabela 4.6 para definição do valor do atributo.

$$
D_{V I}=\frac{\left(\frac{\sum_{i=1}^{n} T_{V}}{n}\right)}{2}
$$

Onde:

- $\mathrm{n}=$ número de linhas avaliadas;

- $\mathrm{T}_{\mathrm{V}}=$ Tempo de viagem.

Tabela 4.13: Conversão da relação de duração da viagem

\begin{tabular}{cc}
\hline $\mathbf{D}_{\mathbf{V I}}$ & Valor do atributo \\
\hline$<20$ & 1 \\
\hline Entre 20 e 30 & 0,8 \\
\hline Entre 31 e 40 & 0,6 \\
\hline Entre 41 e 50 & 0,4 \\
\hline Entre 51 e 60 & 0,2 \\
\hline$>60$ & 0 \\
\hline
\end{tabular}

Fonte: elaborado pelo autor

\subsubsection{Distância entre pontos ou estações $\left(D_{I S}\right)$}

Este atributo tem seu valor obtido diretamente da tabela de conversão, baseando-se na política de implantação de pontos de embarque e desembarque de passageiros (PED) adotada por cada órgão gerenciador do transporte público. Ferraz (1990) definiu padrões de acessibilidade conforme a distância média de caminhada do usuário até o PED, sendo 
estes padrões utilizados aqui para valorar a distância mínima entre PED ou estações adotada para o sistema em avaliação.

Tabela 4.14: Conversão da distância entre pontos ou estações

\begin{tabular}{ccc}
\hline Distância mínima adotada & Padrão de acessibilidade & Valor do atributo \\
\hline$<250$ metros & Bom & 1 \\
\hline Entre 250 e 400 metros & Regular & 0,5 \\
\hline$>400$ metros & Ruim & 0,1 \\
\hline
\end{tabular}

Fonte: adaptado de Ferraz (1990)

\subsubsection{Lotação $\left(\boldsymbol{L}_{\boldsymbol{O}}\right)$}

O indicador Lotação $\left(\mathrm{L}_{\mathrm{O}}\right)$ considera os atributos Veículos lotados $\left(\mathrm{V}_{\mathrm{LO}}\right)$, Quantidade de assentos por veículo $\left(\mathrm{Q}_{\mathrm{AS}}\right)$ e Quantidade de portas no veículo ( $\left.\mathrm{Q}_{\mathrm{PO}}\right)$, sendo calculado pela média dos três atributos. Desta forma, tem-se:

$$
L_{O}=\frac{V_{L O}+Q_{A S}+Q_{P O}}{3}
$$

\subsubsection{Veículos lotados $\left(V_{L O}\right)$}

A medição do atributo de veículos lotados necessita de levantamento em campo, onde se define o trecho crítico das linhas e observa-se, por amostra, a lotação dos veículos naquele trecho. A partir destes dados, calcula-se o atributo com base no número de veículos que apresentaram lotação acima da permitida em contrato, conforme a Equação 4.8. Após, utiliza-se a Tabela 4.15 para conversão, elaborada conforme os valores mínimos e máximos admitidos por BHTrans (2012).

$$
V_{L O}=\frac{V_{O}-V_{L}}{V_{O}}
$$

Onde:

- $\mathrm{V}_{\mathrm{O}}=$ Número de veículos observados;

- $\mathrm{V}_{\mathrm{L}}=$ Número de veículos lotados observados.

Tabela 4.15: Níveis de referência de lotação de veículos

\begin{tabular}{ccc}
\hline $\mathbf{V}_{\mathbf{L O}}$ & Nível de serviço & Valor do atributo \\
\hline$>0,98$ & $\mathrm{~A}$ & 1 \\
\hline Entre 0,98 e 0,96 & $\mathrm{~B}$ & 0,75 \\
\hline
\end{tabular}




\begin{tabular}{ccc}
\hline Entre 0,95 e 0,92 & $\mathrm{C}$ & 0,5 \\
\hline Entre 0,91 e 0,46 & $\mathrm{D}$ & 0,25 \\
\hline$<0,46$ & $\mathrm{E}$ & 0 \\
\hline
\end{tabular}

Fonte: adaptado de BHTrans (2012)

\subsubsection{Quantidade de assentos por veículo $\left(Q_{A S}\right)$}

O atributo de quantidade de assentos por veículo mede a capacidade dos veículos considerando o nível máximo de conforto (todos os passageiros sentados), sendo definido pela média do número de assentos de todos os veículos do sistema. Após o cálculo desta média, utiliza-se a Tabela 4.16 para conversão e valoração do atributo.

$$
Q_{A S}=\frac{\sum_{i=1}^{n} A_{V}}{n}
$$

Onde:

- $\mathrm{A}_{\mathrm{V}}=$ Assentos por veículo;

- $\mathrm{n}=$ Número de veículos do sistema.

Tabela 4.16: Quantidade de assentos por veículo

\begin{tabular}{cc}
\hline $\mathbf{Q}_{\mathrm{AS}}$ & Valor do atributo \\
\hline$>40$ & 1 \\
\hline Entre 31 e 40 & 0,75 \\
\hline Entre 21 e 30 & 0,5 \\
\hline Entre 15 e 20 & 0,25 \\
\hline$<15$ & 0,1 \\
\hline
\end{tabular}

Fonte: elaborado pelo autor

\subsubsection{Quantidade de portas no veículo $\left(Q_{P O}\right)$}

Este atributo mede a facilidade de embarque e desembarque dos passageiros a partir do número de portas no veículo. Este também contribui para medir o conforto da movimentação dos passageiros, visto que um veículo com mais portas exige menos caminhamento dos passageiros dentro do mesmo. Utiliza-se a Tabela 4.17 para encontrar o valor final do atributo.

$$
Q_{P O}=\frac{\sum_{i=1}^{n} P_{V}}{n}
$$


Onde:

- $\mathrm{P}_{\mathrm{V}}=$ Portas no veículo;

- $\mathrm{n}=$ Número de veículos do sistema.

Tabela 4.17: Quantidade de portas no veículo

\begin{tabular}{cc}
\hline QPo & Valor do atributo \\
\hline$>2,5$ & 1 \\
\hline Entre 2 e 2,5 & 0,5 \\
\hline Entre 1 e 1,9 & 0,1 \\
\hline
\end{tabular}

Fonte: elaborado pelo autor

\subsubsection{Segurança $\left(S_{G}\right)$}

$\mathrm{O}$ indicador Segurança $\left(\mathrm{S}_{\mathrm{G}}\right)$ considera os atributos Assaltos $\left(\mathrm{A}_{\mathrm{ST}}\right)$ e Acidentes de trânsito com o veículo $\left(\mathrm{A}_{\mathrm{CI}}\right)$, sendo obtido pela média dos atributos, conforme Equação 4.11 .

$$
S_{G}=\frac{A_{S T}+A_{C I}}{2}
$$

\subsubsection{Assaltos $\left(A_{S T}\right)$}

O atributo Assaltos é calculado a partir da ocorrência do evento dentro dos veículos de transporte coletivo durante as viagens, com ou sem interrupção das mesmas. Conforme a metodologia de BHTrans (2012), o valor do atributo é considerado para grupos de 10000 viagens realizadas, conforme Equação 4.12.

$$
A_{S T}=\left(\frac{A_{O}}{V_{R}}\right) \times 10000
$$

Onde:

- $\mathrm{A}_{\mathrm{O}}=$ Número de assaltos a ônibus registrados;

- $\mathrm{V}_{\mathrm{R}}=$ Número total de viagens realizadas no período.

Para conversão do resultado e obtenção do valor final dos atributos $A_{S T}$ e $A_{C I}$, utiliza-se a Tabela 4.18, elaborada considerando o valor aceitável de assaltos e acidentes a cada 10000 viagens utilizado por BHTrans (2012). 
Tabela 4.18: Assaltos e acidentes registrados a cada 10000 viagens

\begin{tabular}{ccc}
\hline \multicolumn{1}{c}{$\mathbf{A}_{\text {ST }}$} & Nível de serviço & Valor do atributo \\
\hline Entre 0 e 1 & A & 1 \\
\hline Entre 1,1 e 2 & B & 0,8 \\
\hline Entre 2,1 e 4 & C & 0,6 \\
\hline Entre 4,1 e 14 & D & 0,4 \\
\hline Entre 14,1 e 24 & E & 0,2 \\
\hline$>24$ & - & 0 \\
\hline
\end{tabular}

Fonte: adaptado de BHTrans (2012)

\subsubsection{Acidentes de trânsito com o veículo $\left(A_{C I}\right)$}

$\mathrm{O}$ atributo Acidentes de trânsito com o veículo assemelha-se ao atributo anterior, pois também considera a ocorrência do evento a cada grupo de 10000 viagens realizadas. Para conversão, também utiliza-se a Tabela 4.18.

$$
A_{C I}=\left(\frac{A_{C}}{V_{R}}\right) \times 10000
$$

Onde:

- $\quad \mathrm{A}_{\mathrm{C}}=$ Número de acidentes de trânsito com ônibus;

- $\mathrm{V}_{\mathrm{R}}=$ Número total de viagens realizadas no período.

\subsubsection{Informação $\left(\boldsymbol{I}_{F}\right)$}

$\mathrm{O}$ indicador Informação $\left(\mathrm{I}_{\mathrm{F}}\right)$ mede as informações disponíveis ao usuário sem necessidade de solicitação, ou seja, informações afixadas ou apresentadas em locais públicos ou, ainda, disponíveis para consulta sem mediação de um atendente. O indicador é calculado pela média dos atributos Informações nos pontos ou estações $\left(\mathrm{I}_{\mathrm{PO}}\right)$, Informações dentro dos veículos $\left(\mathrm{I}_{\mathrm{VE}}\right)$ e Informações prévias $\left(\mathrm{I}_{\mathrm{PR}}\right)$.

$$
I_{F}=\frac{I_{P O}+I_{V E}+I_{P R}}{3}
$$

\subsubsection{Informações nos pontos ou estações $\left(I_{P O}\right)$}

Este atributo reflete a existência ou não de informações ao usuário nos pontos de embarque e desembarque de passageiros - PED e nas estações do transporte coletivo por ônibus. $\mathrm{O}$ atributo é calculado pela média das informações em 3 níveis: linhas que 
atendem o PED, itinerários das linhas e previsão de chegada no PED (ou quadro de horários ou, ainda, headway das linhas).

Para o cálculo, PED com uma informação, em qualquer um dos três níveis, chama-se N1. Os PED que possuem informações em dois níveis rotulam-se N2, e os que possuem os três níveis de informações são chamados N3. Os PED sem informações são considerados apenas para o número total de $\mathrm{PED}$ do sistema $(\mathrm{P})$.

Dessa forma, o atributo IPO é calculado conforme a Equação 4.15.

$$
I_{P O}=\frac{(N 1 / p)+(N 2 / p)+(N 3 / p)}{3}
$$

Onde:

- N1 = Número de PED com um nível de informação;

- $\quad \mathrm{N} 2$ = Número de PED com dois níveis de informações;

- $\quad \mathrm{N} 3$ = Número de PED com três níveis de informações;

- $\mathrm{P}=$ Número total de PED do sistema.

\subsubsection{Informações dentro dos veículos $\left(I_{V E}\right)$}

$\mathrm{O}$ atributo Informações dentro dos veículos $\left(\mathrm{I}_{\mathrm{VE}}\right)$ considera a informação disponível ao usuário afixada ou apresentada dentro dos veículos em dois níveis: quadro de horários e itinerários. Seguindo a metodologia do atributo $\mathrm{I}_{\mathrm{PO}}$, tem-se a Equação 4.16.

$$
I_{V E}=\frac{(V 1 / V)+(V 2 / V)}{2}
$$

Onde:

- $\quad$ V1 = Número de veículos com um nível de informação;

- $\quad$ V2 = Número de veículos com dois níveis de informações;

- $\mathrm{V}=$ Número total de veículos no sistema.

\subsubsection{Informações prévias $\left(I_{P R}\right)$}

Neste atributo, consideram-se as informações disponíveis para os usuários na internet, seja em portal do órgão gerenciador ou outro, e a divulgação do endereço nos veículos e/ou PED/estações. Desta forma, se existem informações disponíveis por este meio de comunicação, com endereço divulgado em locais públicos, o atributo recebe valor 1 . Caso não existam as informações ou publicidade do endereço, o atributo recebe valor 0 . 


\subsubsection{Veículos $\left(V_{E}\right)$}

$\mathrm{O}$ indicador Veículos $\left(\mathrm{V}_{\mathrm{E}}\right)$ mede a qualidade dos veículos oferecidos de acordo com as exigências principais dos usuários. Para tal, considera os atributos Viagens interrompidas por falha mecânica $\left(\mathrm{V}_{\mathrm{IN}}\right)$, Veículos acessíveis $\left(\mathrm{V}_{\mathrm{AC}}\right)$ e Veículos limpos $\left(\mathrm{V}_{\mathrm{LI}}\right)$, sendo o indicador resultado da média destes atributos.

$$
V_{E}=\frac{V_{I N}+V_{A C}+V_{L I}}{3}
$$

\subsubsection{Viagens interrompidas por falha mecânica $\left(V_{I N}\right)$}

$\mathrm{O}$ atributo Viagens interrompidas por falha mecânica é medido conforme metodologia adotada por BHTrans (2012), em que as interrupções são consideradas a partir dos quilômetros $(\mathrm{km})$ produtivos, que é a quilometragem realizada em viagens pelos veículos do sistema durante o período avaliado. O atributo é calculado para cada 100000 $\mathrm{km}$ produtivos.

BHTrans (2012) considera como falha mecânica as seguintes interrupções: defeito de roleta, pneu furado, porta, problema elétrico, defeito freio de porta, entrada de ar, embreagem, freio, motor, roda e outros problemas mecânicos.

$$
V_{I N}=\left(\frac{I_{N}}{K_{p}}\right) \times 100000
$$

Onde:

- $\mathrm{I}_{\mathrm{N}}=$ Número de interrupções por falha mecânica;

- $\mathrm{K}_{\mathrm{P}}=$ Número total de quilômetros produtivos do sistema no período.

Utiliza-se, para conversão e definição do valor do atributo, a Tabela 4.18.

\subsubsection{Veículos acessíveis $\left(V_{A C}\right)$}

$\mathrm{O}$ atributo mede a acessibilidade de cadeirantes e pessoas com mobilidade reduzida aos veículos do sistema avaliado. Para tal, considera-se acessível o veículo que possui elevador, piso baixo ou porta no mesmo nível das estações.

$$
V_{A C}=\frac{V_{C}}{V_{I}}
$$

Onde:

- $\mathrm{V}_{\mathrm{C}}=$ Número de veículos acessíveis no sistema;

- $\mathrm{V}_{\mathrm{I}}=$ Número total de veículos do sistema. 


\subsubsection{Veículos limpos $\left(V_{L I}\right)$}

Para medição deste atributo, é necessária pesquisa de campo por amostragem, onde os veículos serão abordados durante as viagens ou nos PC's e será avaliada qualitativamente o seu estado de conservação quanto à limpeza do piso, bancos, balaústres e lataria.

$$
V_{L I}=\frac{V_{V}-V_{S}}{V_{V}}
$$

Onde:

- $\mathrm{V}_{\mathrm{S}}=$ Número de veículos sujos;

- $\mathrm{V}_{\mathrm{V}}=$ Número de veículos avaliados.

\subsubsection{Tripulação $\left(\boldsymbol{T}_{R}\right)$}

$\mathrm{O}$ indicador Tripulação $\left(\mathrm{T}_{\mathrm{R}}\right)$ mede a relação dos usuários com a tripulação (operadores embarcados nos veículos). Para tal, considera os atributos Velocidade do veículo ( $\left.\mathrm{V}_{\mathrm{EL}}\right)$, Cortesia da tripulação $\left(\mathrm{C}_{\mathrm{OR}}\right)$ e Obediência à solicitação de parada $\left(\mathrm{P}_{\mathrm{AR}}\right)$, multiplicados pelos pesos encontrados na Matriz da Qualidade.

Para que se demonstre a opinião dos usuários, todos estes atributos são calculados sobre o número de reclamações, conforme o método de cálculo do Índice de Reclamações dos Usuários - IRU, utilizado por BHTrans (2012), que considera o número de reclamações a cada 100000 passageiros transportados. Utiliza-se, também, a Tabela 4.19 para conversão dos valores dos atributos.

É necessário que canais de reclamações (telefone, internet e outros) sejam divulgados junto aos usuários. Caso não exista tal divulgação, o indicador deve receber valor 0 , por não ser possível medir as relações.

$$
T_{E}=0,75 V_{E L}+0,15 C_{O R}+0,1 P_{A R}
$$

Tabela 4.19: Reclamações a cada 100000 passageiros

\begin{tabular}{ccc}
\hline \multicolumn{1}{c}{ AST $_{\text {Sível de serviço }}$} & Valor do atributo \\
\hline Entre 0 e 1,5 & A & 1 \\
\hline Entre 1,6 e 3 & B & 0,8 \\
\hline Entre 3,1 e 6 & $\mathrm{C}$ & 0,6 \\
\hline Entre 6,1 e 21 & $\mathrm{D}$ & 0,4 \\
\hline
\end{tabular}




\begin{tabular}{ccc}
\hline Entre 21,1 e 36 & E & 0,2 \\
\hline$>36$ & - & 0 \\
\hline
\end{tabular}

Fonte: adaptado de BHTrans (2012)

\subsubsection{Velocidade do veículo $\left(V_{E L}\right)$}

Este atributo considera as reclamações dos usuários quanto a freadas bruscas, excesso de velocidade e outras relacionadas à condução do veículo, utilizando a Equação 4.22.

$$
V_{E L}=\left(\frac{R_{V}}{P_{T}}\right) x 100000
$$

Onde:

- $\mathrm{R}_{\mathrm{V}}=$ Número de reclamações sobre velocidade no período;

- $\mathrm{P}_{\mathrm{T}}=$ Número total de passageiros transportados no período avaliado.

\subsubsection{Cortesia da tripulação $\left(C_{O R}\right)$}

$\mathrm{O}$ atributo considera as reclamações dos usuários com respeito ao comportamento da tripulação, medindo, portanto, a relação entre operadores e usuários.

$$
C_{O R}=\left(\frac{R_{C}}{P_{T}}\right) \times 100000
$$

Onde:

- $\mathrm{R}_{\mathrm{C}}=$ Número de reclamações sobre comportamento da tripulação no período;

- $\quad \mathrm{P}_{\mathrm{T}}=$ Número total de passageiros transportados no período avaliado.

\subsubsection{Obediência à solicitação de parada $\left(P_{A R}\right)$}

Neste atributo são consideradas as reclamações quanto à não obediência à solicitação de parada do veículo pelo usuário para embarque ou desembarque.

$$
P_{A R}=\left(\frac{R_{P}}{P_{T}}\right) x 100000
$$

Onde:

- $\quad \mathrm{R}_{\mathrm{P}}=$ Número de reclamações sobre desobediência à solicitação de parada no período;

- $\mathrm{P}_{\mathrm{T}}=$ Número total de passageiros transportados no período avaliado. 


\subsubsection{Tarifa $\left(\boldsymbol{T}_{A}\right)$}

$\mathrm{O}$ indicador Tarifa $\left(\mathrm{T}_{\mathrm{A}}\right)$ considera os atributos Valor da tarifa $\left(\mathrm{T}_{\mathrm{AR}}\right)$ e Integração tarifária $\left(\mathrm{I}_{\mathrm{NT}}\right)$ para medir a relação econômica entre o usuário e o sistema de transporte coletivo por ônibus. Calcula-se o indicador a partir da média destes atributos, conforme a Equação 4.25.

$$
T_{A}=\frac{T_{A R}+I_{N T}}{2}
$$

\subsubsection{Valor da tarifa $\left(T_{A R}\right)$}

Este atributo mede a relação entre o valor da tarifa e a renda do usuário. Como a renda varia de um local para o outro e este índice está sendo elaborado para ser aplicado em qualquer cidade do país, será considerado o valor do salário mínimo vigente no período avaliado. $\mathrm{O}$ atributo procura conhecer o valor máximo que uma pessoa gastaria para se deslocar no trajeto casa-centro-casa por motivos estudantis ou a trabalho (desconsiderase o uso de vale-transporte) e, portanto, considera-se duas viagens, sem integração, por dia útil em linha troncal ou diametral, que geralmente possuem a maior tarifa do sistema (tarifa cheia), excetuando-se serviços especiais. Dessa forma, o atributo é calculado conforme a Equação 4.26.

$$
T_{A R}=\frac{\left(T_{C} x 2\right) x D_{v}}{S_{M}}
$$

Onde:

- $\mathrm{T}_{\mathrm{C}}=$ Valor da tarifa cheia;

- $\mathrm{D}_{\mathrm{U}}=$ Número de dias uteis do mês (ou período) avaliado;

- $\mathrm{S}_{\mathrm{M}}=$ Valor do salário mínimo vigente no período avaliado.

Conforme Lima (1996), o padrão médio aceitável no Brasil é de, no máximo, 6\% da renda comprometida com a tarifa do transporte público. Porém, neste trabalho, como é utiliza-se o salário mínimo e não a renda média do usuário (variável espacialmente) considera-se $10 \%$ (ou 0,1 ) como o pior valor aceitável na Tabela 4.20, utilizada para a conversão do resultado e definição do valor do atributo.

Tabela 4.20: Participação da tarifa do transporte público na renda

\begin{tabular}{cc}
\hline $\mathbf{T}_{\mathbf{A R}}$ & Valor do atributo \\
\hline Entre 0 e 0,02 & 1 \\
\hline Entre 0,021 e 0,04 & 0,8 \\
\hline Entre 0,041 e 0,06 & 0,6 \\
\hline
\end{tabular}




\begin{tabular}{cc}
\hline Entre 0,061 e 0,08 & 0,4 \\
\hline Entre 0,081 e 0,1 & 0,2 \\
\hline$>0,1$ & 0 \\
\hline
\end{tabular}

Fonte: elaborado pelo autor

\subsubsection{Integração tarifária $\left(I_{N T}\right)$}

O atributo de integração tarifária parte do princípio da existência desta no sistema, seja de ônibus para ônibus ou entre diferentes modos de transporte público, aplicando-se valor 0 ao atributo caso não haja integração. Caso não seja cobrada tarifa de transporte público por ônibus na cidade avaliada $\left(\mathrm{T}_{\mathrm{C}}=0\right)$, este atributo recebe valor 1 .

Para o cálculo do atributo utiliza-se o maior valor de desconto que o usuário terá ao usar a integração, relacionando-se este ao valor da tarifa cheia, que é a maior tarifa do sistema desconsiderando-se os serviços especiais. Obtém-se, então, a Equação 4.27.

$$
I_{N T}=\frac{V_{D}}{T_{C}}
$$

Onde:

- $\mathrm{V}_{\mathrm{D}}=$ Valor máximo de desconto para o usuário;

- $\mathrm{T}_{\mathrm{C}}=$ Valor da tarifa cheia.

\section{6 ÍNDICE DE AVALIAÇÃO DA QUALIDADE DO TRANSPORTE PÚBLICO POR ÔNIBUS A PARTIR DA DEFINIÇÃO DE SERVIÇO ADEQUADO - IQTP}

Após o cálculo de todos os oito indicadores, procede-se o cálculo do índice geral de avaliação da qualidade do sistema. Para tal, são considerados os pesos atribuídos aos indicadores na etapa 4.4 (Valoração dos indicadores), resultando na Equação 4.28, que é o índice proposto nesta pesquisa.

$$
I Q_{T P}=0,06 P_{N}+0,08 T_{E}+0,08 L_{O}+0,06 S_{G}+0,12 I_{F}+0,12 V_{E}+0,24 T_{R}+0,24 T_{A}
$$

A partir do índice proposto encontra-se o resultado da avaliação da qualidade do transporte público por ônibus, obedecendo a definição legal de serviço adequado no Brasil. O índice retornará um valor entre 0 e 1 que, multiplicado por 100, demonstra percentualmente o diagnóstico do sistema, facilitando a apresentação gráfica dos números e a comparação com os resultados de outras cidades ou regiões dentro da mesma cidade.

BHTrans (2012) utiliza uma tabela de referência sobre os resultados do seu Índice de Desempenho Operacional - IDO, classificando-o por níveis de qualidade, desde 
"Inadmissível" até "Excelência". Sugere-se a aplicação da mesma para análise do resultado do IQ $\mathrm{IP}_{\mathrm{TP}}$, conforme demonstra a Tabela 4.21.

Tabela 4.21: Níveis de qualidade do serviço de transporte público por ônibus

\begin{tabular}{ccc}
\hline IQ & Nível de serviço & Situação \\
\hline $0,9 \leq \mathrm{IQ}_{\mathrm{TP}} \leq 1$ & $\mathrm{~A}$ & Excelência \\
\hline $0,8 \leq \mathrm{IQ}_{\mathrm{TP}}<0,9$ & $\mathrm{~B}$ & Eficiência \\
\hline $0,6 \leq \mathrm{IQ}_{\mathrm{TP}}<0,8$ & $\mathrm{C}$ & Admissível \\
\hline $0,3 \leq \mathrm{IQ}_{\mathrm{TP}}<0,6$ & $\mathrm{D}$ & Admissível temporariamente \\
\hline $0 \leq \mathrm{IQ}_{\mathrm{TP}}<0,3$ & $\mathrm{E}$ & Inadmissível \\
\hline
\end{tabular}

Fonte: adaptado de BHTrans (2012)

\subsection{TÓPICOS CONCLUSIVOS}

- As pesquisas de campo apresentaram resultados expressivos. A primeira forneceu uma quantidade considerável de atributos a serem considerados no índice, e a segunda demonstrou a similaridade entre estes atributos, visto os pesos muito próximos.

- A aplicação do método QFD permitiu a atribuição de pesos em somente dois dos oito indicadores, por tão próximas serem as notas médias resultantes da pesquisa de relevância para o usuário. Diante deste cenário, é possível que a aplicação do método possa ser substituída pela atribuição de pesos através destas notas médias, parametrizando-as para que somem 1.

- O IQTP apoia o gestor do sistema e seus operadores na busca contínua pela qualidade do serviço, funcionando como uma ferramenta que permite visualizar os pontos críticos do serviço e indica os setores que respondem com maior intensidade a investimentos, traduzindo estes em benefícios imediatos à população.

- O IQTP é um índice genérico quanto à metodologia de aplicação e parâmetros adotados. A definição dos pesos deve ser realizada periodicamente (sugere-se de forma anual) em cada região onde o método será aplicado. Desta forma, o índice é capaz de medir a qualidade de acordo com o atendimento às necessidades daquela população, considerando mais importantes aqueles atributos que mais carecem atenção de acordo com os usuários. 
- Para a aplicação do $\mathrm{IQ}_{\mathrm{TP}}$ pode ser construída uma simples planilha eletrônica com macros para que o cálculo do índice seja automático a partir da inserção dos dados que se pede, facilitando o monitoramento contínuo do sistema. 


\section{ESTUDO DE CASO}

\subsection{APRESENTAÇÃO}

Neste capítulo realiza-se a aplicação do método em um estudo de caso, demonstrando seus procedimentos de cálculo na prática e a apresentação gráfica dos resultados. $\mathrm{O}$ estudo de caso é realizado com base nos dados da cidade de Belo Horizonte, capital do Estado das Minas Gerais, dados estes fornecidos pela Empresa de Transportes e Trânsito de Belo Horizonte S/A - BHTrans, empresa pública responsável pela gestão do transporte público na cidade. Os dados foram solicitados à Diretoria de Transporte Público - DTP, reunindo informações apuradas para o mês de novembro de 2013, último mês típico antes da implantação do sistema de Bus Rapid Transit - BRT na cidade. Dispensaram-se os dados após a implantação do sistema pelo motivo de este ainda sofrer ajustes e constantes alterações de linhas, itinerários e horários, o que compromete o cálculo do índice para um determinado período.

O capítulo inicia-se com um breve histórico do transporte público na cidade, passando após para a descrição dos dados e cálculos dos atributos e indicadores, até os procedimentos para cálculo do $\mathrm{IQ}_{\mathrm{TP}}$. Conclui-se com a apresentação dos resultados e uma análise sucinta dos mesmos.

\subsection{UM BREVE HISTÓRICO DO SISTEMA DE TRANSPORTE PÚBLICO DE BELO HORIZONTE}

Belo Horizonte é a capital do Estado das Minas Gerais desde sua fundação, em 12 de dezembro de 1897. Pertence à Mesorregião Metropolitana de Belo Horizonte, composta por 34 municípios, possui 330,95 $\mathrm{km}^{2}$ de área e uma população de aproximadamente 2,5 milhões de habitantes.

Na cidade, o transporte público foi municipalizado em 1991 com a criação da Empresa de Transporte e Trânsito de Belo Horizonte S/A - BHTrans, empresa pública responsável pela gestão do transporte público e do trânsito da cidade. A empresa realiza a concessão do serviço e, por contrato, realiza a função de agente de regulação e fiscalização do transporte público.

Em 1997 a BHTrans elaborou o Plano de Reestruturação do Sistema de Transporte Coletivo, chamado de BHBUS, redesenhando o sistema de transporte coletivo da cidade. A partir do BHBUS criaram-se estações de integração, fazendo com que muitas linhas que ligavam os bairros ao centro se tornassem linhas alimentadoras, ligando os bairros às estações, e de lá os passageiros eram transferidos para as linhas troncais. Para a baldeação criou-se o cartão de créditos eletrônicos BHBUS, onde é possível a realização de integrações tarifárias entre os tipos de linhas.

O sistema dividiu-se em nove tipos de linhas: 
- Alimentadoras (cor amarela): fazem a ligação dos bairros com as estações de integração ou estações de metrô;

- Troncais (cor verde): ligam as estações ao Centro, outras estações ou outros polos, podendo ser diretas ou paradoras;

- Semi-expressas (cor verde): ligam bairros distantes à região central, passando pelos principais corredores;

- Interbairros (cor laranja): fazem o percurso bairro a bairro sem passar pela região central;

- Circulares (cor amarela): atendem a área central;

- Diametrais (cor azul): ligam bairros de diferentes regiões passando pelo Centro;

- Radiais (cor azul): ligam as regiões sem estações de integração ou corredores ao Centro;

- Executivas (cor cinza): ligam bairros de classe média-alta a regiões específicas da cidade, com veículos e tarifas diferenciadas;

- Vilas e Favelas (cor amarela): linhas operadas por micro-ônibus que atendem as comunidades e aglomerados onde veículos de grande porte têm dificuldade de acesso, ligando estas aos principais corredores.

Em 2008, com a nova licitação do transporte coletivo, a BHTrans implantou novas regras para o sistema, com mudança no modo de pagamento das viagens e a organização das empresas operadoras em 4 consórcios. Também se definiram métodos tecnológicos de gestão do sistema, compartilhados entre a BHTrans e os consórcios operadores.

Em março de 2014 entra em operação o BRT de Belo Horizonte, chamado MOVE, aumentando o sistema tronco-alimentador e ligando as estações ao Centro a partir de corredores segregados e faixas exclusivas para ônibus, utilizando veículos equipados com ar condicionado e suspensão a ar. Com estações de transferência ao longo dos corredores, diminuem-se os tempos de embarque e desembarque e pagamento da tarifa (fora do veículo).

As características sociais da população, que podem ter peso no comportamento da demanda de transportes e na consideração dos atributos do índice, mostram-se espacialmente distribuídas entre as regiões apresentadas na Figura 3.1. Conforme destacou Gomide et al. (2006), quanto a renda mensal, um dos aspectos sociais mais sensíveis, encontram-se valores mais elevados nas regiões Centro-Sul e Pampulha, porém, dentro destas e das outras regiões existem comunidades e aglomerados que 
registram números mais baixos. Sendo assim, não se podem generalizar as diferenças sociais entre as regiões de Belo Horizonte.

\subsection{APLICAÇÃO DO MÉTODO}

A aplicação do método na cidade de Belo Horizonte segue a ordem de cálculos descritos no Capítulo 4, onde primeiro medem-se os atributos, depois os indicadores e, por fim, o $\mathrm{IQ}_{\mathrm{TP}}$.

\subsubsection{Pontualidade $\left(\boldsymbol{P}_{N}\right)$}

O indicador Pontualidade é calculado a partir da média dos atributos $\mathrm{A}_{\mathrm{TR}}$ e $\mathrm{I}_{\mathrm{TI}}$. A partir dos valores dos atributos, descritos em sequência, encontrou-se o valor 1 para o indicador $\mathrm{P}_{\mathrm{N}}$ após a aplicação da Equação 4.1, sendo:

- $\quad \mathrm{A}_{\mathrm{TR}}=1$

- $\mathrm{I}_{\mathrm{TI}}=1$

\subsubsection{Viagens atrasadas $\left(A_{T R}\right)$}

O atributo de viagens atrasadas é obtido através da relação entre o número de viagens não realizadas e realizadas com atraso e o número de viagens programadas. Em Belo Horizonte, apresentaram-se os seguintes valores para a relação:

- $\mathrm{V}_{\mathrm{A}}=11764$

- $\mathrm{V}_{\mathrm{N}}=10323$

- $\mathrm{V}_{\mathrm{T}}=688212$

Aplicando-se a Equação 4.2, encontra-se o valor de 0,97. Utilizando a Tabela 4.10 para conversão do atributo, encontra-se para $A_{T R}$ o valor de 1.

\subsubsection{Cumprimento dos itinerários $\left(I_{T I}\right)$}

Em Belo Horizonte, os veículos do sistema de transporte público são rastreados continuamente, facilitando a realização da medida de cumprimento dos itinerários. Porém, conforme os procedimentos de cálculo do $\mathrm{IQ}_{\mathrm{TP}}$, essa medida é realizada através da quilometragem programada e realizada para o sistema. Encontraram-se os seguintes valores:

- $\mathrm{Q}_{\mathrm{R}}=14530539$

- $\mathrm{Q}_{\mathrm{E}}=14530539$

Explica-se que $\mathrm{Q}_{\mathrm{E}}$ não foi informada pela empresa e, portanto, utilizou-se o mesmo valor para $Q_{R}$ para que o uso de dados surreais não invalide o atributo. Com os valores 
iguais e a aplicação da Equação 4.3, encontra-se o valor 1 para $\mathrm{I}_{\mathrm{TI}}$, de acordo com a conversão da Tabela 4.11.

\subsubsection{Tempo $\left(T_{E}\right)$}

$\mathrm{O}$ indicador Tempo $\left(\mathrm{T}_{\mathrm{E}}\right)$ considera os atributos Tempo de espera $\left(\mathrm{T}_{\mathrm{ES}}\right)$, Duração da viagem $\left(D_{\mathrm{VI}}\right)$ e Distância entre pontos ou estações $\left(\mathrm{D}_{\mathrm{IS}}\right)$, aplicando pesos 0,71, 0,16 e 0,13 a estes, respectivamente. Encontrou-se o valor 0,4 para $T_{E}$, sendo:

- $\mathrm{T}_{\mathrm{ES}}=0,4$

- $\quad \mathrm{D}_{\mathrm{VI}}=0,6$

- $\mathrm{D}_{\mathrm{IS}}=0,1$

\subsubsection{Tempo de espera $\left(T_{E S}\right)$}

O tempo de espera é determinado a partir do headway médio das linhas em dias úteis. Como o principal tipo de linha (em número de viagens e passageiros transportados) em Belo Horizonte é a diametral, utilizarou-se apenas o headway deste tipo para cálculo do atributo. A BHTrans informou o headway médio já calculado para tipo de linha, dispensando a aplicação da Equação 4.5. O valor informado é de 00:18 minutos (calculado para o dia 19 de novembro de 2013). Utilizando-se a Tabela 4.12 para conversão do atributo encontra-se o valor 0,4 para $\mathrm{T}_{\mathrm{ES}}$.

\subsubsection{Duração da viagem $\left(D_{V I}\right)$}

A BHTrans forneceu a informação de tempo médio de viagem das linhas diametrais da cidade no dia 19 de novembro de 2013, calculado em 01:08. Aplicando-se a Equação 4.6 encontra-se um total de 00:34 minutos para o atributo Ao realizar a conversão a partir da Tabela 4.13, aplica-se ao atributo o valor final de 0,6 .

\subsubsection{Distância entre pontos ou estações $\left(D_{I S}\right)$}

Conforme informado pela BHTrans, fora do hipercentro de Belo Horizonte, permite-se o caminhamento de até 600 metros entre um PED e outro em áreas com declividade de até $10 \%$, e até 300 metros onde a declividade é maior. Dessa forma, a distância média adotada é de 450 metros para implantação de PED. Aplicando este número à Tabela 4.14 , encontra-se o valor 0,1 para $\mathrm{D}_{\text {IS. }}$.

\subsubsection{Lotação $\left(\boldsymbol{L}_{\boldsymbol{O}}\right)$}

O indicador Lotação $\left(\mathrm{L}_{\mathrm{O}}\right)$ considera os atributos Veículos lotados $\left(\mathrm{V}_{\mathrm{LO}}\right)$, Quantidade de assentos por veículo $\left(\mathrm{Q}_{\mathrm{AS}}\right)$ e Quantidade de portas no veículo ( $\left.\mathrm{Q}_{\mathrm{PO}}\right)$, resultando, neste estudo de caso, no valor 0,67, após a aplicação da Equação 4.7, sendo:

- $\mathrm{V}_{\mathrm{LO}}=0,25$

- $\mathrm{Q}_{\mathrm{AS}}=0,75$ 
- $\mathrm{Q}_{\mathrm{PO}}=1$

\subsubsection{Veículos lotados $\left(V_{L O}\right)$}

A medição do atributo de veículos lotados necessita de levantamento em campo. A partir de dados coletados pelo sistema utilizado no monitoramento das viagens em Belo Horizonte, foram analisadas 587182 viagens, estando 85310 com lotação acima da permitida de acordo com o contrato regulado pela BHTrans. Dessa forma, têm-se:

- $\mathrm{V}_{\mathrm{O}}=587182$

- $\mathrm{V}_{\mathrm{L}}=85310$

A partir da Equação 4.8, encontrou-se o valor 0,85 para o atributo. A partir da Tabela 4.15 , converte-se o valor para 0,25 para $\mathrm{V}_{\mathrm{LO}}$.

\subsubsection{Quantidade de assentos por veículo $\left(Q_{A S}\right)$}

O atributo de quantidade de assentos por veículo mede a capacidade dos veículos considerando o nível máximo de conforto (todos os passageiros sentados). A BHTrans informou o número médio de assentos para os 3040 veículos do sistema, dispensando a aplicação da Equação 4.9. O valor informado é de 38 assentos. Utilizando-se a Tabela 4.16 para conversão encontra-se o valor 0,75 para $Q_{\text {AS. }}$.

\subsubsection{Quantidade de portas no veículo $\left(Q_{P O}\right)$}

Este atributo mede a facilidade de embarque e desembarque dos passageiros a partir do número de portas no veículo. Em Belo Horizonte, no mês de novembro de 2013, tem-se:

- $\quad \sum_{i=1}^{n} P_{V}=8984$

- $\mathrm{n}=3040$

Aplicando-se a Equação 4.10, encontrou-se o valor de 2,96 portas por veículo. Utilizando-se a Tabela 4.17, tem-se o valor 1 para $Q_{\text {PO. }}$

\subsubsection{Segurança $\left(S_{G}\right)$}

$\mathrm{O}$ indicador Segurança $\left(\mathrm{S}_{\mathrm{G}}\right)$ é obtido pela média dos atributos Assaltos $\left(\mathrm{A}_{\mathrm{ST}}\right)$ e Acidentes de trânsito com o veículo $\left(\mathrm{A}_{\mathrm{CI}}\right)$, obtendo, em Belo Horizonte, o valor 1, sendo:

- $\quad \mathrm{A}_{\mathrm{ST}}=1$

- $\mathrm{A}_{\mathrm{CI}}=1$

\subsubsection{Assaltos $\left(A_{S T}\right)$}

O atributo Assaltos é calculado a partir da ocorrência do evento dentro dos veículos de transporte coletivo a cada 10000 viagens realizadas. A BHTrans informou que não 
ocorreram assaltos a veículos do sistema durante o mês de novembro de 2013, aplicando a este atributo o valor 0 . A partir da Tabela 4.18, converte-se este valor para 1, definindo o valor final de $\mathrm{A}_{\mathrm{ST}}$.

\subsubsection{Acidentes de trânsito com o veículo $\left(A_{C I}\right)$}

$\mathrm{O}$ atributo de acidentes de trânsito com o veículo também considera a ocorrência do evento a cada 10000 viagens. De acordo com informações da BHTrans, temos:

- $\mathrm{A}_{\mathrm{C}}=28$

- $\mathrm{V}_{\mathrm{R}}=680425$

Aplicando-se a Equação 4.12 encontra-se o valor 0,41. De acordo com a Tabela 4.18, a conversão resulta no valor 1 para $\mathrm{A}_{\mathrm{CI}}$.

\subsubsection{Informação $\left(I_{F}\right)$}

O indicador Informação $\left(\mathrm{I}_{\mathrm{F}}\right)$ é calculado a partir da média dos atributos Informações nos pontos ou estações $\left(\mathrm{I}_{\mathrm{PO}}\right)$, Informações dentro dos veículos $\left(\mathrm{I}_{\mathrm{VE}}\right)$ e Informações prévias $\left(\mathrm{I}_{\mathrm{PR}}\right)$, resultando no valor 0,72 , neste estudo de caso, sendo:

- $\mathrm{I}_{\mathrm{PO}}=0,16$

- $\mathrm{I}_{\mathrm{VE}}=1$

- $\quad \mathrm{I}_{\mathrm{PR}}=1$

\subsubsection{Informações nos pontos ou estações $\left(I_{P O}\right)$}

Este atributo reflete a existência ou não de informações ao usuário nos pontos de embarque e desembarque de passageiros - PED e estações do transporte coletivo por ônibus. Classificaram-se as informações em 3 níveis: linhas que atendem o PED, itinerários das linhas e previsão de chegada.

Em Belo Horizonte existem 8760 PED, sendo 2281 destes seletivos, ou seja, possuem informação de linhas que param no PED (Nível 1). Destes 2281 PED, 1430 possuem mapas de itinerário resumido das linhas que param naquele local (Nível 2). Destes 1430 PED, 653 possuem painéis digitais que informam o tempo previsto de aproximação do veículo no local (Nível 3). Desta forma, temos:

- $\mathrm{N} 1=2281$

- $\quad \mathrm{N} 2=1430$

- $\mathrm{N} 3=653$

- $\mathrm{P}=8760$

Aplicando-se a Equação 4.15, tem-se o valor 0,16 para $\mathrm{I}_{\mathrm{PO}}$. 


\subsubsection{Informações dentro dos veículos $\left(I_{V E}\right)$}

$\mathrm{O}$ atributo Informações dentro dos veículos ( $\left.\mathrm{I}_{\mathrm{VE}}\right)$ considera a informação nos veículos em dois níveis: quadro de horários e itinerários. Em Belo Horizonte, todos os 3040 veículos do sistema são dotados de mapa de itinerário resumido afixado na lateral interna do veículo, sobre um dos focos de iluminação. Também possuem quadro de horários afixado em balaústre próximo à porta central do veículo. Desta forma, dispensa-se a aplicação da Equação 4.16, sendo que o atributo possui valor 1 .

\subsubsection{Informações prévias $\left(I_{P R}\right)$}

Neste atributo, consideram-se as informações disponíveis para os usuários na internet, seja em portal do órgão gerenciador ou outro, desde que divulgado nos veículos e/ou PED/estações. Em Belo Horizonte, é divulgado em todos os veículos, estações e PED com mapas de itinerário resumido o site da BHTrans (www.bhtrans.pbh.gov.br), onde são encontradas as informações de itinerários, quadros de horários e integração tarifária das linhas do sistema. Desta forma, o valor de $\mathrm{I}_{\mathrm{PR}}$ é 1 .

\subsubsection{Veículos $\left(V_{E}\right)$}

$\mathrm{O}$ indicador Veículos $\left(\mathrm{V}_{\mathrm{E}}\right)$ resulta da média dos atributos Viagens interrompidas por falha mecânica $\left(\mathrm{V}_{\mathrm{IN}}\right)$, Veículos acessíveis $\left(\mathrm{V}_{\mathrm{AC}}\right)$ e Veículos limpos $\left(\mathrm{V}_{\mathrm{LI}}\right)$, recebendo valor 0,8 neste estudo de caso, pois:

- $\mathrm{V}_{\mathrm{IN}}=0,6$

- $\mathrm{V}_{\mathrm{AC}}=0,81$

- $\mathrm{V}_{\mathrm{LI}}=0,98$

\subsubsection{Viagens interrompidas por falha mecânica $\left(V_{I N}\right)$}

$\mathrm{O}$ atributo Viagens interrompidas por falha mecânica mede as interrupções a partir dos quilômetros produtivos, calculando-se o atributo para grupos de $100000 \mathrm{~km}$. Para Belo Horizonte, em novembro de 2013, têm-se:

- $\mathrm{I}_{\mathrm{N}}=484$

- $\mathrm{K}_{\mathrm{P}}=14530569$

Aplica-se a Equação 4.18, resultando em 3,33. Convertendo-se o valor de acordo com a Tabela 4.18, tem-se $\mathrm{V}_{\mathrm{IN}}=0,6$.

\subsubsection{Veículos acessíveis $\left(V_{A C}\right)$}

$\mathrm{O}$ atributo mede a acessibilidade de cadeirantes e pessoas com mobilidade reduzida aos veículos do sistema avaliado. Para tal, em Belo Horizonte, temos a seguinte configuração de veículos:

- $\mathrm{V}_{\mathrm{C}}=2457$ 
- $\mathrm{V}_{\mathrm{I}}=3040$

Ao aplicar a Equação 4.19 encontra-se o valor 0,81 para $\mathrm{V}_{\mathrm{AC}}$.

\subsubsection{Veículos limpos $\left(V_{L I}\right)$}

Para medição deste atributo, é necessária pesquisa de campo por amostragem. Em Belo Horizonte, no mês de novembro de 2013, foram abordados para vistoria durante o horário de operação 610 veículos. Destes, 13 estavam sujos, de acordo com a equipe que realizou a atividade. Então têm-se:

- $\mathrm{V}_{\mathrm{S}}=13$

- $\mathrm{V}_{\mathrm{V}}=610$

Aplicando-se a Equação 4.20, encontramos $\mathrm{V}_{\mathrm{LI}}=0,98$.

\subsubsection{Tripulação $\left(T_{R}\right)$}

$\mathrm{O}$ indicador Tripulação $\left(\mathrm{T}_{\mathrm{R}}\right)$ considera os atributos Velocidade do veículo ( $\left.\mathrm{V}_{\mathrm{EL}}\right)$, Cortesia da tripulação $\left(\mathrm{C}_{\mathrm{OR}}\right)$ e Obediência à solicitação de parada $\left(\mathrm{P}_{\mathrm{AR}}\right)$, aplicando pesos 0,75, 0,15 e 0,1 a estes, respectivamente. De acordo com a Equação 4.21, $\mathrm{T}_{\mathrm{R}}=0,95$, neste estudo de caso, visto que:

- $\mathrm{V}_{\mathrm{EL}}=1$

- $\mathrm{C}_{\mathrm{OR}}=0,8$

- $\mathrm{P}_{\mathrm{AR}}=0,8$

\subsubsection{Velocidade do veículo $\left(V_{E L}\right)$}

A BHTrans recebeu, em novembro de 2013, 116 reclamações de usuários sobre a velocidade dos veículos, sendo transportados 36618394 passageiros no mesmo período. Portanto, têm-se:

- $\mathrm{R}_{\mathrm{V}}=116$

- $\mathrm{P}_{\mathrm{T}}=36618394$

Aplicando-se a Equação 4.22, encontra-se o valor 0,32 para o atributo. Ao converter na Tabela 4.19, $\mathrm{V}_{\mathrm{EL}}$ recebe valor 1.

\subsubsection{Cortesia da tripulação $\left(C_{O R}\right)$}

Registraram-se, em Belo Horizonte, 600 reclamações sobre o comportamento da tripulação em novembro de 2013. Desta forma, têm-se:

- $\mathrm{R}_{\mathrm{C}}=600$

- $\mathrm{P}_{\mathrm{T}}=36618394$ 
Aplicando-se a Equação 4.23, encontra-se o valor 1,64. A partir da Tabela 4.19, o atributo recebe valor 0,8 .

\subsubsection{Obediência à solicitação de parada $\left(P_{A R}\right)$}

Os usuários de Belo Horizonte registraram, na BHTrans, 11529 reclamações sobre desobediência à solicitação de parada durante todo o ano de 2013. Não se obteve o valor específico para o mês de novembro, então, calculou-se a média mensal de reclamações, visto que a atitude é independente de qualquer fator sazonal. Encontrou-se 961 reclamações por mês. Então têm-se:

- $\quad \mathrm{R}_{\mathrm{P}}=961$

- $\quad \mathrm{P}_{\mathrm{T}}=36618394$

Ao aplicar a Equação 4.24, encontra-se 2,62. Realizando a conversão pela Tabela 4.19, $\mathrm{P}_{\mathrm{AR}}$ recebe valor 0,8 .

\subsubsection{Tarifa $\left(\boldsymbol{T}_{A}\right)$}

$\mathrm{O}$ indicador Tarifa $\left(\mathrm{T}_{\mathrm{A}}\right)$ é resultado da média entre os atributos Valor da tarifa $\left(\mathrm{T}_{\mathrm{AR}}\right)$ e Integração tarifária $\left(\mathrm{I}_{\mathrm{NT}}\right)$. Neste estudo de caso encontrou-se $\mathrm{T}_{\mathrm{A}}=0,5$, pois:

- $\quad \mathrm{T}_{\mathrm{AR}}=0$

- $\quad \mathrm{I}_{\mathrm{NT}}=1$

\subsubsection{Valor da tarifa $\left(T_{A R}\right)$}

Em novembro de 2013, um mês com 20 dias úteis, o salário mínimo brasileiro era de $\mathrm{R} \$ 678,00$. Em Belo Horizonte, a tarifa cheia do sistema era de $\mathrm{R} \$ 2,65$. Desta forma, temos:

- $\mathrm{T}_{\mathrm{C}}=2,65$

- $\mathrm{D}_{\mathrm{U}}=20$

- $\mathrm{S}_{\mathrm{M}}=678$

Aplicando-se a Equação 4.26, encontra-se o valor 0,16, ou seja, 16\%. De acordo com a Tabela 4.20, o atributo recebe valor 0 .

\subsubsection{Integração tarifária $\left(I_{N T}\right)$}

Em Belo Horizonte existem várias combinações de integrações tarifárias. A integração com maior desconto ocorre aos domingos, onde o usuário que utilizar o cartão BHBUS em duas linhas dentro do intervalo de 90 minutos paga, no máximo, o valor da tarifa cheia. Desta forma, se o usuário utilizar duas linhas de tarifa $\mathrm{R} \$ 2,65$, o desconto será de $\mathrm{R} \$ 2,65$. Então: 
- $\mathrm{V}_{\mathrm{D}}=2,65$

- $\mathrm{T}_{\mathrm{C}}=2,65$

Aplicando-se a Equação 4.27, temos $\mathrm{I}_{\mathrm{NT}}=1$.

\subsection{ANÁLISE DOS RESULTADOS}

Após o cálculo dos indicadores, pode-se proceder para o cálculo do $\mathrm{IQ}_{\mathrm{TP}}$ para o sistema de transporte coletivo por ônibus de Belo Horizonte. Os resultados dos indicadores são apresentados na Tabela 5.1.

Tabela 5.1: Indicadores do sistema de transporte coletivo por ônibus de Belo Horizonte

\begin{tabular}{cc}
\hline Indicador & Valor \\
\hline $\mathrm{P}_{\mathrm{N}}$ & 1 \\
\hline $\mathrm{T}_{\mathrm{E}}$ & 0,4 \\
\hline $\mathrm{L}_{\mathrm{O}}$ & 0,67 \\
\hline $\mathrm{S}_{\mathrm{G}}$ & 1 \\
\hline $\mathrm{I}_{\mathrm{F}}$ & 0,72 \\
\hline $\mathrm{V}_{\mathrm{E}}$ & 0,8 \\
\hline $\mathrm{T}_{\mathrm{R}}$ & 0,95 \\
\hline $\mathrm{T}_{\mathrm{A}}$ & 0,5 \\
\hline Fonte: elaborado pelo autor
\end{tabular}

Fonte: elaborado pelo autor

A partir dos valores encontrados para os indicadores, pode-se calcular o IQTP a partir da Equação 4.28. Encontrou-se, para este estudo de caso, o valor de 0,74. Ou seja, no mês de novembro de 2013, o sistema de transporte público por ônibus de Belo Horizonte atendia em $74 \%$ as especificações de serviço adequado adotadas na Lei de Concessão dos Serviços Públicos.

Utilizando-se a Tabela 4.21 para análise do resultado, encontramos que o sistema de transporte público por ônibus de Belo Horizonte, em novembro de 2013, encontrava-se em situação "Admissível”, com nível de serviço "C". A apresentação do IQ ${ }_{\text {TP }}$ de acordo com a tabela pode ser conferida no Gráfico 5.1, convertendo-se os resultados para percentagens (multiplicando-os por 100). 


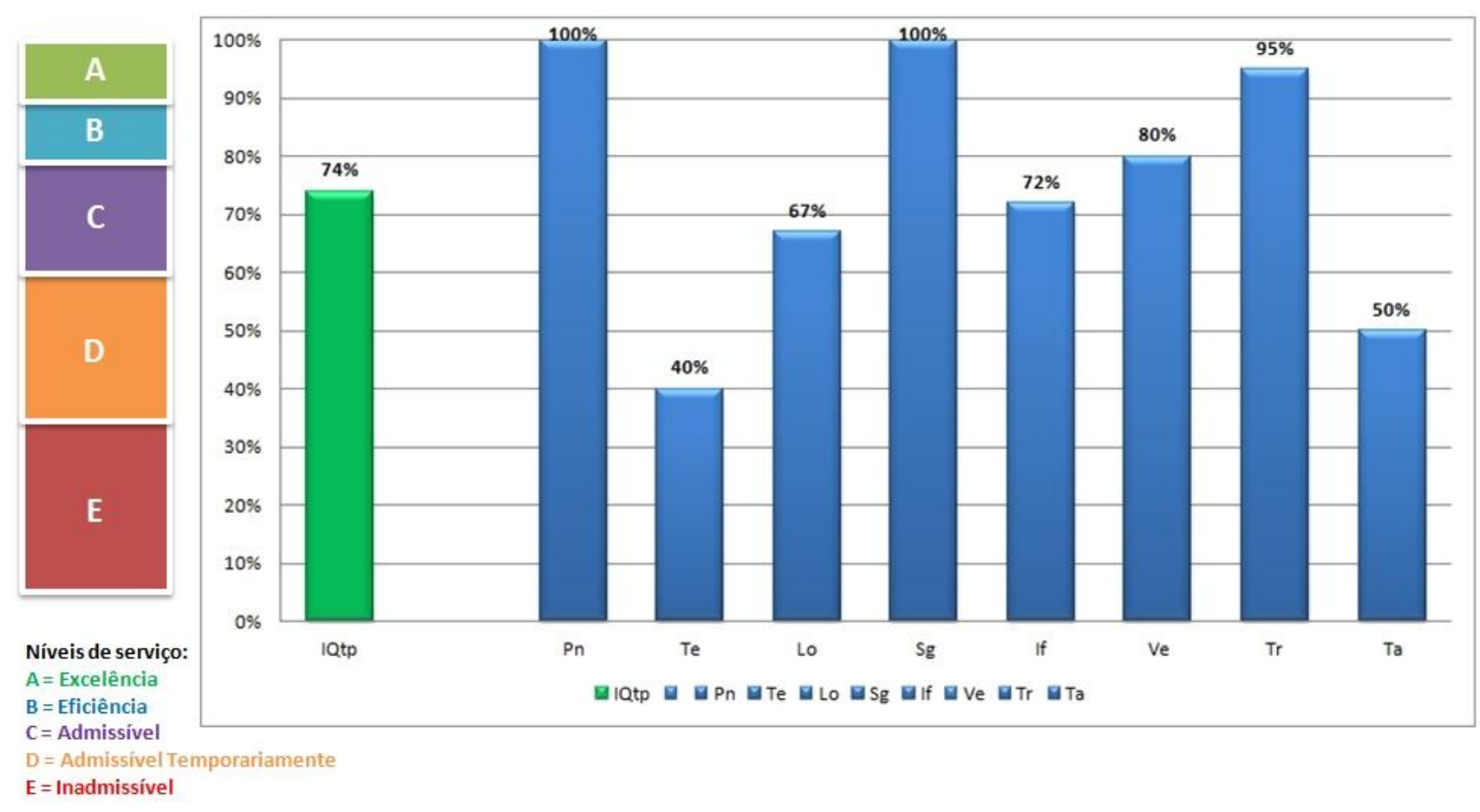

Gráfico 5.1: IQTP de Belo Horizonte/MG

Fonte: elaborado pelo autor

Conforme o índice, os indicadores que necessitam de ações mais enérgicas são Tempo $\left(\mathrm{T}_{\mathrm{E}}\right)$ e Tarifa $\left(\mathrm{T}_{\mathrm{A}}\right)$, que se encontra em “D”- Admissível Temporariamente.

Em $\mathrm{T}_{\mathrm{E}}$, as menores notas foram encontradas nos atributos acerca do tempo de espera ( $\left.\mathrm{T}_{\mathrm{ES}}\right)$ e distância de caminhada até o PED ( $\left.\mathrm{D}_{\mathrm{IS}}\right)$. Sugestão para solução é a diminuição o headway das linhas, especialmente em horários de pico, ação que poderá impactar positivamente, inclusive, o indicador Lotação $\left(\mathrm{L}_{\mathrm{O}}\right)$. Ressalta-se que já houve uma redução do headway a partir da implantação do BRT, onde algumas linhas troncais têm headways inferiores a 3 minutos, sendo necessário ajustar os headways das linhas alimentadoras a estas troncais. Sobre a distância, é necessário rever a política de implantação dos PED, diminuindo os espaços entre estes.

Em $\mathrm{T}_{\mathrm{A}}$ é crítico o valor da tarifa. Em 2013, após manifestações populares, houve redução da tarifa a partir da isenção de impostos, indo de $\mathrm{R} \$ 2,80$ para $\mathrm{R} \$ 2,65$. Seguindo tal procedimento, é possível reduzir ainda mais a tarifa a partir de isenção de outros impostos (a níveis estadual e federal), subsídio das gratuidades (que representam 12\% do valor da tarifa) e políticas federais de redução do valor do combustível (diesel).

\subsection{TÓPICOS CONCLUSIVOS}

- O índice mostrou-se de fácil aplicação durante o teste, mesmo que algumas equações tenham sido suprimidas devido ao formato dos dados recebidos. 
- A cidade de Belo Horizonte apresentou um índice "Admissível” da qualidade do transporte público, sendo necessário pouco esforço em atributos específicos para que este índice chegue a "Eficiência" (> 80\%). Tais ações podem ser direcionadas a partir da investigação dos dados que retornaram baixas notas nos cálculos dos indicadores. 


\section{CONCLUSÃO}

O transporte público urbano é muito mais importante para as cidades do que muitos inclusive usuários, acreditam, tendo um papel essencial na formação, organização e crescimento das cidades, além de contribuir para o desenvolvimento humano, permitindo que as pessoas acessem oportunidades. Contrariando tais aspectos positivos inerentes ao serviço, temos observado a migração em massa dos usuários para o transporte motorizado individual, não só aumentando os congestionamentos, mas condenando as cidades a todas as externalidades provindas do excesso de veículos nas ruas.

A resposta para conter o avanço do transporte individual é o investimento em um transporte público de qualidade, que seja capaz de atrair o passageiro. Um serviço tão essencial precisa ser monitorado permanentemente e ser alvo de ações contínuas de melhoria. Porém, as cidades têm suas particularidades, e o serviço de transporte público acompanha o desenvolvimento destas. A partir deste cenário, cada cidade deverá construir um método de monitoramento do serviço de acordo com suas possibilidades.

Este cenário influenciou a concepção desta pesquisa. O índice $\mathrm{IQ}_{\mathrm{TP}}$ desenvolvido aqui se diferencia de outros inúmeros índices já elaborados exatamente por ter como prioridade ser um método genérico (quanto à sua construção) a todas as cidades do país que operam o serviço de transporte público a partir da Lei de Concessão dos Serviços Públicos. As equações, parâmetros e dados necessários ao índice foram elaborados para que cidades de qualquer porte possam utilizá-lo. Esta generalidade ainda produz o benefício da comparação entre cidades, podendo o índice ser aplicado em regiões diferentes de uma mesma cidade.

A elaboração desta ferramenta considerou as técnicas e informações colhidas por diversos pesquisadores do tema, reunindo o conhecimento adquirido e adaptando as metodologias para o alcance dos objetivos deste índice, definidos na introdução da pesquisa, tornando o $\mathrm{IQ}_{\mathrm{TP}}$ uma método atual, abrangente e útil para aplicação nos universos acadêmico e técnico, mostrando-se ainda flexível para adaptação às realidades das cidades que queiram utilizá-lo para avaliação do sistema de transporte público por ônibus, como também contribui metodologicamente para a elaboração de índices para avaliação de outros modos de transporte público.

\subsection{LIMITAÇÕES E RECOMENDAÇÕES}

Durante a realização da pesquisa encontraram-se algumas limitações que poderiam dificultar a elaboração de um índice genérico. Para suprir tais dificuldades, fazem-se recomendações para o caso de aplicação do método.

Inicialmente, na realização da pesquisa de relevância para o usuário, foram entrevistados passageiros das linhas com maior demanda por região administrativa. Após as entrevistas ocorreu a discussão se esta decisão poderia influenciar os usuários 
quanto ao indicador Lotação. Portanto, sugere-se que esta pesquisa seja realizada de forma aleatória entre as linhas do sistema.

Outra limitação referente à pesquisa de relevância para o usuário é a inexistência de cadeirantes entre os entrevistados, considerando que estes não foram excluídos da amostra, apenas não estiveram presentes usuários nestas condições nos dias de pesquisa. A opinião de usuários que necessitam de atenção especial para o seu deslocamento é interessante para a qualidade do sistema, portanto sugere-se que seja considerada nas amostras das pesquisas a se realizar a proporção de cadeirantes dentro da população da região avaliada. Pode-se considerar também a realização de uma análise demográfica dos respondentes, a fim de se conhecer os grupos que contribuíram para o índice.

$\mathrm{Na}$ definição das intensidades das correlações da matriz do método QFD, nesta pesquisa, foram consideradas a prática da pesquisa e os comentários dos autores consultados, além da avaliação posterior de um especialista. Para a aplicação prática do método, sugere-se que um grupo técnico seja formado com especialistas que conheçam a rotina do sistema em avaliação, a fim de que as forças de correlação sejam definidas a partir de dados discutidos e consensuados.

Este também é um momento muito importante para a prática da inclusão popular no processo de planejamento e avaliação do transporte público. Trazendo a população, ou no mínimo um representante instituído destes, é possível encontrar correlações imperceptíveis aos gestores e operadores do sistema, tornando o índice ainda mais próximo da qualidade exigida pelos usuários. A participação popular também auxilia os gestores na interpretação das características de qualidade exigida, podendo o momento servir como um diagnóstico do sistema a partir dos participantes deste.

A pesquisa bibliográfica demonstrou que muitos autores consideram atributos diferentes na elaboração de métodos de avaliação da qualidade do transporte coletivo. Tal heterogeneidade revela que os atributos considerados pelos usuários podem variar de região para região ou entre períodos. Justifica-se também que, se um atributo do serviço é melhorado ao nível de excelência, outros atributos passarão a ser mais exigidos, exatamente por estarem mais deficientes naquele momento. Este comportamento é positivo na medida em que demonstra o caráter dinâmico da qualidade exigida, reforçando a necessidade de melhoria contínua do serviço ofertado.

Devido a tal, sugere-se que as pesquisas de campo junto ao usuário sejam realizadas com certa frequência, principalmente quando houver alterações no sistema de transporte público, fazendo com que o índice se adapte à evolução da cidade. Novos estudos precisam ser desenvolvidos na busca pelo conhecimento desta variação de opinião do usuário espacialmente e ao longo do tempo. Saber os principais motivos que ocasionam este fenômeno contribuirá para diversas áreas do planejamento de transporte público.

$\mathrm{O} \mathrm{IQ}_{\mathrm{TP}}$ não pretende ser um índice definitivo, sendo elaborado com vistas à continuação da discussão sobre a importância da qualidade do transporte público, a 
utilização de novos métodos e a busca por um método único que meça a qualidade e reporte situações críticas do transporte público. Dessa forma, contribuir para o estado da arte e colaborar para que cada vez estejamos mais próximos de um serviço humano e eficiente. 


\section{REFERÊNCIAS}

AKAO, Y. (1996). Introdução ao Desdobramento da Qualidade. Minas Gerais: Fundação Christiano Ottoni, Escola de Engenharia da UFMG. 1996. 187 p.;

ANTP (1997). Associação Nacional de Transportes Públicos. Transporte humano - cidades com qualidade de vida. Coordenadores: Ailton Brasiliense Pires, Eduardo Alcântara Vasconcellos, Ayrton Camargo e Silva. Apresentação: Rogério Belda. São Paulo, ANTP, 1997. 312 p. Il.;

(2002). Associação Nacional de Transportes Públicos. Desenvolvimento Urbano, Transporte e Trânsito no Brasil. Propostas para debate. São Paulo: ANTP, julho de 2002;

(2012). Associação Nacional de Transportes Públicos. Sistema de Informações da Mobilidade Urbana - Relatório Comparativo 2003-2011. ANTP, dezembro/2012;

ANTUNES, E. M. (2009). Avaliação da qualidade do transporte público por ônibus sob o ponto de vista do usuário em cidades médias paranaenses. Maringá : UEM, 2009. 115 f.: Il. ; 30 cm. Dissertação (Mestrado em Engenharia Urbana) - Universidade Estadual de Maringá, Programa de Pós-Graduação em Engenharia Urbana, 2009;

ARPINI, B. P.; RIBEIRO, M. F. (2012). Avaliação da qualidade no serviço de transporte coletivo urbano de passageiros na Grande Vitória e priorização de ações para melhoria por meio do método Quality Function Deployment - QFD. Trabalho de Conclusão de Curso. Departamento de Engenharia de Produção, Centro Tecnológico, Universidade Federal do Espírito Santo;

BASTIDAS, G.; NERY, R.; CARVALHO, M. M. (2001). Uso do QFD no setor de serviços: Avaliação de uma transportadora rodoviária de carga. In: ENCONTRO NACIONAL DE ENGENHARIA DE PRODUÇÃO, 21, 2001, Salvador. Anais... Salvador: Associação Brasileira de Engenharia de Produção, 2001;

BERNARDES, L. L. (2006). Avaliação da qualidade do serviço de transporte rodoviário interestadual de passageiros através do desenvolvimento de um sistema de indicadores. Dissertação (Mestrado em Transportes) - Departamento de Engenharia Civil e Ambiental, Faculdade de Tecnologia, Universidade de Brasília, Brasília, DF. 138 p.;

BERTOZZI, P. P.; LIMA JÚNIOR, O. F. (1998) A qualidade no serviço de transporte público sob as óticas do usuário, do operador e do órgão gestor. Revista dos Transportes Públicos - ANTP - Ano 21 - 1998 - 4º trimestre;

BHTRANS (2012). Empresa de Transportes e Trânsito de Belo Horizonte S/A. Cartilha de apresentação do IDO - Índice de Desempenho Operacional: metodologia de cálculo, composição dos índices, geração de relatórios. Desenvolvimento: Francisco Augusto de Oliveira, João Ernani Antunes Costa e Mateus Wille Batista de Oliveira. Publicação em 19 de dezembro de 2012;

(2013). Empresa de Transportes e Trânsito de Belo Horizonte S/A. Relatório gerencial: Sistema de Transporte Coletivo Convencional de Passageiros por Ônibus - Resultados Operacionais Novembro 2013. Diretoria de Transporte Público. Superintendência de Regulação do Transporte. Gerência de Contratos de Concessão e Tarifas. Elaboração: Gisele Nunes G. Carvalho. Relatório;

BLANCHET, L. A. (2000). Concessão e permissão de serviços públicos: comentários a lei $n^{\circ}$ 8987, de 13 de fevereiro de 1995, e a lei $n^{\circ}$ 9074, de 7 de julho de 1995. Curitiba - PR - Editora Juruá; 
BRAGA, G. A. (1995). Qualidade no transporte coletivo urbano - ônibus. Dissertação de mestrado apresentada ao Programa de Pós-Graduação em Transportes da Universidade de Brasília;

BRASIL (1988). Constituição da República Federativa do Brasil. Brasília/DF;

(1995, a). Lei Federal no 8.987/95, de 13 de fevereiro de 1995. Brasília/DF;

(1995, b). Lei Federal no 9.074 de 07 de julho de 1995. Brasília/DF;

(1998). Decreto $n^{o} 2.521$, de 20 de março de 1998. Brasília/DF;

(2014). Decreto $n^{o} 8.243$, de 23 de maio de 2014. Brasília/DF;

BRINCO, R. (2006) Transporte Urbano e Dependência do Automóvel. Porto Alegre: FEE, 2006. Documentos FEE n. 65;

BUBICZ, M. E.; SELLITTO, M. A. (2009). Qualidade em serviço de transporte de passageiros: um estudo de caso no sistema urbano de Porto Alegre. Revista Produção Online. ISSN 1676-1901 / Vol. IX / Num. IV / 2009. Associação Brasileira de Engenharia de Produção - ABEPRO, Universidade Federal de Santa Catarina - UFSC;

CAMPOS, V. F. (1992). TQC: Controle da Qualidade Total (no estilo japonês). Belo Horizonte, MG: Fundação Christiano Otoni, Escola de Engenharia da UFMG, 1992 (Rio de Janeiro,: Bloch Ed.);

CARDOSO, O. R. C. (1995). Foco da Qualidade Total de serviços no conceito do produto ampliado. Tese de Doutorado - Universidade Federal de Santa Catarina - Florianópolis - SC;

CARDOSO, B. C. (2006). Qualidade de serviço no setor de transportes sob a ótica da Teoria dos Topoï. [Rio de Janeiro] 2006. XIV, 238 p. 29,7 cm (COPPE/UFRJ, M.Sc., Engenharia de Transportes, 2006). Dissertação - Universidade Federal do Rio de Janeiro, COPPE;

CARDOSO, C. E. P. (2008). Análise do transporte coletivo urbano sob a ótica dos riscos e carências sociais. Tese de Doutorado, Programa de Pós-graduação em Serviço Social, Pontifícia Universidade Católica de São Paulo, São Paulo, SP;

CHENG, L. C.; MELO FILHO, L. D. R. (2010). QFD: Desdobramento da Função Qualidade na Gestão de Desenvolvimento de Produtos. Belo Horizonte: Blucher, 2010. 568p.;

; SCAPIN, C. A.; OLIVEIRA, C. A.; KRAFETUSKI, E.; DRUMOND, F. B.; BOAN, F. S. (1995). QFD: planejamento da qualidade. Belo Horizonte: Universidade Federal de Minas Gerais, Escola de Engenharia, Fundação Cristiano Ottoni, 1995;

CNI (2012). Confederação Nacional da Indústria. Cidades: mobilidade, habitação e escala: um chamado à ação. / Confederação Nacional da Indústria. - Brasília;

CNT (2002). Confederação Nacional do Transporte. Pesquisa da Seção de Passageiros CNT - 2002 Relatório Analítico: Avaliação da Operação dos Corredores de Transporte Urbano por Ônibus no Brasil. CNT, 2002;

CORDEIRO, C. O.; DA SILVA, H. M. B. C.; CARVALHO, R. L.; DACOL, S.; MACHADO, W. V. (2006). A qualidade do sistema de transporte coletivo por ônibus em Manaus. ABEPRO - XXVI ENEGEP - Fortaleza, CE, Brasil, 9 a 11 de Outubro de 2006;

CORREIA, D. E. R. (2004). Metodologia para avaliação da qualidade da informação para o planejamento de transportes. Dissertação apresentada ao programa de Pós-Graduação em Transportes da Universidade de Brasília; 
COSTA, N. A. A. (1994). Análise das diferentes abordagens do gerenciamento da qualidade: Estudo de caso em três empresas catarinenses. Florianópolis. Dissertação de mestrado. EPS/UFSC;

COUTO, D. M. (2011). Regulação e Controle Operacional no Transporte Coletivo Urbano: Estudo de Caso no Município de Belo Horizonte/MG. Dissertação (Mestrado em Engenharia) - Universidade Federal de Minas Gerais, Belo Horizonte, 2011;

CRAINIC, T. G.; GENDREAU, M.; POTVIN, J. Y. (2009). Intelligent freight-transportation systems: Assessment and the contribution of operations research. Transportation Research Part C: Emerging Technologies, 17(6), 541-557;

DA ROSA, E. K.; DOS SANTOS, F. P.; PEREIRA, I. P. L.; DA SILVA CORREA, M.; NUNES, M. C.; DA SILVA MAIA, F. L. (2013). Avaliação da qualidade no transporte de usuários da trensurb em horários de maior fluxo através do QFD: Desdobramento da Função Qualidade. Cippus, 2(2), 50-64. Editora UnilaSalle, ISSN: 2238-9032;

DA SILVA, A. P.; DE MORAIS, T. M. O. Q.; SILVA, A. P. Q.; SANTOS, E. (2004). Exclusão social, transporte e políticas públicas. In. CNT e Anpet (Orgs.) Transporte em Transformação IX. Brasília: LGE;

DEKEYSER, S.; WATSON, R. (2006). Extending Google Docs to collaborate on research papers. Toowoomba, Queensland, AU: The University of Southern Queensland, Australia, 23, p. 2008;

DEPARTMENT FOR TRANSPORT, UK (2003). Making Connections: Final Report on Transport and Social Exclusion. Social Exclusion Unit. Office of the Deputy Prime Minister, February 2003;

FERRAZ, A. C. P. (1990). Eficiência e eficácia no transporte público urbano em cidades brasileiras de porte médio. Tese de Livre Docência. São Carlos: Universidade de São Paulo-USP/Escola de Engenharia de São Carlos, 1990;

; TORRES, I. G. E. (2004). Transporte Público Urbano. $2^{a}$ Edição. São Carlos: RiMa, 2004, 410 p.;

GOMIDE, A. Á. (2003). Transporte urbano e inclusão social: elementos para políticas públicas. Texto para Discussão N ${ }^{\circ}$ 960. IPEA - Instituto de Pesquisa Econômica Aplicada. ISSN 1415-4765. Brasília, julho de 2003;

; LEITE, S. K.; REBELO, J. (2006). Transporte público e pobreza urbana: um índice-síntese de serviço adequado. Texto para Discussão No 1209. IPEA - Instituto de Pesquisa Econômica Aplicada. Brasília, agosto de 2006;

(2011). A Política das Reformas Institucionais no Brasil: A reestruturação do Setor de Transportes. Tese (doutorado) - Escola de Administração de Empresas de São Paulo. Fundação Getúlio Vargas. São Paulo;

GRÖNROOS, C. (1995). Marketing: gerenciamento e serviços: uma competição por serviços na hora da verdade. Rio de Janeiro: Campus;

HOFFMANN, J. M. L. (1991). Avaliação: mito e desafio - uma perspectiva construtivista. Educação e Realidade, Porto Alegre, 1991;

HOLZ, R. F.; BOFFO, G. H.; MUNIZ, R. P. D.; ANDRADE, L. R. B.; ECHEVESTE, M. E. (2010). Uso do QFD para avaliação da satisfação dos usuários de rodovias concedidas no RS. In: CONGRESSO 
DE PESQUISA E ENSINO EM TRANSPORTES, 24, 2010, Salvador. Anais... Salvador: ANPET, 2010

HORIZONTE, B. (2014). Prefeitura Municipal de Belo Horizonte. Regiões Administrativas de Belo Horizonte. Disponível em: $<$ http://portalpbh.pbh.gov.br/pbh/ecp/contents.do?evento $=$ conteudo\&idConteudo $=17708 \& \mathrm{chPlc}=1770$ $8 \& \&$ IdPlc $=\&$ app=salanoticias. $>$. Acessado em 11 dez. 2014;

IBGE (2008). Instituto Brasileiro de Geografia e Estatística. Regiões de influência das cidades 2007. Rio de Janeiro;

ISHIKAWA, K. (1993). Controle de qualidade total à maneira japonesa. Rio de Janeiro; Campus; 1993. 221 p. ilus.;

ITRANS (2004). Mobilidade e Pobreza: Relatório Final. Instituto de Desenvolvimento e Informação em Transporte. (Itrans) Brasília: 42p.;

JAMMAL, M. F. (2010). Análise dos requisitos de qualidade do transporte coletivo urbano de São José do Rio Preto - SP usando o método QFD. Dissertação (Mestrado em Engenharia Urbana) - Programa de Pós-Graduação em Engenharia Urbana, Universidade Federal de São Carlos, São Carlos, 2010;

KORZENOWSKI, A. L.; FACCIO, K.; DEXHEIMER, L.; ECHEVESTE, M. L.; FERRONATTO, L. G. (2008). QFD no serviço de transporte coletivo urbano por ônibus utilizando análise de componentes principais para priorização dos requisitos dos usuários. In: CONGRESSO DE PESQUISA E ENSINO EM TRANSPORTES, 22, 2008, Fortaleza. Anais... Fortaleza: ANPET, 2008;

LIKERT, R. (1932). A technique for the measurement of attitudes. Archives of psychology;

LIMA, I. M. O. (1996). O velho e o novo na gestão da qualidade do transporte urbano. EDIPRO - 1996 $-1^{\mathrm{a}}$ edição -232 p.;

LIMA JÚNIOR, O. F. (1995). Qualidade em serviços de transportes: conceituação e procedimento para diagnóstico. São Paulo, Tese (Doutorado) - Escola Politécnica, Universidade de São Paulo;

; GUALDA, N. D. F. (1995). Qualidade em serviços de transportes: conceituação e procedimentos para diagnóstico. In: Congresso da Associação Nacional de Pesquisa e Ensino em Transportes. São Carlos, 1995. Anais, v. 2, p. 668-679. São Paulo: ANPET, IX, 1995;

MANHEIN, M. L. (1979a). Principles of transport system analysis. Highway Research Record, n. 180;

(1979b). The demmand for transportation. In: Fundamentals of transportation system analysis. Massachussets: The MIT Press, pp. 58-90;

MORAIS, J. S. (2012). Proposta de método para avaliação da qualidade do transporte público urbano por ônibus utilizando a Teoria das Representações Sociais. T.DM - 013²012, Departamento de Engenharia Civil e Ambiental, Universidade de Brasília, Brasília, DF. 108 p.;

MORAIS, M. P.; LIMA, R. (2001). Breves considerações sobre a natureza da pobreza brasileira. Nota Técnica. Dirur/Ipea. Brasília: Ipea, janeiro de 2001;

OLIVEIRA, O. J. (2003). Gestão da Qualidade-Tópicos Avançados. Cengage Learning Editores;

OLIVEIRA, R. R. de. (2006). Aplicação da metodologia QFD no transporte rodoviário interestadual de passageiros em Vitória/ES. Dissertação (Mestrado em Transportes) - Programa de Pós-Graduação em Engenharia Civil, Universidade Federal do Espírito Santo, Vitória, 2006; 
PARASURAMAN, A.; ZEITHAML, V. A.; BERRY, L. L. (1988). Servqual: a multiple-item scale for measuring consumer perceptions of service quality. Journal of Retailing 64 (1) : 12-40;

PÊGO, F. F. (2006). Aplicação da metodologia QFD no transporte coletivo urbano de passageiros. Dissertação (Mestrado em Transportes) - Programa de Pós-Graduação em Engenharia Civil, Universidade Federal do Espírito Santo, Vitória, 2006;

RAMOS, M. W. (2013) Qualidades medida e percebida no sistema de transporte coletivo por ônibus: estudo de caso de Belo Horizonte. Dissertação (mestrado) - Universidade Federal de Minas Gerais, Escola de Engenharia;

RICHARDSON, R. J.; PERES, J. A. S.; WAMDERLEY, J. C. V.; CORREIA, L. M.; PERES, M. H. M. (2012). Pesquisa social: métodos e técnicas. 3. Ed. - 14. Reimpr. - São Paulo : Atlas, 2012;

RODRIGUES, M. O. (2006). Avaliação da qualidade do transporte coletivo da cidade de São Carlos. Dissertação de Mestrado. Escola de Engenharia de São Carlos, Universidade de São Paulo;

ROSA, S. J. (2006). Transporte e exclusão social: a mobilidade da população de baixa renda da Região Metropolitana de São Paulo e trem metropolitano - Dissertação - Escola Politécnica de São Paulo USP;

SEDU/PR; NTU (2002). Secretaria Especial de Desenvolvimento Urbano da Presidência da República. Associação Nacional das Empresas de Transportes Urbanos. Prioridade para o Transporte Coletivo Urbano - Relatório Técnico. Relatório elaborado por Maurício Cadaval e Carlos Henrique R. Carvalho com base em estudos técnicos sobre prioridade para o transporte coletivo, realizados pela PROTRAN Engenharia, e na pesquisa sobre corredores de transporte realizada pela Confederação Nacional do Transporte - CNT. Agosto, 2002;

SILVA, D. M.; DANILEVICZ, A. M. F.; LINDAU, L. A. (2000). Perfil da tecnologia embarcada para onibus urbano por meio da aplicação do QFD. In: Transporte em Transformação V, CNT, Ed. Makron Books, 2000;

SILVEIRA, A. D. (2002). Análise da preferência do cliente na implantação de melhorias em distribuição rodoferroviária de arroz com origem no Rio Grande do Sul. Dissertação (Mestrado em Logística) Mestrado Profissionalizante em Engenharia, Escola de Engenharia, Universidade Federal do Rio Grande do Sul, Porto Alegre, 2002;

SPERANDIO, C. C. S. (2005). Aplicação da metodologia QFD para priorização dos itens de fiscalização do transporte ferroviário de cargas sob a percepção do cliente. Dissertação (Mestrado em Transportes) - Programa de Pós-Graduação em Engenharia Civil, Universidade Federal do Espírito Santo, Vitória, 2005;

SOUTO, M. J. V. (2002). Direito administrativo regulatório. Rio de Janeiro - RJ - Editora Lúmen Júris;

VALENTE, A. M. (2008). Qualidade e produtividade nos transportes. São Paulo: Cengage Learning, 2008;

VASCONCELLOS, E. A. (2001). Transporte urbano, espaço e eqüidade: análise das políticas públicas. Annablume;

VASCONCELOS, A. S. (2004). O equilíbrio econômico-financeiro nas concessões de rodovias federais no Brasil. Monografia. Instituto Serzedello Corrêa - Tribunal de Contas da União. Brasília-DF; 
WEBER, F. D.; MANCUSO, A. C.; SENNA, L. A.; \& ECHEVESTE, M. E. (2013). Quality Function Deployment in Airport Terminals: The Airport of Porto Alegre Case. Journal of Traffic and Logistics Engineering, Vol, 1, No. 2 December 2013;

WORLD BANK (2004). Making services working for the poor. World Development Report. 
ANEXOS 
ANEXO I - Questionário 1 


\section{AVALIAÇÃO DA QUALIDADE DO TRANSPORTE PÚBLICO - QUESTIONÁRIO 1}

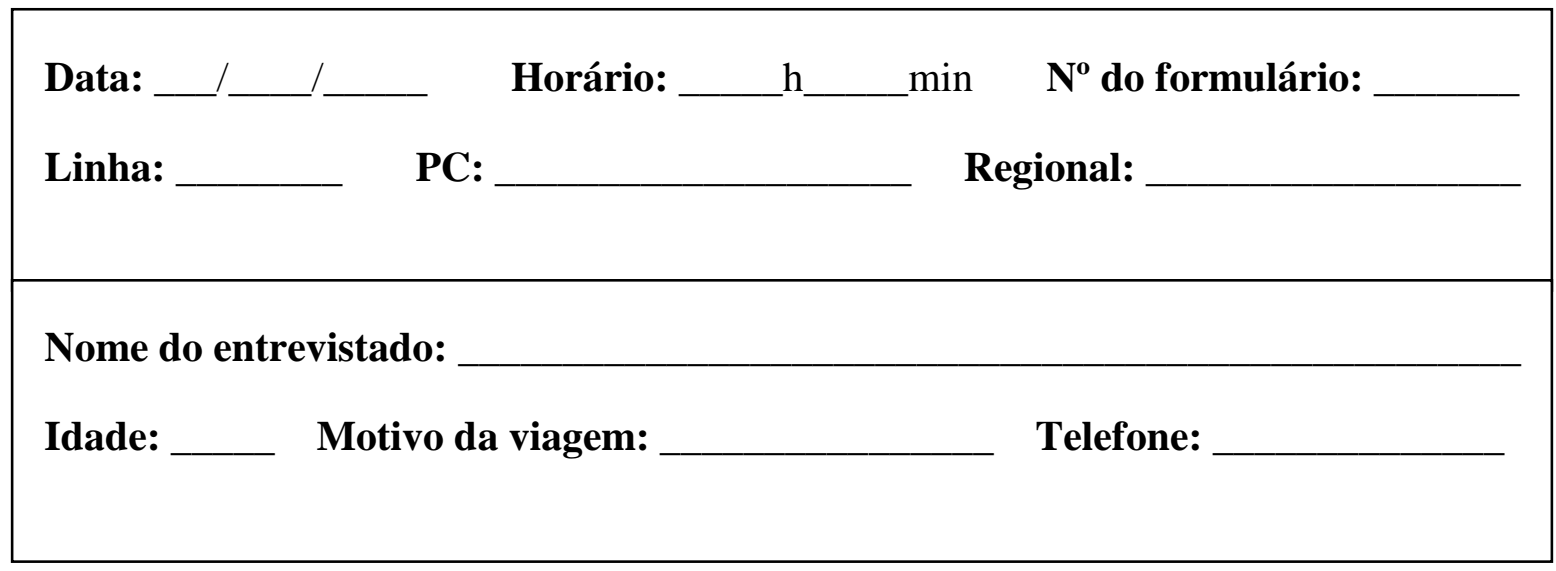

"Quais são os 3 itens que você considera mais importante para a qualidade do serviço de transporte público, considerando:”

1) TARIFA
a)
b)
c)

2) PONTUALIDADE
a)
b)
c)

3) CONDIÇÕES DOS VEÍCULOS

a)

b) 
c)

4) TEMPO DE VIAGEM

a)

b)

c)

5) LOTAÇÃO

a)

b)

c)

6) SEGURANÇA

a)

b)

c)

7) INFORMAÇÕES

a)

b)

c)

8) COMPORTAMENTO DOS OPERADORES

a) 
b)

c) 
ANEXO II - Questionário 2 


\section{AVALIAÇÃO DA QUALIDADE DO TRANSPORTE PÚBLICO - QUESTIONÁRIO 2}

Nome:

Idade:

Cidade:

Estado:

E-mail:

TRANSPORTE PÚBLICO DE QUALIDADE

Olá! Este questionário busca elencar quais os fatores são mais importantes para o usuário do transporte público por ônibus, visando contribuir para o planejamento de um transporte de qualidade para todos. Contribua respondendo a estas simples questões sobre a importância dos fatores que influenciam na sua decisão de usar ou não o transporte público.

Para responder as questões, basta dedicar um valor de 1 a 5 para cada quesito, de acordo com a escala abaixo. Favor preencher TODOS os itens.

\begin{tabular}{|c|c|c|c|c|}
\hline 1 & 2 & 3 & 4 & 5 \\
\hline $\begin{array}{c}\text { Pouco } \\
\text { Importante }\end{array}$ & Importante & $\begin{array}{c}\text { Muito } \\
\text { Importante }\end{array}$ \\
\hline
\end{tabular}

\section{QUESTÕES}

9) Para você, qual a importância destes itens em um serviço de transporte público por ônibus de qualidade?

( ) PONTUALIDADE - cumprimento dos horários estabelecidos;

( ) TEMPO - tempo gasto na espera do ônibus e no percurso até o seu destino;

( ) INFORMAÇÕES - horários, itinerários, etc.;

( ) VEÍCULOS - condições de operação, limpeza, etc.;

( ) TRIPULAÇÃO - comportamento de motoristas, cobradores e demais operadores;

( ) SEGURANÇA - sentir-se seguro enquanto usa o transporte público;

( ) LOTAÇÃO - veículos muito cheios ou com pouco espaço;

( ) TARIFA - valores pagos para uso do transporte público. 
10) Sobre PONTUALIDADE, qual a importância destes aspectos em um serviço de transporte público por ônibus de qualidade?

( ) Viagens não atrasarem;

( ) Cumprimento dos itinerários.

11) Sobre TEMPO, qual a importância destes aspectos em um serviço de transporte público por ônibus de qualidade?

( ) Distância entre pontos ou estações;

( ) Tempo de espera;

( ) Duração da viagem.

12) Sobre INFORMAÇÕES, qual a importância destes aspectos em um serviço de transporte público por ônibus de qualidade?

( ) Informações prévias - por internet, mídia ou panfletos;

( ) Informações nos pontos ou estações;

( ) Informações dentro dos veículos.

13) Sobre VEÍCULOS, qual a importância destes aspectos em um serviço de transporte público por ônibus de qualidade?

( ) Viagens interrompidas por veículos quebrados;

( ) Veículos e estações acessíveis a portadores de necessidades especiais;

( ) Veículos limpos.

14) Sobre TRIPULAÇÃO, qual a importância destes aspectos em um serviço de transporte público por ônibus de qualidade?

( ) Cortesia e boa educação dos operadores;

( ) Alta velocidade e freadas bruscas;

( ) Obediência à solicitação de parada.

15) Sobre SEGURANÇA, qual a importância destes aspectos em um serviço de transporte público por ônibus de qualidade?

( ) Assaltos dentro dos veículos;

( ) Acidente de trânsito com os veículos. 
16) Sobre LOTAÇÃO, qual a importância destes aspectos em um serviço de transporte público por ônibus de qualidade?

( ) Veículos muito cheios;

( ) Quantidade de assentos por veículo;

( ) Quantidade de portas nos veículos.

17) Sobre TARIFA, qual a importância destes aspectos em um serviço de transporte público por ônibus de qualidade?

( ) Valor da tarifa;

( ) Integração tarifária.

Agradecemos sua disposição em contribuir para a realização desta pesquisa. 
ANEXO III - Matriz da Qualidade 


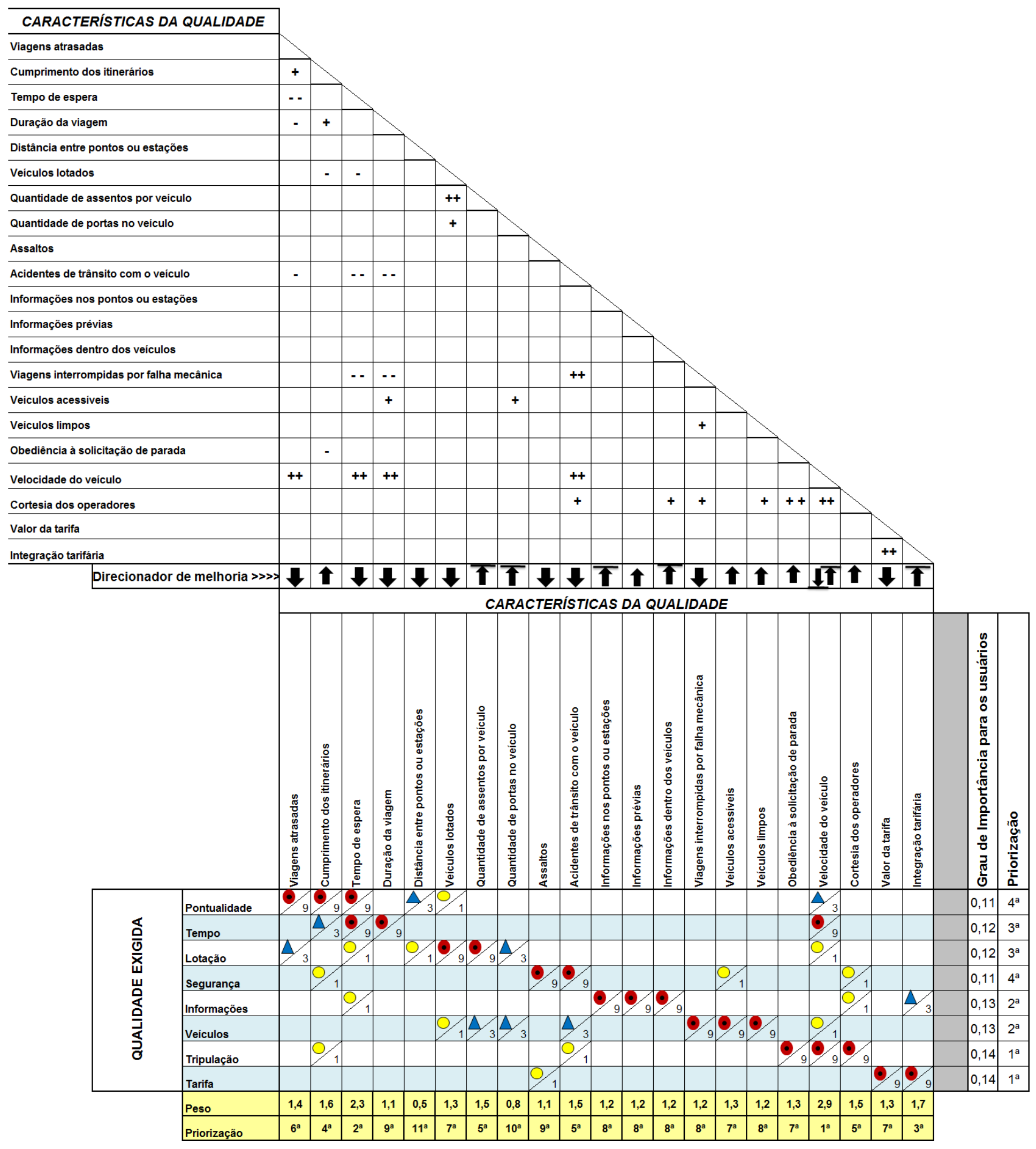




\begin{tabular}{|c|c|c|}
\hline \multicolumn{3}{|c|}{$\begin{array}{c}\text { Correlação entre requisitos de cliente } \\
\text { e de serviço }\end{array}$} \\
\hline$\odot$ & Forte & 9 \\
\hline$\triangle$ & Moderada & 3 \\
\hline$\bigcirc$ & Fraca & 1 \\
\hline
\end{tabular}

\begin{tabular}{|c|c|}
\hline \multicolumn{2}{|c|}{ Correlação $\mathbf{C Q}$ x $\mathbf{C Q}$} \\
\hline++ & Posit. Forte \\
\hline+ & Posit. Fraco \\
\hline & Inexistente \\
\hline- & Neg. Fraca \\
\hline-- & Neg. Forte \\
\hline
\end{tabular}

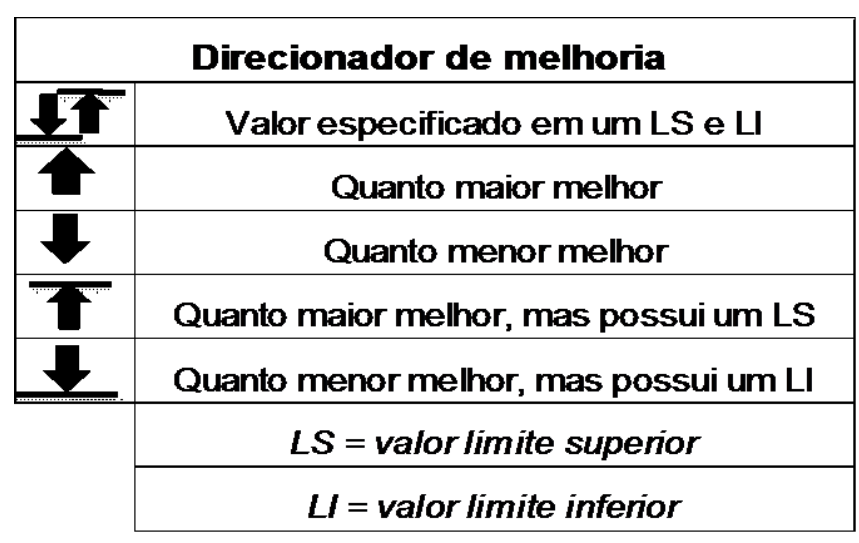

